\title{
CONDENSATION OF FUEL ONTO THE ABOVE-CORE STRUCTURE DURING AN LMFBR CORE-DISRUPTIVE ACCIDENT
}

University of Virginia for

U. S. Nuclear Regulatory Commission 


\section{DISCLAIMER}

This report was prepared as an account of work sponsored by an agency of the United States Government. Neither the United States Government nor any agency Thereof, nor any of their employees, makes any warranty, express or implied, or assumes any legal liability or responsibility for the accuracy, completeness, or usefulness of any information, apparatus, product, or process disclosed, or represents that its use would not infringe privately owned rights. Reference herein to any specific commercial product, process, or service by trade name, trademark, manufacturer, or otherwise does not necessarily constitute or imply its endorsement, recommendation, or favoring by the United States Government or any agency thereof. The views and opinions of authors expressed herein do not necessarily state or reflect those of the United States Government or any agency thereof. 


\section{DISCLAIMER}

Portions of this document may be illegible in electronic image products. Images are produced from the best available original document. 


\section{NOTICE}

This report was prepared as an account of work sponsored by the United States Government. Neither the United States nor the United States Nuclear Regulatory Commission, nor any of their employees, nor any of their contractors, subcontractors, or their employees, makes any warranty, express or implied, nor assumes any legal liability or responsibility for the accuracy, completeness or usefulness of any information, apparatus, product or process disclosed, nor represents that its use would not infringe privately owned rights.

Available from

National Technical Information Service Springfield, Virginia 22161

Price: Printed Copy $\$ 8.00$; Microfiche $\$ 3.00$

The price of this document for requesters outside of the North American Continent can be obtained from the National Technical Information Service. 


\title{
CONDENSATION OF FUEL ONTO THE ABOVE-CORE STRUCTURE DURING AN LMFBR CORE-DISRUPTIVE ACCIDENT
}

\author{
P. L. Gardner \\ Principal Investigators: \\ C. A. Erdman \\ A. B. Reynolds
}

Manuscript Completed: August 1977

Date Published: October 1977

University of Virginia

School of Engineering and Applied Science

Department of Nuclear Engineering

Charlottesville, VA 22901

UVA/529106/NE77/101

Prepared for

Division of Reactor Safety Research

Office of Nuclear Regulatory Research

U. S. Nuclear Regulatory Commission

Under Contract No. AT(49-24)-0316

YSTRIEUTIONC 


\section{ABSTRACT}

Condensation of a pure, saturated vapor onto a vertical, melting substrate is analyzed for both one- and two-material situations. The condensate and me1t regions are treated as laminar boundary layers in the steady-state analyses. The convective momentum and energy transport terms in the conservation equations and the shear stress at the condensate/vapor interface are found to be non-negligible; neglection of these terms results in overestimating the phase-change rates by a factor of 2 to 3 . The phase-change rates are reduced if the vapor is moving upward at low speed rather than stagnant.

Examination of the one-material situation indicates that the solution to the full transient condensation-induced melting problem may be approximated by using a transient, conduction-only model for short times and a steady-state, flowing-film model for long times. This concept is extrapolated to the two-material situation in order to obtain a simulation of the transient solution.

The models are applied to the specific case of uranium dioxide condensing onto solid stainless steel. Condensate solidification occurs for this pair of materials; however, this solidification may be neglected without introducing a serious error in the other phasechange rates. The condensation heat flux for this pair of materials is a very weak function of the initial substrate temperature and the vapor temperature.

The results of this analysis have applications in the area of LMFBR accident analysis. Condensation of the fuel (a mixture of 
uranium dioxide and plutonium dioxide) onto the above-core structure (steel) is a mechanism for reducing the energy available to mechanically damage the primary system boundary. Condensation will also alter the radioactive aerosol source term available for potential release from the primary system. The condensation rates developed in this analysis will have to be factored into an overall accident analysis code in order to assess the degree to which condensation will reduce the consequences of a core disruptive accident. The present results do, however, indicate that fuel condensation induces rapid melting of the steel: the fuel-pin cladding (e.g., in the fission-gas-plenum region) may completely melt in 10 to $40 \mathrm{~ms}$ following contact with fuel vapor; the fuel assembly wall, which is 8 times thicker than the fuel-pin cladding, will require 0.65 to $2.5 \mathrm{~s}$ to completely melt . 
TABLE OF CONTENTS

$\underline{\text { PAGE }}$

ABSTRACT. . . , , , , , , , , , , , , , , , , , ii LIST OF FIGURES . . . . . . . . . . . . . . . . . . . . . , . . . vi LIST OF TABLES • . . . . . . . , , . . . . . . . . . . . . , viii LIST OF SYMBOLS ... . . . . . . . . . . . . , . , . . , . . ix

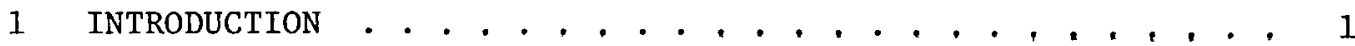

1.1 Background and Motivation for Current Work. . . . . . 1

1.2 Review of Previausly Published Analyses of Phase-Change Problems . . . . . . . . . . . . 4

1.3 Organization of Work Reported . . . . . . . . . . . . 6

2 STEADY-STATE ANALYSES . . . . . . . . . . . . . . . . . . 8

2.1 Generic Assumptions . . . . . . . . . . . . . . 8

2.2 Upward-Flowing Vapor . . . . . . . . . . . . . 18

2.2.1 Mode1 Development . . . . . . . . . . . 18

2.2.2 Integration Starting Values . . . . . . . . . 26

2.2 .3 Results . . . . . . . . . . . . . . . 35

2.3 Importance of Convective Transport Terms and Shear Stress at the Condensate/Vapor Interface . . : . 41

2.4 Inclusion of Condensate Solidification (Infinite Viscosity). . . . . . . . . . . . . . . . 48

2.5 Alternate Treatment of Solidified Condensate (Rigid). 64

3 TRANSIENT ANALYSIS--SINGLE FILM . • . . . . . . . . . . . . . 76

3.1 Full Transient Solution . . . . . . . . . . . . 78

3.2 Simulation of Transient . . . . . . . . . . . . . 88

3.2.1 Solution for Short Times . . . . . . . . . 89 
TABLE OF CONTENTS (cont'd)

PAGE

3.2.2 Solution for Long Times. . . . . . . . . 94

3.2.3 Combination and Comparison with Full

Transient . . . . . . . . . . . . . 98

4 TRANSIENT ANALYSIS--MULTIPLE FILMS. . . . . . . . . . 104

5 CONCLUDING SUMMARY AND RECOMMENDATIONS. . . . . . . . 112

REFERENCES . . . . . . . . . . . . . . . . . . 117

APPENDICES . . . . . . . . . . . . . . . . . . . 121

A. Fuel and Steel Properties . . . . . . . . . 121

B. Equation Summary for Infinite Viscosity Treatment

of Solidified Condensate . . . . . . . . . . . . 124

C. Treatment of Solidified Condensate as an Infinitely

Viscous Fluid when Convective Transport Terms Are

Neglected . . . . . . . . . . . . . . . . . 128

D. Transient Conduction-Only Treatment of Condensation-

Induced Melting . . . . . . . . . . . . . 131

D.1 Equation Summary . . . . . . . . . . 131

D.2 Effective Heat of Fusion ........... . 134

D.3 Results . . . . . . . . . . . . 135

E. Equation Summary for Single-Film Treatment of SteadyState Condensation-Induced Melting. . . . . . . . 140 


\section{LIST OF FIGURES}

2-1 Cylindrical half-sectional schematic representation of the intact-pin channel geometry. (Initial region thicknesses are given in parentheses, and the phases are identified $[\mathrm{S}=$ solid, $\mathrm{L}=$ liquid, $\mathrm{V}=$ vapor $]$ at the top.) . . . . . . . . . . . , , , , , ,

2-2 Schematic of geometry used for condensation of an upward-flowing vapor onto a melting substrate, ., , ,

2-3 Spatial sequencing of key events for upward-flowing vapor condensing onto a vertical, melting substrate, , :

2-4 Dimensionless condensation mass flux ( $\mathrm{cv})$, dimensionless condensate film thickness $\left(\Delta_{c}\right)$, and ratio of melt thickness to condensate thickness $(Z)$ as a function of dimensionless axial location (X) for the steadystate condensation of upward-flowing fuel vapor at temperature $\mathrm{T}_{\mathrm{cV}}$ onto melting steel with $\mathrm{T}_{\mathrm{o}, \mathrm{ms}}=800 \mathrm{~K}$.
(a) $\mathrm{T}_{\mathrm{CV}}=4000 \mathrm{~K}$,
(b) $\mathrm{T}_{\mathrm{cV}}=5000 \mathrm{~K}$,
(c) $\mathrm{T}_{\mathrm{cv}}=6000 \mathrm{~K}$

2-5 Dimensionless average condensation mass flux as a function of the dimensionless averaging length for the steadystate condensation of upward-flowing fuel vapor onto melting steel with $\mathrm{T}_{\mathrm{o}, \mathrm{ms}}=800 \mathrm{~K} ., \ldots . . . . . .$.

2-6 Condensation heat transfer coefficient averaged over $1.2 \mathrm{~m}$ as a function of vapor speed for the steadystate condensation of flowing fuel vapor onto a melting steel substrate with $\mathrm{T}_{\mathrm{o}, \mathrm{ms}}=800 \mathrm{~K} ., \ldots, \ldots$, ,

2-7 Steady-state (a) fuel condensation and (b) steel melting mass fluxes as a function of vapor temperature showing the effect of vapor shear and convective terms. . . . . . . . . . . . . . . . .

2-8 Schematic of the geometry used to analyze the steadystate condensation and solidification of stagnant vapor onto a vertical, melting substrate when the solidified condensate is treated as an infinitely viscous fluid... . . . . . . . . . . . . . . 


\section{LIST OF FIGURES (cont'd)}

2-9 Schematic of the geometry used to analyze the steadystate condensation and solidification of stagnant vapor onto a vertical, melting substrate when the solidified condensate is treated as rigid . . . . . . . . . . 65

3-1 Schematic of geometry used for analyzing transient condensation of a stagnant vapor onto a substrate of the same material . . . . . . . . . . . . . . 79

3-2 Transient film buildup and substrate meltaway during condensation of a stagnant vapor onto its solid

3-3 Schematic of geometry used for the short-time (conduction-only) solution of a condensation-induced melting problem

3-4 Schematic of the geometry used for the long-time (flowingfilm) solution of a condensation-induced melting problem

4-1 Spatially averaged condensation heat transfer coefficients as a function of time for stagnant fuel condensing onto vertical steel . . . . . . . . . . . . . . . 108

4-2 Spatially averaged condensation heat flux as a function of time and substrate length for stagnant fuel condensing onto vertical steel . . . . . . . . . . . . 110

D-1 Schematic of geometry used for a conduction-only treatment of transient condensation and solidification of a material onto a melting substrate composed of a different material 
LIST OF TABLES

PAGE

2-1 Effect of Vapor Shear and Convective Terms on the Steady-State Condensation of Stagnant Fuel Vapor

onto a Vertical Steel Substrate.. . . . . . . . . . . 46

2-2 Local Ratio of the Frictional Shear Stress to the Excess-Momentum-F1ux Shear Stress for the SteadyState Condensation of Upward-Flowing Fuel onto

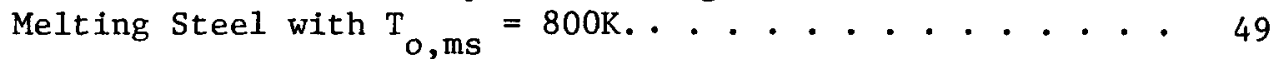

2-3 Interface Temperature Following Contact of Fuel Vapor and Solid Steel: (a) Stagnant-Vapor/Vertical-Substrate;

(b) Flowing-Vapor/Horizontal-Substrate. . . . . . . . 51

2-4 Effect of Fuel Condensate Solidification during the Steady-State Condensation of Stagnant Fuel onto Vertical

Steel. . . . . . . . . . . . . . . . .

2-5 Phase Change Mass Fluxes and Velocity of the Solidified Condensate Averaged over an Axial Length of $1.2 \mathrm{~m}$ for the Steady-State Condensation of Stagnant Fuel onto

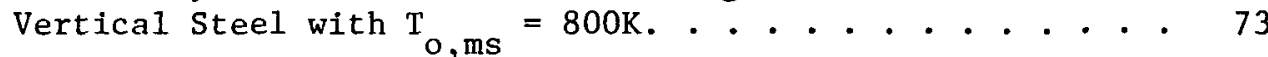

3-1 Comparison of Full and Simulated Transient Solutions of Condensation-Induced Melting in Vertical Orientation. . . 100

4-1 Simulation of Transient Condensation of Stagnent Fuel onto Vertical Steel.. . . . . . . . . . . . . . 106

A-1 Summary of Fuel and Steel Properties. . . . . . . . . . 122

D-1 Dimensionless Results for Conduction-only Treatment of Transient Condensation of Fuel onto Melting Steel. . . . 136

D-2 Film Thicknesses and Phase-Change Rates for a Conductiononly Treatment of Transient Fuel Condensation onto

Melting Steel. ................. 139 


\section{LIST OF SYMBOLS ${ }^{\dagger}$}

A coefficient in temperature profile (T or $\theta$ ) or in dimensionless stream function ( $F$ ); collection of terms in $\mathrm{H}$ (Eq. 2.2-28)

a coefficient in velocity profile $(u)$; dimensionless parameter (Eq. 2.4-30)

B coefficient in temperature profile ( $T$ or $\theta$ ) or in dimensionless stream function (F); collection of terms in $\mathrm{H}$ (Eq. 2.2-29)

b coefficient in velocity profile (u); dimensionless parameter (Eq. 2.4-31)

C coefficient in temperature profile $(\theta)$; collection of terms in $\mathrm{H}$ (Eq. 2.2-30)

c specific heat

D coefficient in dimensionless stream function ( $F$ )

d coefficient in temperature profile $(T)$

E coefficient in dimensionless stream function (F)

F general function designator

F dimensionless stream function (having form $\mathrm{A}+\mathrm{Bn}+\mathrm{D \eta}^{2}+\mathrm{En}^{3}$ )

f coefficient in temperature profile (T); Darcy-Weisbach friction factor

G coefficient in dimensionless temperature profile $(\theta)$; dimensionless parameter (Eqs. 2.2-34 and 3.1-24)

$\mathrm{Gr}_{\mathrm{x}}^{*} \equiv \frac{\mathrm{gx}^{3}}{4 \nu_{\mathrm{c}}^{2}}$ effective Grashoff number

$g$ acceleration due to gravity $\left(9.8 \mathrm{~m} / \mathrm{s}^{2}\right)$

$\mathrm{H}$ coefficient in dimensionless temperature profile $(\theta)$; integration constant (Eq. 2.2-27); dimensionless parameter (Eq. 3.1-25)

$\mathrm{h}_{\mathrm{cV}} \equiv \frac{\dot{\mathrm{m}}_{\mathrm{cV}} \mathrm{L}_{\mathrm{cV}}}{\mathrm{T}_{\mathrm{cV}}-\mathrm{T}_{\mathrm{o}, \mathrm{ms}}}$ condensation heat transfer coefficient

${ }_{A}$ number of symbols have multiple definitions and are redefined within each subsection of the text. 


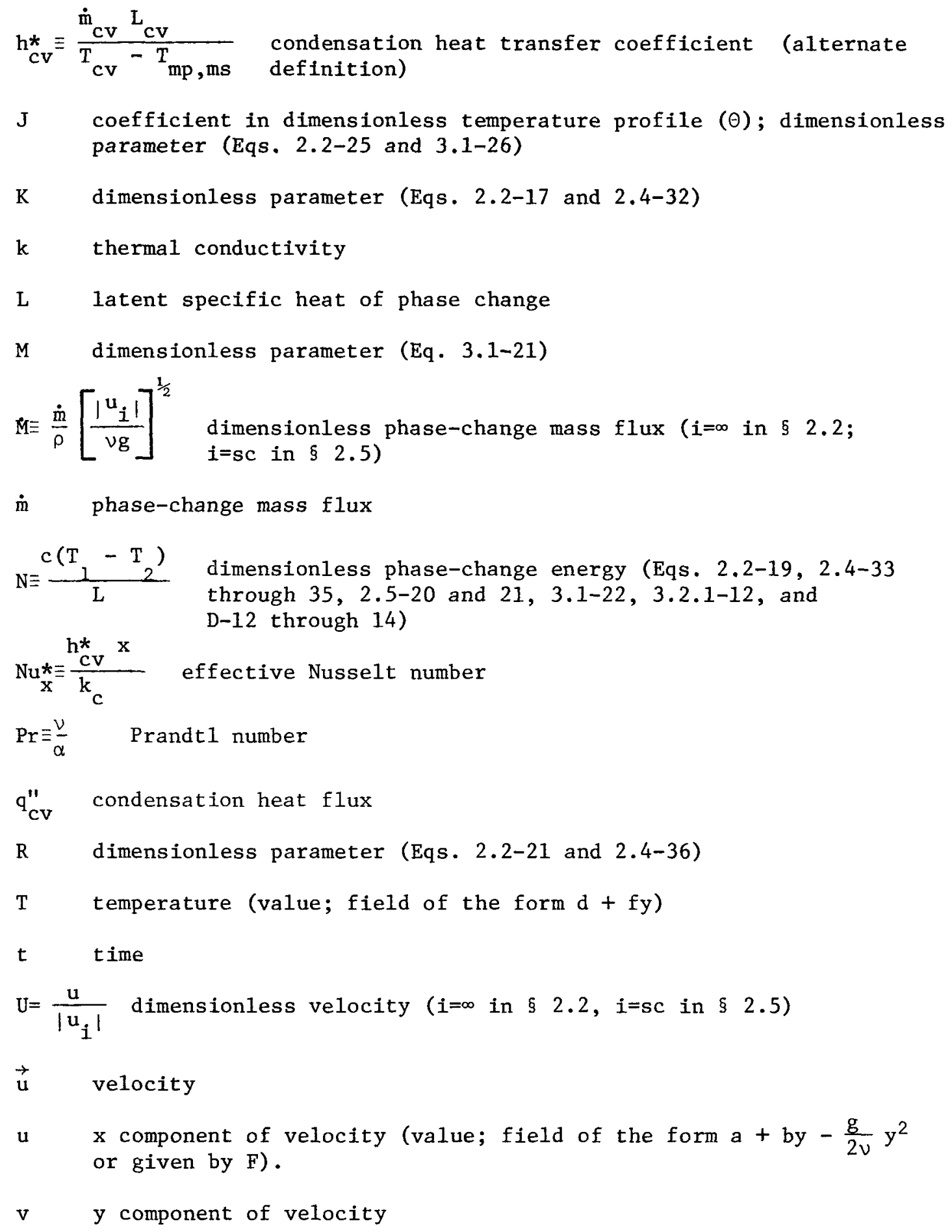




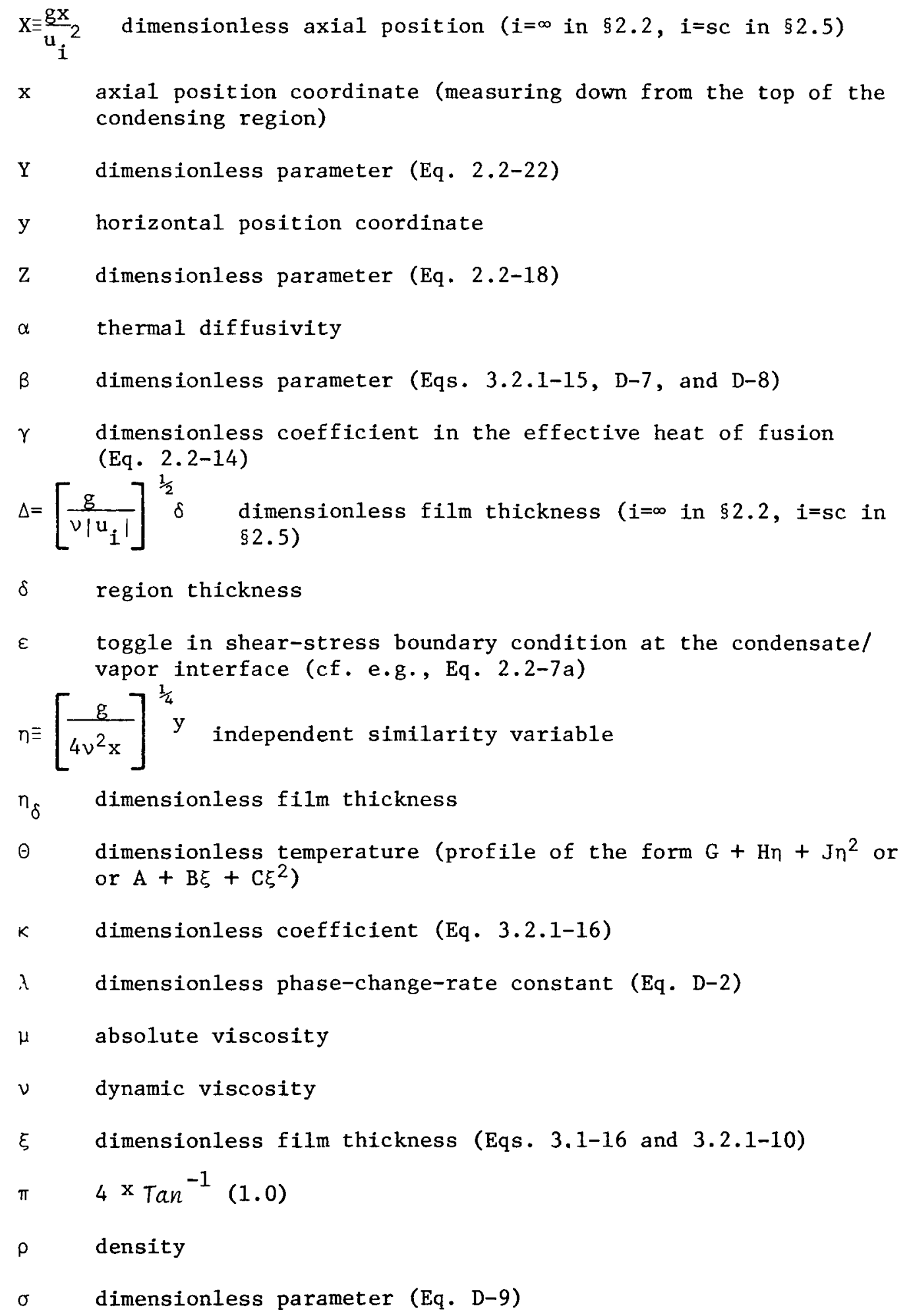




$$
\begin{array}{ll}
\tau & \text { shear stress (Eq. } 2 \cdot 1-1) \\
\vec{\nabla} & \text { vector differential operator }
\end{array}
$$

\section{Subscripts}

c condensate

cv condensation; condensing vapor; condensate/vapor interface

L characteristic length

m me1t

mp melting point

ms melting; me1table solid substrate; substrate-solid/melt interface

o initial condition

sc solidification of condensate; solidified condensate; interface between solid and liquid phases of the condensing species

ss steady state

$\infty \quad$ free-stream vapor condition

\section{Superscripts}

* non-standard definition

' differentiation

\section{Overscore}

\footnotetext{
- average quantity over region in y direction

average quantity over region in $\mathrm{x}$ direction

$\rightarrow \quad$ vector
} 


\section{SECTION 1}

\section{INTRODUCTION}

\subsection{Background and Motivation for Current Work}

Current analysis methods ${ }^{1}$ indicate that the core region of a liquid-meta1-cooled fast breeder reactor (LMFBR) could reach a relatively high energy state for certain postulated core-disruptive accidents $(C D A)$. This would result in the fuel, a mixture of $\mathrm{UO}_{2}$ and $\mathrm{PuO}_{2}$, being brought to a state of high temperature and high pressure with some of the fuel having been vaporized. This high pressure region will attempt to expand against the constraint provided by the surrounding sodium and structural members within the reactor vessel. The path of least resistance along which the material will move during the expansion is upward through the fuel assembly structure. The structure in this region should be relatively intact and relatively cold, at least during the early stages of the expansion. The large mass of steel present and its associated large surface area would facilitate removal of energy from the core material as it expands through the above-core region. Removal of energy from the expanding core material is important for several reasons. As the core material expands, it is performing work on the surroundings. This work initially appears as an increase in the kinetic energy of the sodium in the reactor vessel. A portion of this kinetic energy will eventually be manifest as strains in the reactor vessel and primary system piping. Should energy be removed from the core material by other means (e.g. heat transfer to 
the structure), this will result in there being less energy available in the core to do mechanical damage to the primary system boundary. There are two other effects associated with the energy reduction which will affect the potential radiological consequences of a CDA should the primary system be ruptured. A reduction in the mass of vapor in the expanding regton accompanies the energy reduction. This is desirable since the vapor is a potential source of submicrometre-size particles ${ }^{2}$ (formed via bulk homogeneous nucleation condensation). These particles are of concern since they would contain plutonium and could be easily transported through the reactor vessel (and out of leakage paths to the environment) due to the small size of the particles.

The further transport of fuel within the reactor vessel is also affected by any energy losses which occur during the expansion through the above-core structure. After traversing the rather constrained geometry of the above-core region, the fuel exits into a relatively open sodium pool. The further motion of this material within the pool is a function of the characteristics of the material as it enters the pool. The motion pattern is bounded by two extremes ${ }^{3}$ : material entering the pool with a high specific momentum (i.e. high density and/or velocity) and at a low pressure will want to penetrate upward through the pool in a jet-like fashion with little radial expansion; material entering with a low specific momentum and at high pressure will tend to expand somewhat spherically, at the point of entrance into the pool with relatively little axial translation.

Simple heat capacity arguments are sufficient to show that, given an infinite amount of time, there is indeed enough cold structure in 
the above-core region to completely condense the fuel vapor produced in most postulated CDA scenarios. The purpose of the present work is to determine the actual rate associated with this energy removal process. This rate must be known in order to assess whether the energy removal occurs rapidly enough to be important in the CDA analysis. A parallel phenomenon which must be considered is the amount of steel melting induced by condensation of fuel onto the structures; due to the finite thickness of the structures, the mass of steel available to serve as a rigid condensing surface is decreasing during the fuel condensation process.

Loss of energy from the expanding core region by condensation onto the above-core structure has been ignored in many CDA analyses. This is a conservative approach since accounting for this energy loss reduces the severity of the consequences of the CDA. Recently, more attention has been focussed on this potential loss of energy. This has resulted in the development of the models required in order to analyze the process.

One simple model ${ }^{4}$ developed at the General Electric Company allows a spatially uniform film of condensed fuel to build up on the structure. The heat transfer is treated using a quasi-static conduction mode1 $(h \sim k / \delta)$, and steel melting is neglected.

The SIMMER computer code ${ }^{5}$, which is being developed at the Los Alamos Scientific Laboratory (LASL), will treat the problem in a fair amount of detail. This code will treat spatial and temporal variations of quantities and includes the steel melting (and other phase changes). 
The SIMMER user must input coefficients to characterize the mass, momentum, and energy transfers between the various materials and regions; these coefficients are not well known a priori.

A modeling effort ${ }^{6}$ is also in progress at the Oak Ridge National Laboratory (ORNL). The fuel condensation and stee1 me1ting processes are to be included in this model; however, the modeling work is still in an early stage, and the modeling techniques to be employed have not been completely specified. The initial model may require the user to input exchange coefficients as is done for the SIMMER code. The proposed work at ORNL also includes a series of small scale experiments in which $\mathrm{UO}_{2}$ will be vaporized within a sodium pool in a closed vessel. These experiments will provide the baseline data required to verify the various analytical models under development.

The purpose of the research being reported here is to provide characterizations of the mass and energy exchange rates associated with condensation of fue1 onto melting steel. The present work has not tried to model the detailed transient motion of core material through the above-core region or to model specific CDA situations; these tasks are being done at ORNL and LASL. The intent has been, rather, to develop information on the exchange rates which may guide the user to selection of proper exchange coefficients to use in SIMMER and to suggest modeling techniques which might be incorporated directly into the ORNL or LASL models to describe these exchanges.

1.2 Review of Previously Published Analyses of Phase-Change Problems Most phase-change analyses are extensions and improvements of the 
pioneering works of Nusselt and Stefan. Nusselt ${ }^{7}$ was the first person to treat the flowing liquid film which results when vapor condenses onto a vertical wall. Stefan ${ }^{8}$ studied the transient conduction heat transfer problem associated with the formation of ice. Most extensions of these works have addressed problems where only one phase-change boundary is considered. As stated previously, condensation of fuel induces melting of the steel substrate; i.e., a second phase change is involved.

A number of authors have considered the melting of a solid due to the condensation of the vapor phase of the same material. Tien and Yen ${ }^{9}$ studied the condensation of stagnant vapor onto its solid in vertical orientation and obtained a steady-state solution. Cho and Epstein $^{10}$ examined the steady-state condensation of a flowing vapor onto a horizontal, melting substrate. Contreras and Thorsen ${ }^{11}$ extended the work of Tien and Yen $^{9}$ to examine the transient portion of the solution. These problems are interesting in that they indicate trends one might expect in the current problem; however, the vapor and the substrate are different materials in the CDA situation.

Several analyses have recently been published which examine situations where more than one liquid region are considered -- that is where the condensed vapor and the melted solid are treated as being discrete immiscible regions. A transient solution was presented by Epstein and Cho ${ }^{12}$ which considered the condensation, and subsequent solidification, of one material onto a meltable substrate composed of a different material; the heat transfer was by conduction, and no 
material flows were allowed; this corresponds to stagnant vapor condensing onto a horizontal substrate. All other previous analyses of multi-film problems have considered steady-state situations. Epstein and $\mathrm{Cho}^{13}$ extended the work of Tien and Yen ${ }^{9}$ by allowing two liquid films to be present. Cho and Epstein ${ }^{14}$ extended their own work ${ }^{11}$ in horizontal orientation in order to include two flowing films.

Further details of these previous analyses of problems involving multiple phase changes will be presented along with the model developments in Sections 2 and 3 .

\subsection{Organization of Work Reported}

The work reported herein is divided into two main categories: steady state and transient. Section 2 will present a number of topics which were considered within the problem of steady-state condensation onto a vertical melting wall when two liquid films must be considered: the effect of upflowing vapor (\$2.2), and allowance for condensate solidification and the possible techniques for treating the solidified condensate ( $\$ 2.4$ and $\$ 2.5)$. A number of other effects found during this study of steady-state problems, though not major advances of the state of the art, will be presented in Section 2.3.

Section 3 will examine transient film condensation under the assumption that the two liquid films can be approximated ${ }^{*}$ by a single film with average properties. The results found for this analysis will

\footnotetext{
*This approximation can be shown to be reasonab1y good for a "proper" selection of average properties; however, this is not the main result which is being presented in section 3 .
} 
be used in Section 4 to support the theory that the transient solution to the multi-film problem can be approximated by combining a transient conduction-only solution with a steady-state film condensation solution. Section 5 will provide an overall summary of the results obtained in this research and make recommendations for further work.

The calculational models developed in this report could be applied to numerous pairs of materials; however, all calculations reported herein are for the specific case of $\mathrm{UO}_{2}$ condensing onto stainless steel. Representative thermophysical properties of these materials used in this analysis are presented in Appendix A. These properties have been used in all calculations reported herein for consistency, even though this has involved the extra work of actually "recalculating" results published by others for the $\mathrm{UO}_{2} /$ steel systems. The other appendices present additional details of several of the models. 


\section{SECTION 2}

\section{STEADY-STATE ANALYSES}

This section begins with a discussion of the assumptions which are common to all of the steady-state analyses to be presented. Three new analyses of condensation-induced melting are presented in the later sections: one examines the effect of vapor velocity on the condensation process ( $\S 2.2)$, and the other two examine the importance and method of treating condensate solidification ( $\$ 2.4$ and 2.5$)$. The effects of several modeling approximations are examined in Section 2.3.

\subsection{Generic Assumptions}

The geometry for the general problem being considered is shown in Figure 2-1. As fuel vapor flows upward past a steel substrate, the fuel condenses and forms a liquid layer or film on the substrate. A portion of the condensed fuel may actually solidify depending on the vapor velocity and temperatures in the system. The high fuel temperatures (4000K to $6000 \mathrm{~K}$ ) being considered and the energy imparted to the substrate by fuel condensation and solidification are of the proper magnitudes to raise the steel to its melting temperature (1700K) and induce steel melting. The solid steel considered here may be the fuel pin cladding, as shown in Figure 2-1, which encloses a gas space above the core-and blanket-fuel pellets. An alternate substrate is the hexagonal fuel pin assembly wall, which would have a small region of sodium separating it from the wall of the adjacent assembly. For either case, the material on the opposite side of the substrate from the vapor is not treated in the steady-state analysis. 


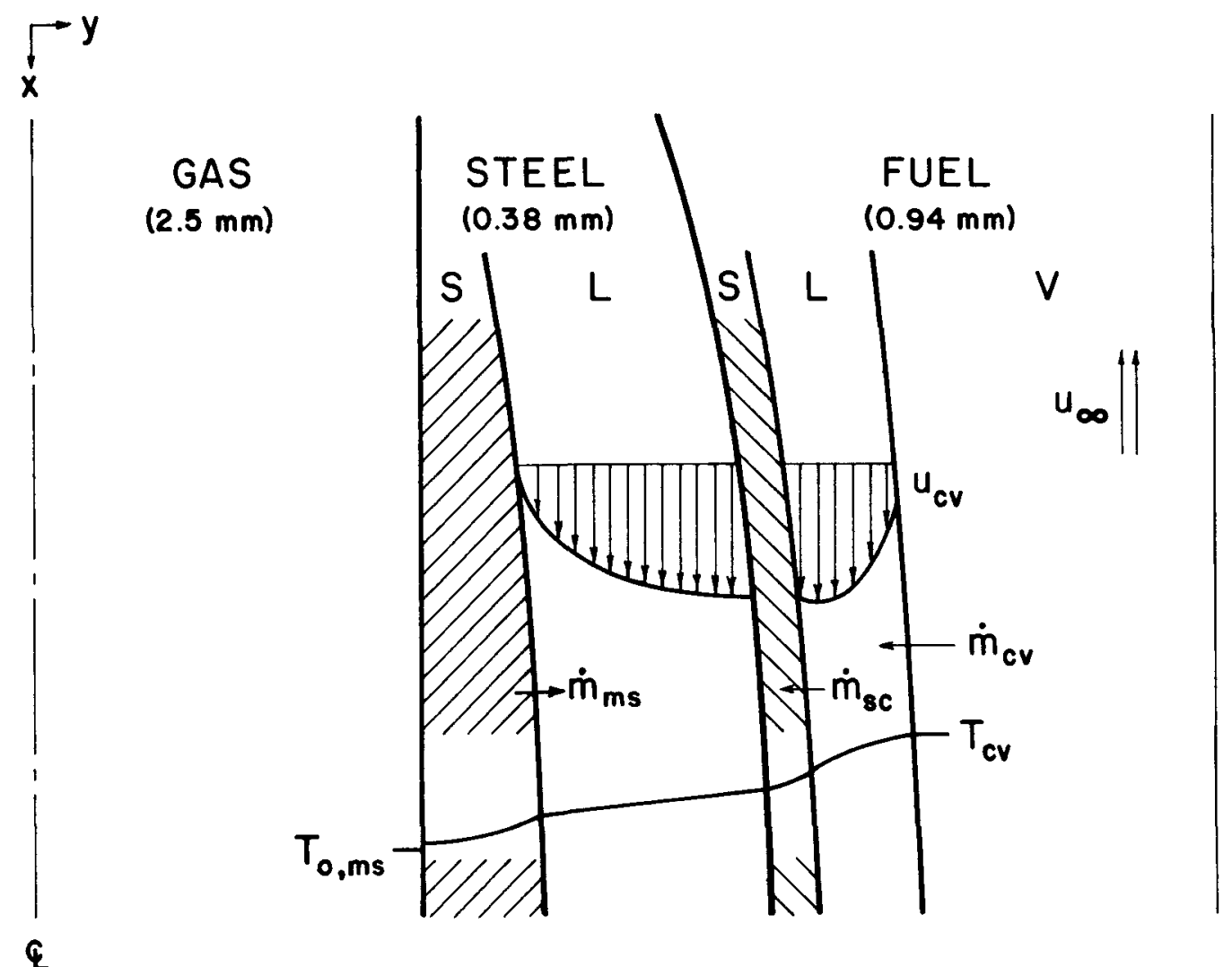

Figure 2-1. Cylindrical Half--Sectional Schematic Representation of the Intact-Pin Channel Geometry. (Initial Region Thicknesses are given in Parentheses, and the Phases are identified $[S=$ solid, $L=1$ iquid, $V=$ vapor $]$ at the top.) 
The problem as stated is rather formidable, and a number of approximations must be made in order to make the problem tractable. In summary, the following assumptions were made in a11 of the steadystate analyses performed:

- steady-state

- vapor: pure, saturated, uniform temperature and axial velocity, no detailed modeling

- excess momentum flux used to approximate shear stress at condensate/vapor interface

- neglect presence of sodium

- liquid regions: smooth, no entrainment by vapor, treat as boundary layers, incompressible, constant transport properties, laminar, no internal heat generation

- substrate: planar, relatively thick

- melting interface is planar

The remainder of this section is devoted to a point by point discussion of this list of assumptions.

The biggest restriction in the present section of the analysis is that of steady state. Actual situations of interest will start in a transient manner and, given sufficient time, will limit to the behaviors given in this section if the other restrictions are satisfied. Steady state implies that the region thicknesses and mass fluxes are constant in time; however, since the substrate is melting, the films depicted in Figure 2-1 are moving to the left. An observer riding on the melt front will see a steady-state situation.

The present analysis does not allow for noncondensable gas to be mixed with the vapor. This gas could actually be present in both 
$\mathrm{CDA}$ and experiment cases of interest and would be composed of fuelpellet/cladding bond gas and/or fission products. Noncondensable gas reduces the condensation rates to various degrees depending on the system orientation. For a mixture of steam and air condensing onto a non-melting wall, a $0.5 \%$ mass fraction of air causes the condensation rate to drop by $50 \%$ for stagnant vapor next to a vertical substrate ${ }^{15}$, whereas the air mass fraction must be on the order of $10 \%$ to obtain the same $50 \%$ reduction when the vapor/gas is flowing over a horizontal substrate ${ }^{16}$. Allowing the substrate to melt ${ }^{17}$ does not significantly alter the effects of noncondensable gas on condensation rates from those reported in Reference 15. Allowing for the noncondensable gas increases the complexity of the modeling; neglection of the gas allowed other aspects of the multi-region problem to be explored more readily. With the restriction of no noncondensables and since only the case of saturated vapor will be considered, the vapor is at a spatially uniform temperature, $\mathrm{T}_{\mathrm{CV}}$.

The free stream vapor velocity, $u_{\infty}$, is taken to be uniform axially. The effect of the vapor flow field on the films can be approximated using a shear stress which will obviate determination of the $\mathrm{y}$ dependence of the vapor velocity ${ }^{18}$. The shear stress is composed of two terms:

$$
\begin{aligned}
\tau_{c v}= & \frac{1}{8} f_{c v}\left(u_{\infty}-u_{c v}\right)\left|u_{\infty}-u_{c v}\right|+t_{c v}\left(u_{\infty}-u_{c v}\right) \\
& \text { (frictiona }) \quad \text { (mass transfer) }
\end{aligned}
$$


where $\mathbf{f}$ is the Darcy-Weisbach friction factor (based on vapor properties) which would be used in a flow calculation in the absence of condensation. Denny and Mi11s ${ }^{19}$ indicated that the mass-transfer component is the dominant term in most engineering applications involving high condensation rates. This was also found to be the case in the present work (cf. Section 2.3). The frictional component of the shear stress was thus neglected in the present work since retaining this term unnecessarily complicates the solution of the problem.

The sodium which might be present in a number of actual situations of interest will be neglected in the current work. Sodium might initially be present in the above-core region as a film on the surface of the structures. Fuel entering this region might initially try to condense on the sodium film. This should lead to vaporization of the sodium which would probably cause the fuel region to break up. The sodium film would have served as an insulative barrier between the fuel and steel during this time. The sodium film could also be stripped off and entrained by the flowing fuel vapor. Mixing sodium with the fuel vapor would quench the fuel vapor. This could lead to bulk condensation of the fuel rather than the surface condensation being considered in the current work. The bulk or homogeneous condensation process could be analyzed using techniques similar to those used by Kennedy ${ }^{20}$ in examining fuel vapor quenching by a noncondensable gas. The quenching process reduces the energy content and thus the work potential of the fuel; however, the energy transferred 
to the sodium would vaporize the sodium, and it will now contribute to the overall expansion work. The system expansion work with sodium entrainment can be a factor of two bigger than the fuel expansion work $^{21}$. Once sodium vapor is present in the fuel vapor stream, the vapor stream would have to be treated using methods slightly more complex than those which are required to treat a noncondensable gas mixed with the fuel vapor.

Surface waves could be present in both stagnant and flowing vapor situations; however, the films will be assumed to remain smooth in the current analyses. Kotake ${ }^{22}$, in analyzing stagnant vapor condensation, showed that the condensation rate increases as the wavelength of the disturbance decreased. Bankoff ${ }^{23}$ additionally showed that condensation has a stabilizing influence on the disturbance should one develop. The local condensation rate increases as the film thins at a given location, and this results in a higher condensation rate which will build up the film thickness. (The reverse behavior is observed if the film is evaporating.) Surface waves are also normally associated with flooding and entrainment phenomena in flowing vapor problems. Flooding refers to the situation where the vapor velocity is sufficiently high that the liquid in the films is flowing upward (with the vapor) rather than draining or flowing downward (against the vapor flow). The tops of the waves may be stripped off and entrained by the vapor for velocities higher than that required to change the film flow behavior from draining to flooding. Since the items discussed in this paragraph are actually transient 
phenomena, they will not be considered in the present steady-state analysis. Upward motion of the liquid will be observed over certain portions of the films in the flowing vapor calculations to be presented in Section 2.2, but will only be that amount due to the shearing action of the vapor on a smooth film surface.

The condensate and melt films will be treated as boundary layers as has been the practice in film condensation problems since the work of Sparrow and Gregg ${ }^{24}$. The materials within the films will be considered incompressible. The transport properties within a film will be constant and evaluated at an average temperature (cf. Appendix A). Discussion of the treatment of the solidified condensate layer is deferred until Sections 2.4 and 2.5.

While there are some CDA situations in which a large amount of power is still being produced in the flowing fuel vapor, this will be neglected in the current analysis. Cho and Epstein ${ }^{25}$ examined this effect (under the additional assumption of no substrate melting) and found that neglection of the internal heat generation in the fuel resulted in underestimating the heat flux into the substrate by less than $15 \%$ for power levels up to 10 times the nominal full power level (nominal power level in the fuel is $\sim 1 \mathrm{GW} / \mathrm{m}^{3}$ ). The viscous dissipation term in the energy equation will also be neglected.

The flow in the liquid layers will be assumed to be laminar. The results of the calculations will actually indicate that a large portion of the film should actually have been treated as turbulent. Allowing for turbulence ${ }^{26-28}$ would result in higher condensation coefficients 
than those obtained from the present laminar analysis. The amount of increase is a function of the Prandtl number (inter alia) and is smaller for the low ( 0.3) Prandt1-number fluids being considered here than it would be for normal fluids such as water.

Several assumptions must be made concerning the geometry of the substrate: it is in the form of a slab, the substrate is relatively thick, and the melting interface is planar. The first of these assumptions is only an approximation when the substrate of interest is the fuel pin cladding; the approximation should be reasonable since the thickness $(0.38 \mathrm{~mm})$ of the cladding is sma11 relative to its mean radius $(2.73 \mathrm{~mm})$. The steady-state analysis must be approached within the restriction that the substrate is infinitely thick in order to maintain constancy of boundary conditions in the moving coordinate frame. It will thus be difficult to say that any of the steady-state analysis applies directly to the actual situations of interest where the substrates are in fact very thin. The steady-state coefficients are of interest for two reasons: they provide a set of limiting results to which transient calculations can be compared when carried out to the steady-state limit; they also result in condensation rates which are conservative from an accident analysis viewpoint, since the steadystate coefficients should underestimate the actual condensation. The third assumption on substrate geometry is required in order for the melting boundary (and thus, through the boundary layer approximations, all regions) to be strictly vertical and parallel to the vapor flow. The melting rate is actually a function of axial position, and there 
will be curvature associated with this interface. This is not a bad approximation as long as the majority of the curvature is confined to a small region relative to the length of total interest. This assumption closely parallels the assumption made in the boundarylayer approximations where the curvature of the boundary layer during its buildup in the leading edge region is assumed to have a minor effect on the total flow field under consideration. Indeed, the boundary-1ayer approximations are not valid in this leading edge region since quantities (e.g. velocity) are varying as rapidly along the direction of flow as they are varying across the layer thickness. In Iine with this third approximation and for visual clarity, the pictorial representation of the geometries for the steady-state problems will have the melting interface vertical. Nothing in the steady-state analysis will, in fact, describe the actual location of this boundary relative to the original substrate boundary; a transient calculation is required to obtain this information.

This completes the discussion of the assumptions which are to be employed in the steady-state analyses. Having made the assumptions above, the conservation equations to be satisfied within the films are given by ${ }^{29}$

$$
\begin{aligned}
& \frac{\partial u}{\partial x}+\frac{\partial v}{\partial y}=0 \\
& u \frac{\partial u}{\partial x}+v \frac{\partial u}{\partial y}=g+v \frac{\partial^{2} u}{\partial y^{2}} \\
& u \frac{\partial \mathbb{v}}{\partial x}+v \frac{\partial T}{\partial y}=\alpha \frac{\partial^{2} T}{\partial y^{2}}
\end{aligned}
$$


where $\mathrm{u}$ and $\mathrm{v}$ are velocity components in the $\mathrm{x}$ and $\mathrm{y}$ directions, respectively, $\mathrm{T}$ is temperature, $v$ is the kinematic (or dynamic) viscosity, $\alpha$ is thermal diffusivity, and $g$ is the acceleration due to gravity. These equations will be altered in several of the following sections as additional assumptions must be made in order to facilitate a solution.

The boundary conditions to be imposed are very similar for all the problems to be discussed in the rest of this section; these will, however, be presented section by section since slightly different coordinate systems are used in the several steady-state problems considered. 


\subsection{Upward-Flowing Vapor}

Epstein and Cho have previously analyzed the cases of stagnant fuel vapor condensing on a vertical substrate ${ }^{13}$ and flowing fuel vapor condensing on a horizontal steel substrate ${ }^{14}$. Neither of these solutions allowed for the possibility that the condensed fuel might solidify. The problem in horizontal orientation utilized the thinfilm approximation ${ }^{14}$; this assumes that the convective transport terms (the left side of Equations 2.1-3 and 2.1-4) could be neglected. Use of this approximation linearizes the conservation equations which simplifies the solution. The body force term (i.e. $g$ in Equation 2.1-3) is, however, not present in the problem in horizontal orientation.

The remainder of this section is devoted to deriving the equations and presenting the results obtained for an extension of these previous works, essentially combining them, in order to examine the effect of upward-flowing vapor.

\subsubsection{Mode1 Development}

The geometry associated with this problem is shown in Figure 2-2. When the thin-film approximation is added to the assumptions already discussed in Section 2.1, the conservation equations are

$$
\begin{aligned}
\frac{\partial u_{i}}{\partial x}+\frac{\partial v_{i}}{\partial y} & =0 \\
0 & =g+v_{i} \frac{\partial^{2} u_{i}}{\partial y^{2}} \\
0 & =\frac{\partial^{2} T_{i}}{\partial y}
\end{aligned}
$$




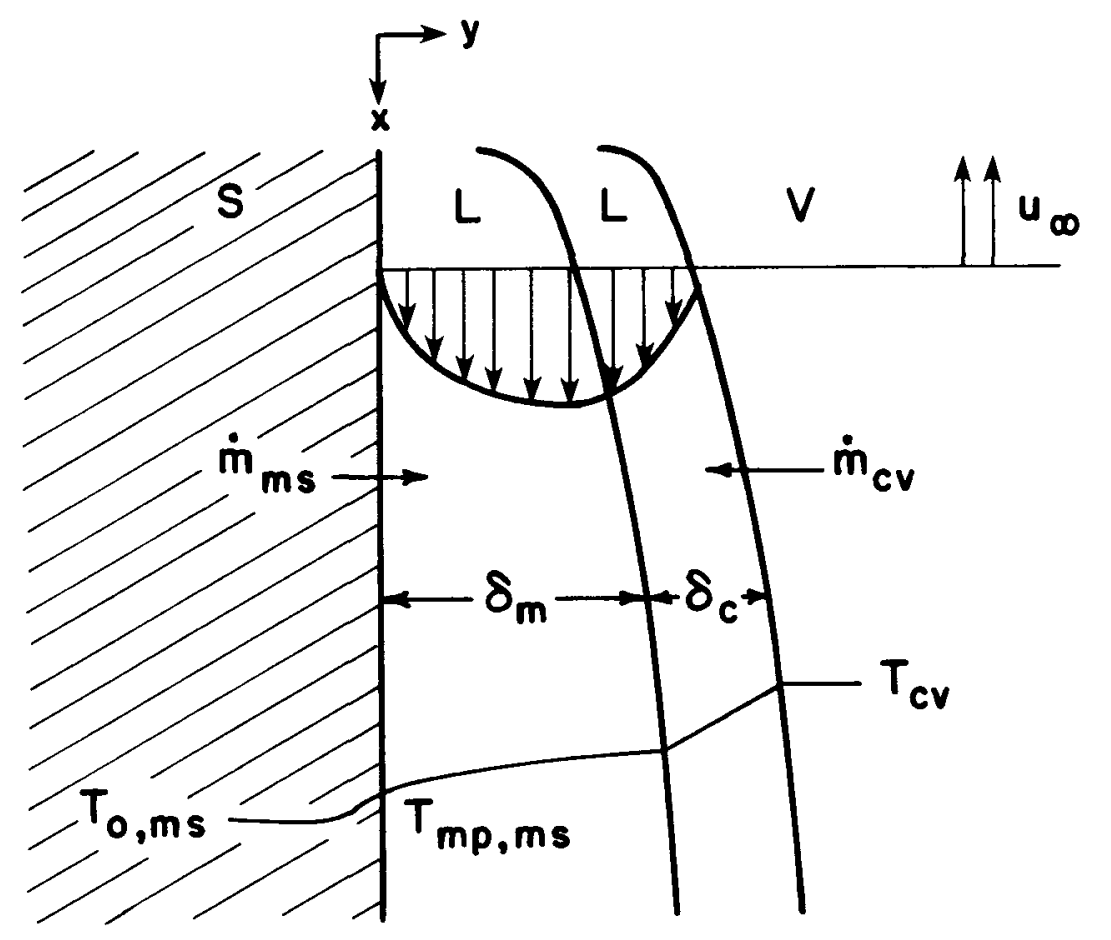

Figure 2-2. Schematic of geometry used for condensation of an upward-flowing vapor onto a melting substrate. 
where the subscript $i$ is a film index ( $i=c$ is the condensate, $i=m$ is the me1t).

The boundary and interface conditions associated with these equations are identical to those used in Reference 14 and are given by

$y=0$

$$
\begin{aligned}
\mathrm{T}_{\mathrm{m}} & =\mathrm{T}_{\mathrm{mp}, \mathrm{ms}} \\
\dot{\mathrm{m}}_{\mathrm{ms}} \mathrm{L}_{\mathrm{ms}}^{*}=k_{\mathrm{m}} \frac{\partial \mathrm{T}_{\mathrm{m}}}{\partial \mathrm{y}} & (2.2-4 \mathrm{a}, 8 \mathrm{a})
\end{aligned}
$$

$\mathrm{y}=\delta_{\mathrm{m}}$

$$
\begin{aligned}
& u_{m}=u_{c} \\
& \mathrm{~T}_{\mathrm{m}}=\mathrm{T}_{\mathrm{c}} \\
& (2.2-5 a, 10 a) \\
& \mu_{m} \frac{\partial u_{m}}{\partial y}=\mu_{c} \frac{\partial u_{c}}{\partial y} \\
& k_{m} \frac{\partial T_{m}}{\partial y}=k_{c} \frac{\partial T_{c}}{\partial y} \\
& (2.2-6 a, 11 a) \\
& \mathrm{y}=\delta_{\mathrm{m}}+\delta_{\mathrm{c}} \\
& \mathrm{T}_{\mathrm{C}}=\mathrm{T}_{\mathrm{cV}} \quad(2.2-12 \mathrm{a}) \\
& u_{c} \frac{\partial u_{c}}{\partial y}=\varepsilon \dot{m}_{c v}\left(u_{\infty}-u_{c v}\right), \quad k_{c} \frac{\partial T_{c}}{\partial y}=\dot{m}_{c v} L_{c v} \quad(2.2-7 a, 13 a)
\end{aligned}
$$

where $\mu$ is the absolute viscosity, $k$ is the thermal conductivity, $\dot{\mathrm{m}}$ is the phase change mass $\mathrm{flux}$, and $\mathrm{L}$ is the heat of phase change. The quantity $\mathrm{L}_{\mathrm{ms}}^{*}$ is an effective heat of fusion for the melting solid given by

$$
\mathrm{L}_{\mathrm{ms}}^{*}=\mathrm{L}_{\mathrm{ms}}+\gamma \mathrm{c}_{\mathrm{ms}}\left(\mathrm{T}_{\mathrm{mp}, \mathrm{ms}}-\mathrm{T}_{\mathrm{o}, \mathrm{ms}}\right)
$$

where $\gamma=1$ in steady-state analyses ${ }^{30}$. The excess momentum flux ${ }^{18}$ has been used in obtaining Equation $2.2-7$ and $\varepsilon=1$ in this equation. The other boundary conditions above are straightforward. 
Equation 2.2-2 and 2.2-3 may be integrated directly twice with respect to $y$ to find

$$
\begin{aligned}
& u_{i}(x, y)=a_{i}(x)+b_{i}(x) y-\frac{g}{2 v_{i}} y^{2} \\
& T_{i}(x, y)=d_{i}(x)+f_{i}(x) y
\end{aligned}
$$

Requiring Equation 2.2-16 to satisfy Equations 2.2-8a,10a,11a, and 12a allows $d_{i}(x)$ and $f_{i}(x)$ to be determined in terms of the $\delta_{i}(x)$ :

$$
\begin{aligned}
& \mathrm{d}_{\mathrm{m}}=\mathrm{T}_{\mathrm{mp}, \mathrm{ms}} \\
& \mathrm{f}_{\mathrm{m}}=\mathrm{Kf}_{\mathrm{c}} \\
& \mathrm{d}_{\mathrm{c}}=\mathrm{T}_{\mathrm{cv}}-(1+\mathrm{Z}) \delta_{\mathrm{c}} \mathrm{f}_{\mathrm{c}} \\
& \mathrm{f}_{\mathrm{c}}=\frac{\mathrm{T}_{\mathrm{cv}}-\mathrm{T}_{\mathrm{mp}, \mathrm{ms}}}{(1+\mathrm{KZ}) \delta_{\mathrm{c}}}
\end{aligned}
$$

where

$$
\begin{aligned}
& \mathrm{K} \equiv \frac{\mathrm{k}_{\mathrm{c}}}{\mathrm{k}_{\mathrm{m}}} \\
& \mathrm{z} \equiv \frac{\delta_{\mathrm{m}}}{\delta_{\mathrm{c}}}
\end{aligned}
$$

Equation 2.2-13a when combined with the above shows that

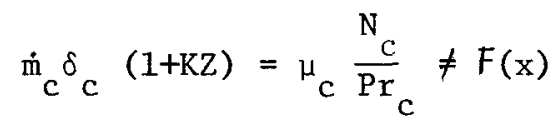

where

$$
\begin{aligned}
\mathrm{N}_{\mathrm{c}} & \equiv \frac{\mathrm{c}_{\mathrm{c}}\left(\mathrm{T}_{\mathrm{cv}}-\mathrm{T}_{\mathrm{mp}, \mathrm{ms}}\right)}{\mathrm{L}_{\mathrm{cv}}} \\
\operatorname{Pr}_{\mathrm{c}} & =\frac{\mu_{\mathrm{c}} \mathrm{c}_{\mathrm{c}}}{\mathrm{k}_{\mathrm{c}}} \quad \text { (Prandt1 number) }
\end{aligned}
$$


From Equation 2.2-9a one finds that

$$
\dot{\mathrm{m}}_{\mathrm{ms}} \mathrm{L}_{\mathrm{ms}}^{*}=\dot{\mathrm{m}}_{\mathrm{CV}} \mathrm{L}_{\mathrm{cV}}
$$

or

$$
\frac{\dot{\mathrm{m}}_{\mathrm{cV}}(\mathrm{x})}{\dot{\mathrm{m}}_{\mathrm{ms}}(\mathrm{x})} \neq F(\mathrm{x})
$$

This last result is a direct consequence of neglecting the convective energy transport within the films.

The coefficients $a_{i}(x)$ and $b_{i}(x)$ needed in Equation 2.2-15 are obtained by forcing the velocity profile to satisfy the boundary conditions given by Equations 2.2-4a through 2.2-7a:

$$
\begin{aligned}
& a_{m}=0 \\
& b_{m}=Y\left[b_{c}+(R-1) Z \frac{g \delta}{v_{c}}\right] \\
& a_{c}=(Y-1) Z \delta_{c} b_{c}+\left[\frac{1}{2}-Y+\frac{1}{2} R Y\right] Z^{2} \frac{g \delta_{c}^{2}}{\nu_{c}} \\
& \varepsilon \frac{\mathrm{N}_{\mathrm{c}}}{\mathrm{Pr}_{\mathrm{c}}} \frac{\mathrm{u}_{\infty}}{\delta_{\mathrm{c}}}+\left[(1+\mathrm{Z})(1+\mathrm{KZ})+\varepsilon \frac{\mathrm{N}_{\mathrm{c}}}{\mathrm{Pr}}\left(\frac{1}{2}+\mathrm{Z}+\mathrm{YZ}^{2}-\frac{1}{2} \mathrm{RYZ}^{2}\right)\right] \frac{\mathrm{g} \delta_{\mathrm{c}}}{\nu_{\mathrm{c}}} \\
& \mathrm{b}_{\mathrm{c}}=\frac{\mathrm{c}}{(1+\mathrm{KZ})+\varepsilon \frac{\mathrm{N}_{\mathrm{C}}}{\mathrm{Pr}}(1+\mathrm{YZ})}
\end{aligned}
$$

where

$$
\begin{aligned}
& \mathrm{R} \equiv \frac{\rho_{\mathrm{m}}}{\rho_{\mathrm{c}}} \\
& \mathrm{Y} \equiv \frac{\mu_{\mathrm{c}}}{\mu_{\mathrm{m}}}
\end{aligned}
$$

and Equation $2.2-13 \mathrm{~b}$ has been used to eliminate $\dot{\mathrm{m}}_{\mathrm{c}}$ in the above equations. 
At this point the problem has been reduced to finding the two film thicknesses as a function of $\mathrm{x}$. Knowing these, the mass transfer rates can be found from Equations 2.2-9b and 2.2-13b.

The two differential equations governing the film thickness are found by performing mass balances on each film at any $x$ location:

$$
\dot{\mathrm{m}}_{\mathrm{ms}}=\frac{\mathrm{d}}{\mathrm{dx}} \int_{0}^{\delta} \rho_{\mathrm{m} m} \mathrm{u}_{\mathrm{m}}(\mathrm{x}, \mathrm{y}) \mathrm{dy}=\frac{\mathrm{d}}{\mathrm{dx}}\left(\rho_{\mathrm{m}} \mathrm{m}_{\mathrm{m}} \overline{\mathrm{u}}_{\mathrm{m}}\right)
$$

and

$$
\dot{\mathrm{m}}_{\mathrm{cv}}=\frac{\mathrm{d}}{\mathrm{dx}} \int_{\delta_{\mathrm{m}}}^{\delta}{ }_{\rho_{c}}^{+\delta} \mathrm{c}_{\mathrm{c}}(\mathrm{x}, \mathrm{y}) \mathrm{dy}=\frac{\mathrm{d}}{\mathrm{dx}} \quad\left(\rho_{c} \delta_{c} \overline{\mathrm{u}_{c}}\right)
$$

where the alternate definition utilizes the film average (over y) velocity, $\bar{u}$. After substituting the coefficients for the velocity profiles from Equations 2.2-4b through 2.2-7b, performing the integrals, and eliminating $\dot{\mathrm{m}}$ via use of Equations $2.2-9 \mathrm{~b}$ and $2.2-13 \mathrm{~b}$, the two mass balances Equations 2.2-23a and 2.2-24a, respective1y, become

$$
\begin{aligned}
& \frac{\nu_{c}{ }_{c}}{\operatorname{Pr}_{c}{ }_{c}(1+K Z)}=J R \frac{d}{d x}\left[\frac { \frac { 1 } { 2 } \mathrm { YZ } ^ { 2 } \delta _ { c } ^ { 2 } } { ( 1 + K Z ) + \varepsilon \frac { N _ { c } } { \operatorname { P r } } ( 1 + Y Z ) } \left\{\varepsilon \frac{N_{c} u_{\infty}}{\operatorname{Pr}{ }_{c}{ }_{c}}\right.\right. \\
& \left.\left.+\left[\left(1+\frac{2}{3} \mathrm{RZ}\right)(1+\mathrm{KZ})+\left(\frac{1}{2}+\frac{2}{3} \mathrm{RZ}+\frac{1}{6} \mathrm{RYZ}^{2}\right) \varepsilon \frac{\mathrm{N}_{\mathrm{c}}}{\mathrm{Pr}_{\mathrm{c}}}\right] \frac{\mathrm{g}_{\mathrm{C}}}{{ }_{{ }_{\mathrm{c}}}}\right\}\right]
\end{aligned}
$$

and

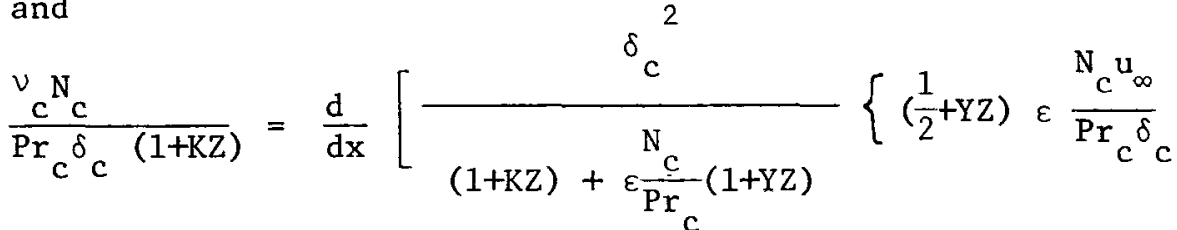

$$
\begin{aligned}
& \left.\left.+\left[\left(\frac{1}{3}+\mathrm{YZ}+\frac{1}{2} \mathrm{RYZ}^{2}\right)(1+\mathrm{KZ})+\left(\frac{1}{12}+\frac{1}{3} \mathrm{YZ}+\frac{1}{4} \mathrm{RYZ}^{2}\right) \frac{\mathrm{N}_{\mathrm{c}}}{\mathrm{Pr}_{\mathrm{c}}}\right] \frac{\mathrm{g} \delta_{\mathrm{c}}}{\nu_{\mathrm{c}}}\right\}\right]
\end{aligned}
$$


where

$$
J \equiv \frac{\mathrm{L}_{\mathrm{ms}}^{*}}{\mathrm{~L}_{\mathrm{cv}}}
$$

Equating these two equations, one finds that

$$
\frac{\mathrm{dH}}{\mathrm{dx}}=0
$$

where $\mathrm{H}$ is an integration constant given by

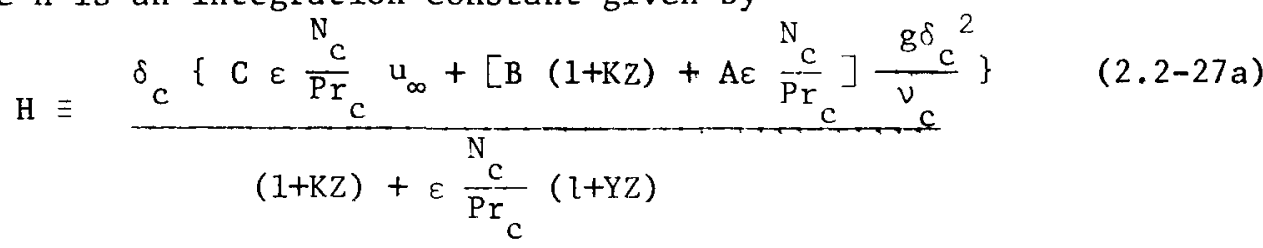

where

$$
\begin{aligned}
& \mathrm{A} \equiv \frac{1}{12}+\frac{1}{3} \mathrm{YZ}+\frac{1}{4}(1-\mathrm{J}) \mathrm{RYZ}^{2}-\frac{1}{3} \mathrm{JR}^{2} \mathrm{YZ}^{3}-\frac{1}{12} \mathrm{JR}^{2} \mathrm{Y}^{2} \mathrm{Z}^{4} \\
& \mathrm{~B} \equiv \frac{1}{3}+\mathrm{YZ}+\frac{1}{2}(1-\mathrm{J}) \mathrm{RYZ}^{2}-\frac{1}{3} \mathrm{JR}^{2} \mathrm{YZ}^{3} \\
& \mathrm{C} \equiv \frac{1}{2}+\mathrm{YZ}-\frac{1}{2} \mathrm{JRYZ}^{2}
\end{aligned}
$$

While the quantity $\mathrm{H}$ is constant, it contains both of the unknowns, $\delta_{c}$ and $z$, which are functions of position. Thus, using relationships from the differential calculus, Equation 2.2-26a may be written as

$$
0=\left.\frac{\partial H}{\partial \delta_{c}}\right|_{Z} \frac{d \delta_{C}}{d x}+\left.\frac{\partial H}{\partial Z}\right|_{\delta} \frac{d Z}{d x}
$$

or

$$
\frac{\mathrm{dz}}{\mathrm{dx}}=-\frac{\left.\frac{\partial \mathrm{H}}{\partial \delta_{\mathrm{c}}}\right|_{\mathrm{Z}}}{\left.\frac{\partial \mathrm{H}}{\partial \mathrm{Z}}\right|_{\delta_{c}}} \frac{\mathrm{d} \delta_{\mathrm{c}}}{\mathrm{dx}}
$$

Equation $2.2-26 c$ provides a relationship between the derivatives with respect to $x$ of the two unknowns $\left(\delta_{c}\right.$ and $\left.z\right)$. This relationship 
may be used to eliminate $\frac{d Z}{d x}$ from Equation 2.2-4b (or Equation 2.2-23b) in order to find

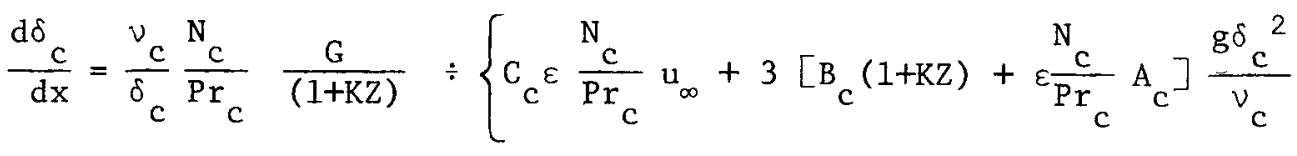

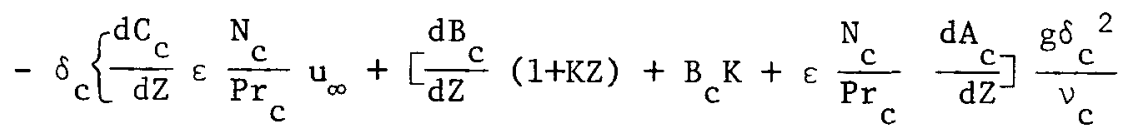

$$
\begin{aligned}
& \left.\left.-\left\{C_{c} \varepsilon \frac{N_{c}}{P r_{c}} u_{\infty}+\left[B_{c}(1+K Z)+\varepsilon \frac{N_{c}}{\operatorname{Pr}_{c}} A_{c}\right] \frac{g_{c}{ }_{c}^{2}}{\nu_{c}}\right\} \frac{1}{G} \frac{d G}{d Z}\right\} \frac{\left(\partial H / \partial \delta{ }_{c}\right)}{(\partial H / \partial Z)_{\delta}}\right\}
\end{aligned}
$$

where*

$$
\begin{aligned}
& A_{C} \equiv \frac{1}{12}+\frac{1}{3} \mathrm{YZ}+\frac{1}{4} \mathrm{RYZ}^{2} \\
& \mathrm{~B}_{\mathrm{C}} \equiv \frac{1}{3}+\mathrm{YZ}+\frac{1}{2} \mathrm{RYZ}^{2} \\
& \mathrm{C}_{C} \equiv \frac{1}{2}+\mathrm{YZ} \\
& \mathrm{G} \equiv(1+\mathrm{KZ})+\frac{\mathrm{N}_{\mathrm{C}}}{\mathrm{Pr}}(1+\mathrm{YZ})
\end{aligned}
$$

At this point in the derivation, the two equations have been specified which must be integrated with respect to $\mathrm{x}$ in order to find the film thicknesses. The condensation and melting rates may be obtained from Equations 2.2-9b and 2.2-13b once the film thicknesses are known. While the differential equations for the film thicknesses are only of first order, the coupling between the two equations is such that they cannot be uncoupled for analytical integration. The

The quantities $A_{C} B_{c}$, and $C_{c}$ are composed of terms appearing in $A, B$, and $C$, respectively, and are in fact the terms which come from the mass balance on the condensate film (Equation 2.2-24b). 
integration was thus performed numerically using a computer subroutine based on the method developed by Bulirsch and Stoer ${ }^{31}$.

The differential equations may be rearranged into forms in which the variables of interest are nondimensionalized with respect to the vapor speed. The key definitions required are

$$
\begin{aligned}
& \mathrm{X} \equiv \frac{\mathrm{gx}}{\mathrm{u}_{\infty}{ }^{2}} \\
& \Delta \equiv\left[\frac{\mathrm{g}}{\nu\left|\mathrm{u}_{\infty}\right|}\right]^{\frac{1}{2}} \delta \\
& \dot{\mathrm{M}} \equiv \frac{\dot{\mathrm{m}}}{\rho}\left[\frac{\left|\mathrm{u}_{\infty}\right|}{\mathrm{g} \nu}\right]^{\frac{1}{2}} \\
& \mathrm{U} \equiv \frac{\mathrm{u}}{\left|\mathrm{u}_{\infty}\right|}
\end{aligned}
$$

along with the previous definition of $z$. The associated liquid film properties are used in $\dot{M}$ (e.g., $\dot{M}_{c v}$ will involve $\rho_{c}, \nu_{c}$, and $\left.\dot{m}_{c v}\right)$. The derivation has not been presented using these forms since it obscures the limiting behavior of the equations for the cases of $u_{\infty} \rightarrow 0$ and $g \rightarrow 0$. The scaling of results with vapor speed means that it is necessary to perform the spatial integration for only a single vapor speed for each $\left(\mathrm{T}_{\mathrm{cv}}, \mathrm{T}_{\mathrm{o}, \mathrm{ms}}\right)$ combination. Results for any other vapor speed may be obtained by multiplying these results by the appropriate powers (given by the dimensionless variables) of the ratio of the vapor speeds for the two cases.

\subsubsection{Integration Starting Values}

A pair of starting values for the problem must be specified in order to integrate Equations $2.2-24 c$ and $2.2-26 c$. These starting values could be, for example, $\delta_{c}$ and $z$ at $x=0$, which will be the top of the condensing region. The selection process is rather complicated 
and is based on an extrapolation of the behaviors found in several upward-flowing-vapor condensation problems where only a single film was present (e.g., problems similar to those solved by Jakob ${ }^{32}$ and by Denny and Mills ${ }^{33}$ ). The theory behind the selection process described below is that the behaviors present in the single film problem (which all had closed-form analytical solutions) should be present in the two $f 11 \mathrm{~m}$ problem. The character of solution and the starting values must be examined for three ranges of vapor speeds: low, moderate and high. The numerical values of the vapor speed which separate these ranges are a function of the substrate length, and the ranges correspond, respectively, to a large, medium, and small characteristic $\mathrm{X}$ for the problem.

\section{Low Speed Vapor}

The films are in a draining situation over the majority of the substrate length when the vapor speed is low. There is no location where the total film thickness, $\left(\delta_{m}+\delta_{c}\right)$, is zero (except for the case when $u_{\infty}=0$ ). The minimum film thicknesses do occur at the top of the condensing region, denoted $x=0$, and the first derivative of each film thickness with respect to $x$ is infinite at this location. As one approaches the location $x=0$ from below (i.e., from $x>0$ ), the films are decreasing in thickness and the mass fluxes are increasing. Figure 2-3 illustrates the spatial sequencing of characteristic events to be observed in the solution. As the films get thinner, it is easier to maintain a larger fraction of the film in an upflow condition due to the increased condensation rate and, 


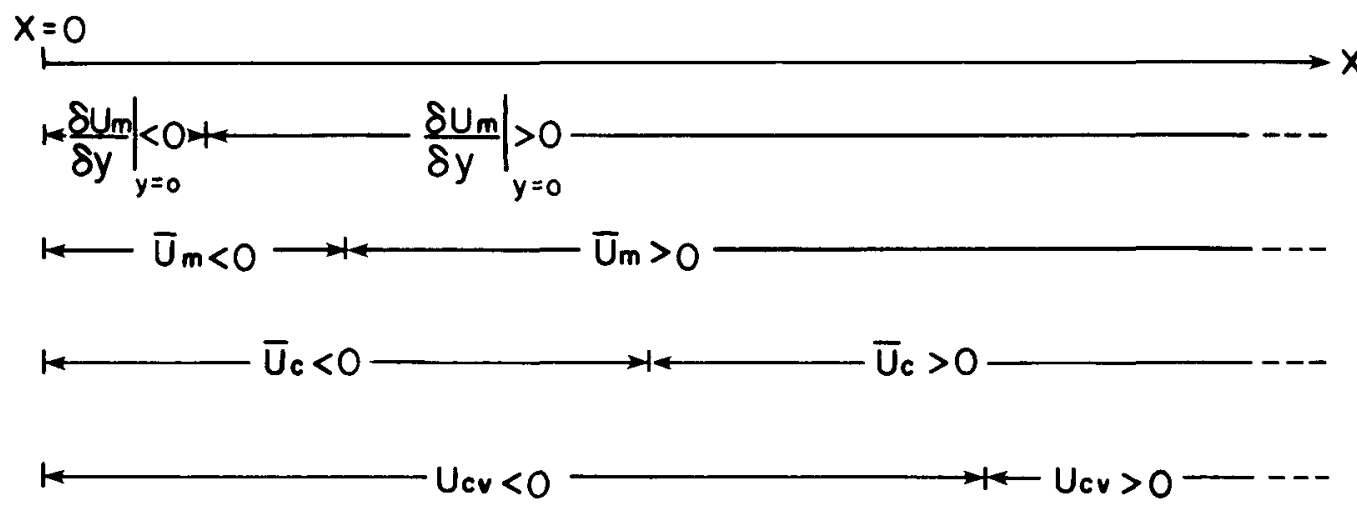

Figure 2-3. Spatial sequencing of key events for upward-flowing vapor condensing onto a vertical, melting substrate. (Figure is "to scale" for $\mathrm{T}_{\mathrm{cV}}=5000 \mathrm{~K}$ and $\mathrm{T}_{\mathrm{o}, \mathrm{ms}}=300 \mathrm{~K}$ if the $X$ axis is actually $x^{\frac{1}{4}}$.) 
thus, the shear stress at the condensate/vapor interface. The variations in quantities with axial location should be monotonic.

The expected behaviors detailed in the preceding paragraph are only qualitative and do not directly provide the specific values of $\delta_{c}$ and $Z$ needed to start the integration. The above conditions are sufficient, however, to determine that the value of the integration constant, $\mathrm{H}$, is negative. This is more easily seen if the expression for $\mathrm{H}$ is rederived using the mean-film-velocity forms of the mass transfer fluxes (Equations 2.2-23a and 24a). This will show that

$$
\mathrm{H}=\left(\rho_{c} \delta_{c} \bar{u}_{c} L_{c v}-\rho_{m} \delta_{m} \bar{u}_{m} L_{m s}^{*}\right) /\left(\rho_{c} L_{c v}\right)
$$

When flow reversal occurs in the condensate film $\left(\bar{u}_{c}=0\right)$, the melt film will still be in downflow (i.e. $\vec{u}_{m}>0$ ). At a higher axial location on the substrate, flow reversal will occur in the melt film $\left(\bar{u}_{m}=0\right)$ with the condensate film in upflow $\left(\bar{u}_{c}<0\right)$. These behaviors force $\mathrm{H}$ to be negative.

While the above discussion was directed toward showing that $\mathrm{H}$ is strictly negative, it is interesting to consider the case of $\mathrm{H}$ being identically zero. If one were to postulate that both film thicknesses were zero at some location simultaneously, then the integration constant would be zero. The problem actually has two solutions: an upflow piece and a (predominantly) downflow piece, where the flow direction refers to the films. The upflow piece is the portion of the solution which actually has both film thicknesses zero simultaneously and is discussed later under the "hjgh vapor speed" heading. The downflow portion is the one appropriate for low vapor 
speed. This portion of the solution exhibits a zero thickness melt film and zero mean velocity in the condensate film at the top of the substrate. The first of these two conditions corresponds to a picture of no melting occurring at the top of the condensing region. This might occur due to an excessive amount of substrate cooling, perhaps being provided by a large mass of sodium being present above the region. While this type of condition may seem appropriate in some instances, normally this type of boundary condition is not imposed on a solution but is one of the results trying to be obtained from the solution. This downflow portion of the $H=0$ solution is actually just one of an infinite number of solutions in which one or more characteristic quantities do not exhibit the expected monatonic behaviors; specifically, the condensate film has minimum film thickness at a location below rather than at the top of the substrate. The appropriate value for the integration constant was actually found by a trial and error process. Two types of solutions could be obtained for arbitrarily chosen, but negative, $\mathrm{H}$ values: as the integration proceeded toward the point of minimum total film thickness either $\delta_{m}$ or $\delta_{c}$ attains a minimum thickness and then increases as the integration continues up the substrate. These behaviors are introduced, respectively, by

$$
\left.\frac{\partial \mathrm{H}}{\partial \delta_{\mathrm{c}}}\right|_{\delta_{\mathrm{m}}}=0
$$

or

$$
\left.\frac{\partial H}{\partial \delta_{m}}\right|_{\delta_{c}}=0
$$


as can be seen by writing Equation 2.2-26b using $\delta_{\mathrm{m}}$ rather than $\mathrm{Z}$.

Both of these partial derivatives must be zero at the same axial

location in order to have both film thickness (and thus other

quantities) exhibit monotonic behaviors. This is equivalent to requiring

$$
\left.\frac{\partial \mathrm{H}}{\partial \delta_{\mathrm{C}}}\right|_{\mathrm{Z}}=0
$$

simultaneously with

$$
\left.\frac{\partial \mathrm{H}}{\partial \mathrm{Z}}\right|_{\delta_{\mathrm{C}}}=0
$$

since the following relationships hold:

$$
\left.\left.\frac{\partial \mathrm{H}}{\partial \delta_{\mathrm{m}}}\right|_{\delta_{\mathrm{c}}} \equiv \frac{1}{\delta_{\mathrm{c}}} \frac{\partial \mathrm{H}}{\partial \mathrm{Z}}\right|_{\delta_{\mathrm{c}}}
$$

and

$$
\left.\left.\frac{\partial \mathrm{H}}{\partial \delta_{c}}\right|_{\delta_{\mathrm{m}}} \equiv \frac{\partial \mathrm{H}}{\partial \delta_{c}}\right|_{\mathrm{Z}}-\left.\frac{\mathrm{Z}}{\delta_{c}} \frac{\partial \mathrm{H}}{\partial \mathrm{Z}}\right|_{\delta_{c}}
$$

This conditions was satisfied numerically by finding the proper $\left(\delta_{C}, Z\right)$ combination required in order to simultaneously zero the two partial derivatives. A Newton-Raphson iterative technique ${ }^{34}$ was used. There are actually three sets of non-negative ordered pairs which will satisfy Equations 2.2-39 and 40 . The two which must be discarded correspond to the cases

i) $\delta_{c} \rightarrow 0 ; \delta_{m} \rightarrow 0 ; Z=$ positive root of $C$

ii) $\delta_{c}{ }^{+\infty} ; \delta_{m}^{+\infty} ; Z=$ positive root of $A \varepsilon \frac{\mathrm{N}_{C}}{\mathrm{Pr}_{\mathrm{C}}}+(1+\mathrm{KZ}) \mathrm{B}$

Two further points should be noted about the condition imposed by Equations 2.2-39 and 40. Firstly, the $\left(\delta_{c}, Z\right)$ pair obtained are 
not the values at $x=0$. This condition actually occurs near, but at a somewhat smaller $\mathrm{x}$ location than, the location of zero wall shear stress (which is also the point of total flow reversal in the melt film). The integration proceeded upward from this condition to find the actual conditions at $x=0$ (a location signified by the derivatives of the film thicknesses heading toward infinite values). Secondly, the condition specified by Equations 2.2-39 and 40 represents a potential singularity in the equations, at least when formulated numerically, since it results in a $\frac{0}{0}$ condition (cf. Equation 2.2-26c). Attempts to find the limiting value of the ratio of the two partial derivatives at this point (or to show that a limit even exists) met with little success.

High Speed Vapor

For very high vapor speeds, the current equations possess a solution where the films are in a (stable) upflow condition over the entire substrate length. In this case, the minimum film thicknesses occur at the bottom of the condensing region and the film thicknesses are identically zero at this point (i.e. $\mathrm{H}=0$ ). This corresponds to case $\underline{i}$ discussed on $p .31$. As the integration proceeds up the plate, the films get thicker and the average flow velocities increase (actually attaining smaller absolute values but still negative). The point is eventually reached where the shear imparted to the film by the condensing vapor is no longer sufficient to support the weight of the film and counteract the wall shear stress. The solution breaks down at this point. For the current materials this occurs 
at dimensionless integration distances, $\mathrm{x}$, of $-6 \times 10^{-3}$ to $-9 \times 10^{-3}$. Expressed in different terms, the vapor velocity must be on the order of -35 to $-45 \mathrm{~m} / \mathrm{s}$ in order to maintain this upflow condition over a $1.2 \mathrm{~m}$ long substrate. The average mass transfer rates resulting from this calculation will be about $5 \%$ lower than those one would calculate using a horizontal geometry, flowing vapor model (e.g. Reference 14). The closeness of the two solutions is due to the gravity term being unimportant when the films are thin, which is the case over the majority of the substrate length in the vertical case. The gravity terms are important in the short region just below the point where the solution breaks down and indeed are responsible for the breakdown.

For high vapor speeds, the possibility of entrainment of liquid from the film into the vapor must be evaluated. Neglecting the effect of condensation on the entrainment process, the work of Ishii and Grolmes 35 predicts that the minimum vapor speed required for entrainment in the cocurrent upflow configuration ranges from $6 \mathrm{~m} / \mathrm{s}$ $\left(\mathrm{T}_{\mathrm{CV}}=6000 \mathrm{~K}\right)$ to $37 \mathrm{~m} / \mathrm{s}\left(\mathrm{T}_{\mathrm{cV}}=4000 \mathrm{~K}\right)$. Thus the applicability of the model derived in Section 2.2.1 to high speed vapor flows is questionable since the vapor speeds required for this cocurrent upflow solution to exist over practical substrate lengths are higher than the minimum speeds required for entrainment (a process not included in the model). Moderate Speed Vapor

The vapor speed is too low in this range in order to have the normal upflow solution $(\mathrm{H}=0)$ hold together over the entire length 
of the substrate. It is possible to use the normal downflow solution $(\mathrm{H}<0)$ to obtain results. This solution nomally has a region in which the flow veloctties in the films are upward. For the moderate vapor speeds, this region will extend over a large portion of the substrate length. For the current materials, a vapor speed greater than $12 \mathrm{~m} / \mathrm{s}$ will result in having net upflow in the condensate film over a $1.2 \mathrm{~m}$ long substrate. The moderate vapor speeds also cause the region in which the film thickness are varying rapidly in the downflow $(\mathrm{H}<0)$ solution to extend over a significant portion of the substrate length. Additionally the films are getting rather thick. These behaviors are, collectively, beginning to violate the assumptions associated with the boundary-layer approximations.

There are two other phenomena which are probably important in this vapor speed range: surface waves and entrainment of the film by the vapor flow. Neither of these effects are included in the present model formulation; however, they may need to be included in order to model this vapor speed range properly.

This vapor speed range has received little analytical attention and is not considered in the current work. Kutateladze and Borishanskii ${ }^{36}$ report that Nusselt ${ }^{7}$ analyzed the effect of vapor velocity on the film condensation coefficients associated with a nonmelting vertical substrate. This work showed that the condensation coefficients associated with moderate upward vapor speeds form a smooth transition between those calculated for low vapor speeds (where $h$ decreases as $\left|u_{\infty}\right|$ increases) and high vapor speeds (where 
$\hat{\mathrm{h}}$ increases as $\left|u_{\infty}\right|$ increases). The original Nusselt paper has not been obtained by the present author; thus it is not possible to say what phenomena were included in order to obtain this transition. Such a smooth transition between the low and high vapor speed ranges cannot be obtained using the model derived in Section 2.2.1.

\subsubsection{Results}

Selected results which have been obtained for the steady-state condensation of upward flowing fuel vapor onto a melting steel substrate are shown in Figure 2-4. These figures show the dimensionless condensation mass flux $\left(\dot{\mathrm{M}}_{\mathrm{CV}}\right)$, the dimensionless thickness of the condensate flim $\left(\Delta_{c}\right)$, and the ratio of melt film thickness to the condensate film thickness $(Z)$ as a function of the dimensionless axial location on the substrate $(\mathrm{X})$. The melting rate may be obtained from $M_{\mathrm{cv}}$ by using Equation 2.2-9b. The insert table in the figures shows the results at $\mathrm{X}=0$. The limiting behavior of the results shown for large $X$ are: $\delta \times x^{-\frac{1}{4}}, Z \rightarrow$ constant, and $\dot{m} \propto \mathrm{x}^{-\frac{1}{4}}$. These behaviors are those associated with the entire $x$ range for stagnant vapor problems; they are the limiting behaviors for thick films in the flowing vapor problem since the surface velocity of the film is large when compared with the vapor velocity.

It has not been possible to specify analytically the variation of the film thicknesses with position along the substrate. Based on an extrapolation of results from a single film problem ${ }^{33}$, one would expect the results to be of the form

$$
\Delta=\xi_{1}\left[1+\xi_{2} x^{\frac{1}{2}}\right]^{\frac{1}{2}}
$$




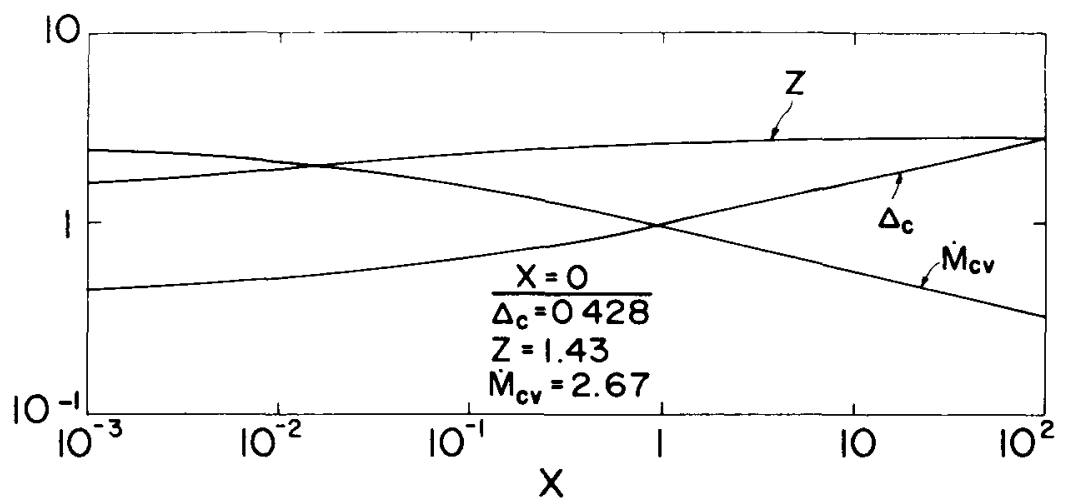

(a) $T_{c v}=4000 \mathrm{~K}$

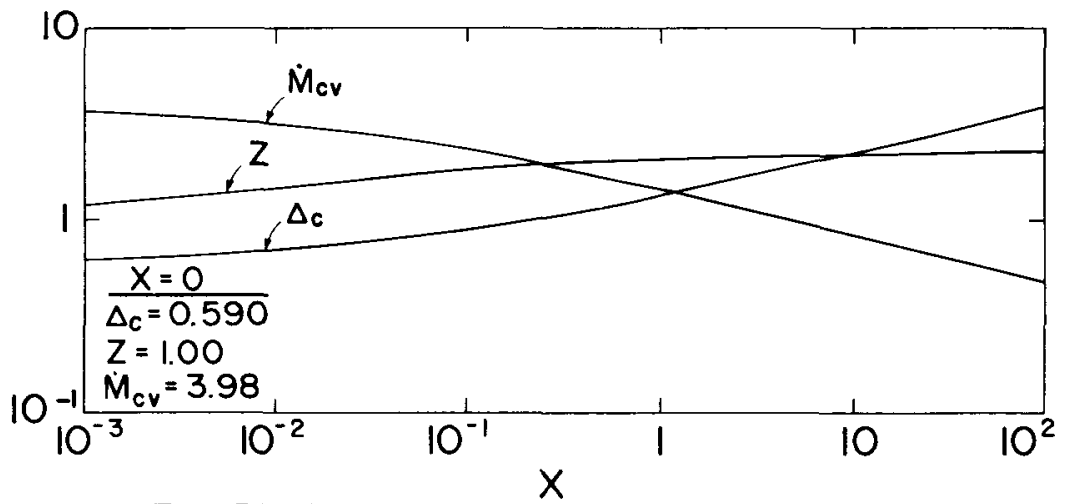

(b) $T_{c v}=5000 \mathrm{~K}$

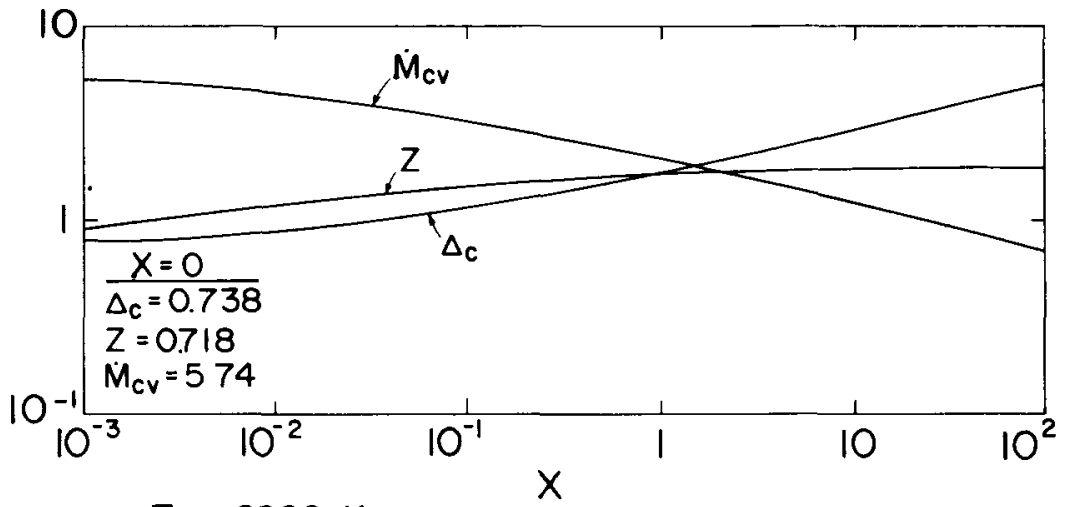

(c) $T_{C V}=6000 \mathrm{~K}$

Figure 2-4. Dimensionless condensation mass flux $\left(\dot{M}_{\mathrm{cV}}\right)$,

dimensionless condensate film thickness $\left(\Delta_{C}\right)$, and ratio of melt thickness to condensate thickness (Z) as a function of dimensionless axial location ( $\mathrm{X}$ ) for the steady-state condensation of upward flowing fuel vapor at temperature $\mathrm{T}_{\mathrm{cv}}$ onto melting steel with $\mathrm{T}_{\mathrm{o}, \mathrm{ms}}=800 \mathrm{~K}$. 
where $\xi_{1}$ and $\xi_{2}$ are positive coefficients. These coefficients are constants in the single film problem (either with or without substrate melting). The form of Equation 2,2-41 and the actual values of $\xi_{1}$ and $\xi_{2}$ can be shown to result from superposition of the following two problem solutions for the single film cases:

i) horizontal substrate, flowing vapor: $\delta \propto \mathrm{x}^{\frac{1}{2}}$

ii) vertical substrate, stagnant vapor: $\delta \propto x^{\frac{1}{4}}$

The current two-film problem results do not follow this pattern identically. It is not clear which quantities (if any) should be obtained by superposition: for example, $\delta_{c}$ and $\delta_{m}$ individually or just the total film thickness, $\delta_{m}+\delta_{c}$.

The results of the several cases calculated using the two-film model are more easily compared by examining spatially averaged results. A quantity of interest in the current work is the average condensation rate. This may be obtained using the definition

$\left.\hat{\mathrm{m}}_{\mathrm{cv}}\right|_{\mathrm{x}=\mathrm{x}_{\mathrm{L}}}=\frac{\int_{\mathrm{O}}^{\mathrm{x}_{\mathrm{L}}} \dot{\mathrm{m}}_{\mathrm{cv}} \mathrm{dx}}{\int_{\mathrm{O}}^{\mathrm{x}_{\mathrm{L}} \mathrm{dx}}}$

which upon use of Equation 2.2-24a becomes

$\left.\hat{\dot{m}}_{c v}\right|_{x=x_{L}}=\frac{\rho_{c}}{x_{L}}\left[\left.\left(\delta_{c} \bar{u}_{c}\right)\right|_{x=x_{L}}-\left.\left(\delta_{c} \bar{u}_{c}\right)\right|_{x=0}\right]$

The results of this calculation for the three cases shown in Figure 2-4 are shown in Figure 2-5 in dimensionless form. While this figure clearly shows that for a fixed vapor speed the average condensation rate decreases with increasing substrate length, it obscures the effect of vapor speed on the average condensation rate for a fixed substrate 


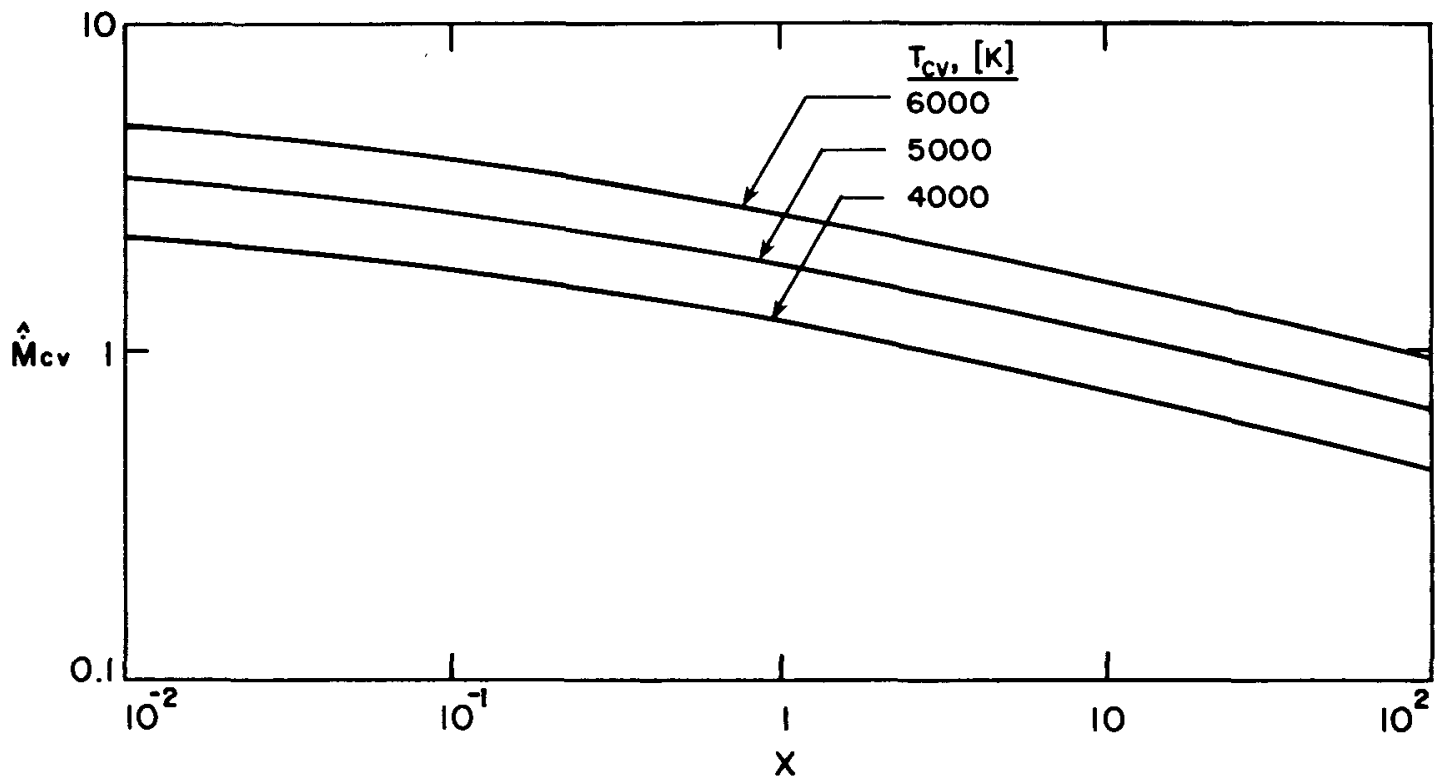

Figure 2-5. Dimensionless average condensation mass flux as a function of the dimensionless averaging length for the steady-state condensation of upward-flowing vapor onto melting steel with $\mathrm{T}_{\mathrm{o}, \mathrm{ms}}=800 \mathrm{~K}$. 
length. In order to illustrate this latter effect, a reference substrate length of $1.2 \mathrm{~m}$ has been chosen and the results shown in Figure 2-5 have been converted to average condensation heat transfer coefficients using the following definition:

$$
\hat{\mathrm{h}}_{\mathrm{cv}} \equiv \frac{\hat{\dot{\mathrm{m}}}_{\mathrm{cv}} \mathrm{L}_{c v}}{\left(\mathrm{~T}_{\mathrm{cv}}-\mathrm{T}_{\mathrm{o}, \mathrm{ms}}\right)}
$$

This condensation coefficient is based on the energy leaving the vapor space rather than the definition commonly used in single film problems which is based on the energy flux into the substrate.

The average condensation heat transfer coefficients implied by Figure 2-5 are shown in Figure 2-6 as a function of the speed of the vapor. The results obtained for condensation of flowing fuel vapor onto a horizontal melting steel substrate (calculated using the model presented in Reference 14) are also shown in this figure for comparison.

Vapor speed is seen to have opposite effects on condensation rates for the two geometries. In vertical orientation, increasing the (upward) speed of the vapor retards the draining flow in the films causing them to be thicker and a bigger resistance to heat transfer. The reverse of this occurs in the horizontally oriented problems. The behavior at $u_{\infty}=0$ is particularly interesting. In the vertical case, the films are still flowing downward due to gravity, and the problen reaches a steady state. In the horizontal case, the flowing vapor is the only force driving the film flow; when the vapor speed is zero, the films do not flow, and the problem reduces to a conduction heat transfer exercise whose steady-state solution of infinite film thickness and zero condensation (coefficient) is reached after an infinite time. 


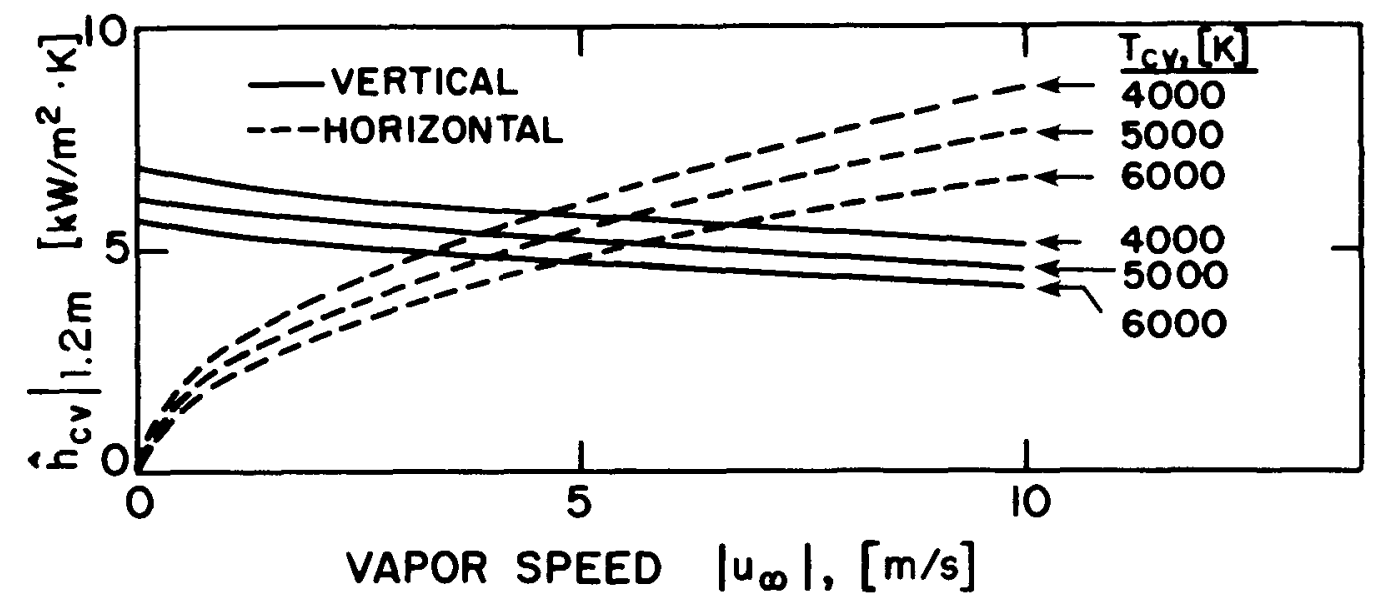

Figure 2-6. Condensation heat transfer coefficient averaged over $1.2 \mathrm{~m}$ as a function of vapor speed for the steadystate condensation of flowing fuel vapor onto a steel substrate with $\mathrm{T}_{\mathrm{o}, \mathrm{ms}}=800 \mathrm{~K}$. 
In addition to the effect of the vapor speed being opposite for the two problem orientations, the reduction in condensation rate in vertically oriented problems is much less than the increase seen in horizontally oriented problems.

As discussed in Section 2.2.2, the net flow in the condensate $\mathrm{f} 1 \mathrm{~lm}$ is upward for vapor speeds ${ }^{*}$ greater than $12 \mathrm{~m} / \mathrm{s}$. When the vapor speed reaches 35 to $45 \mathrm{~m} / \mathrm{s}$ it is possible to have a situation where all film flows are upward and the films are thinnest at the bottom of the condensing region. The condensation coefficients for this range of vapor speeds may be closely approximated by extending the lines in Figure 2-6 for horizontal cases using a $\left|u_{\infty}\right|^{\frac{1}{2}}$ extrapolation. The current model is probably not strictly applicable for vapor speeds between 12 and $40 \mathrm{~m} / \mathrm{s}$. This is the velocity range where surface waves and entrainment could be important phenomena. Based on earlier work, 7,36 the condensation coefficient should initially continue to decrease, pass through a minimum, and then increase with increasing vapor speed.

2.3 Importance of Convective Transport Terms and Shear Stress at the Condensate/Vapor Interface

The importance of several modeling approximations in the two-film problem will be examined in this section. Specific topics to be examined are the convective transport terms, $(\vec{u} \cdot \vec{\nabla})(u, T)$, in the

\footnotetext{
* The vapor speeds stated are a function of the substrate length, and all numbers given in this paragraph are for a $1.2 \mathrm{~m}$ long substrate.
} 
conservation equations and the shear stress at the condensate/vapor interface.

A number of these topics have been examined previously for singlefilm, stagnant-vapor, vertical, non-melting-wall cases. Rosenhow 37 found that inclusion of the convective energy transport in the film resulted in higher condensetion rates than those calculated from the Nusselt ${ }^{7}$ analysis (no convective terms). Sparrow and Gregg ${ }^{24}$ retained both convective terms and found the condensation rates to be lower than those obtained from the Nusselt ${ }^{7}$ analysis; the degree of the reduction increases with decreasing PrandtI number. These last two analyses neglected the shear stress at the condensate/vapor interface as was done in the Nusselt work to which the results were compared. Koh et al. ${ }^{38}$ found that including the shear stress at the condensate/vapor interface resulted in lower condensation rates than are calculated when this shear stress is neglected; this effect is also more important at low Prandt 1 number than at high Prandtl numbers. The shear stress was also examined by Rosenhow et a1. ${ }^{28}$ however it is difficult to draw meaningful conclusions from this paper.*

These items will now be discussed for the two-film condensationinduced melting problem. The modeling approximations will all be discussed first, and then a comparative results summary wi11 be presented.

\footnotetext{
* The results were presented as plots of Nusselt number versus Reynolds number for various values of the (spatially constant) shear stress at the condensate/vapor interface; however, for a given substrate length, the shear stress and Reynolds number are not completely independent. Convective transport terms were neglected but the film was allowed to be turbulent in this analysis.
} 
The convective transport terms were assumed negligible in the previous section in order to linearize the conservation equations. Having found that solution, it was possible to go back and at least estimate the magnitude of the terms which were neglected. These terms appeared to be important over the range of vapor speeds from 0 to $10 \mathrm{~m} / \mathrm{s}$; however, the terms were unimportant over a longer length of substrate for the higher vapor speeds. Since the vapor motion opposes the gravity-driven film flow, there will always be a region where the velocities in the films are small and in which the convective terms should be the least important.

These calculations did not indicate what effect the inclusion of these terms would have on the predicted condensation rates. To examine this effect several non-flowing vapor problems have been examined. The stagnant vapor problem is easier to work with mathematically since similarity transforms exist for gravity-driven film flow problems which will convert the partial differential equations to a system of ordinary differential equations.

Epstein and Cho ${ }^{13}$ have presented a solution to the problem of steady-state condensation of a non-flowing vapor onto a vertically oriented melting substrate. The problem considered both the condensate and melt films. The shear at the condensate/vapor interface utilized Equation 2.2-7a with $\varepsilon=1$ and $u_{\infty}=0$. The convective terms in both the momentum and energy equations were retained. After performing the similarity transform, the integral approximation was employed. This requires the momentum and energy equations to be 
satisfied after they have been integrated across the film (i.e. the y direction) rather than to be satisfied at each point within the films. This reduces the system of ordinary differential equations to a system of nonlinear algebraic equations which are much easier to solve. The integral approximation has been shown to agree very well with the solutions obtained by satisfying the conservation equations pointwise. 39

A second modeling approximation examined was the neglection of the convective momentum terms but retaining the convective energy terms. This linearizes the momentum equation and allows the velocity field to be specified in terms of the (unknown) film thicknesses for use in the energy equation. It was hoped that retention of the convective energy terms would be more important than the convective momentum terms in terms of generating the correct condensation rate. This model was derived and solved using the same equations and techniques as were used in Reference 13 except the momentum equation to be used is

$$
0=g+v_{i} \frac{\partial^{2} u_{i}}{\partial y^{2}}
$$

which after the similarity transformation is applied becomes

$$
F_{i}^{\prime \prime \prime}+1=0
$$

(replacing Equations 7 and 9 of Reference 13).

A third modeling approximation examined was the neglection of both convective momentum and energy terms for stagnant vapor condensation. The equations for this model may be obtained by 
setting $u_{\infty}=0$ in the derivation presented in Section 2.2.1. Calculations were performed with this model both with $(\varepsilon=1)$ and without $(\varepsilon=0)$ the shear at the condensate vapor interface. This modeling approximation with $\varepsilon=0$ would be the Nusselt approximation for the two-film problem, since it utilizes the same approximations he employed in his now classic single film condensation work ${ }^{7}$.

A summary of the results calculated by applying each of these models to the fuel/stee1 system is presented in Table 2-1. The main point to be illustrated here is the effect of these approximations on the condensation and melting mass fluxes. This is shown graphically in Figure 2-7 for $\mathrm{T}_{\mathrm{O}, \mathrm{ms}}=800 \mathrm{~K}$. As the degree of modeling sophistication is reduced (moving from curve 4 to curve 1) both phase change rates are being progressively overestimated. The inclusion of the shear stress at the condensate/vapor interface is equal in importance to the combined importance of the two convective terms. Each of the convective terms are approximately equal in importance, with the convective momentum terms being slightly more important than the convective energy terms. From Table 2-1, the convective energy terms have little effect on the film thicknesses; these seem to be controlled more by the convective momentum terms. Both of the mass fluxes become weaker functions of both $T_{c v}$ and $T_{0}, m s$ as the degree of modeling sophistication is increased.

These results indicate that the absolute mass transfer rates presented in Section 2.2.3 may be too high by as much as a factor of 2 . The general trend shown for the effect of vapor speed on the condensation process should, however, still be correct. 
TABLE 2-1

Effect of Vapor Shear and Convective Terms on the Steady-State Condensation of Stagnant Fuel Vapor onto a Vertical, Steel Substrate

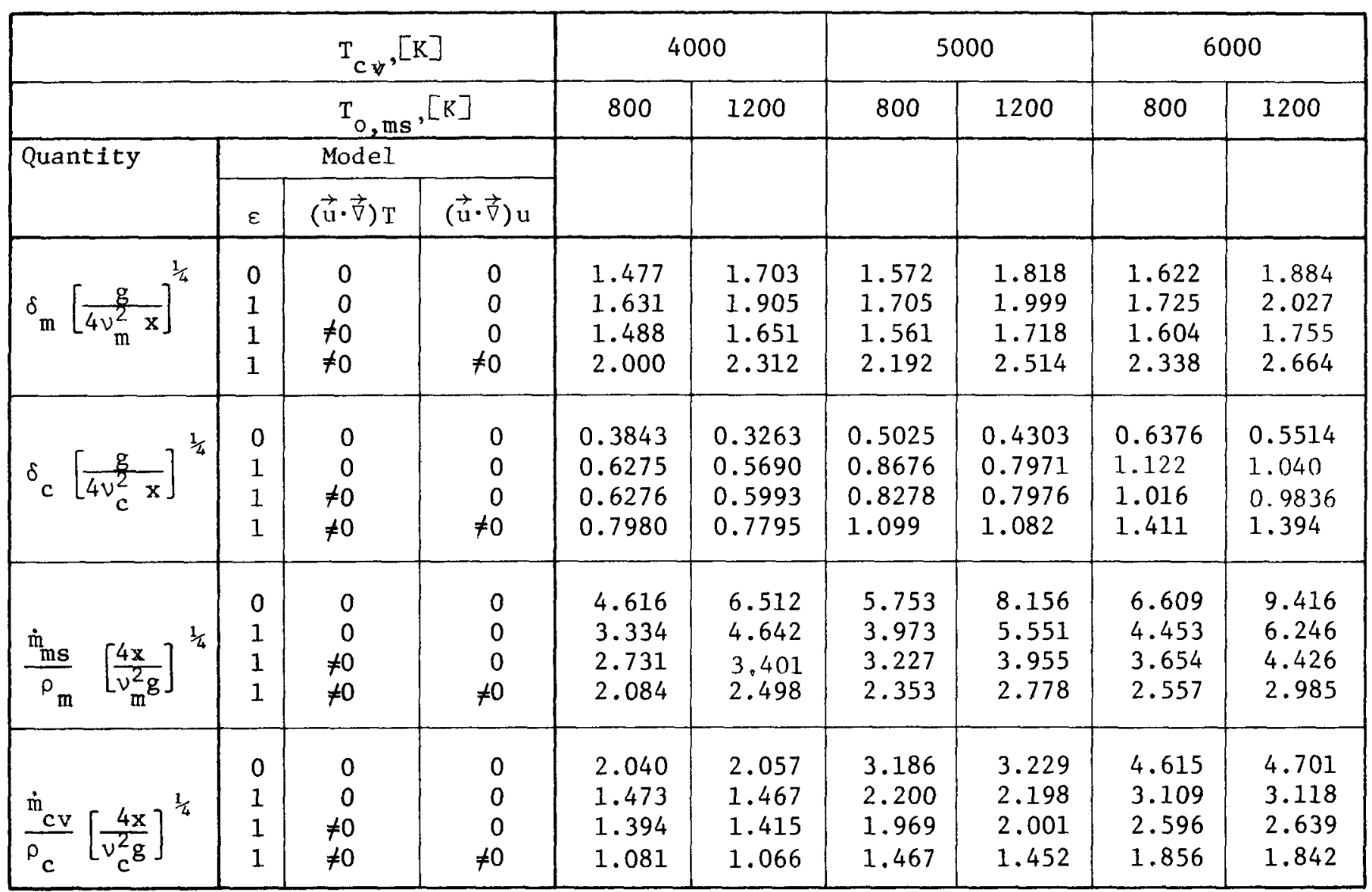




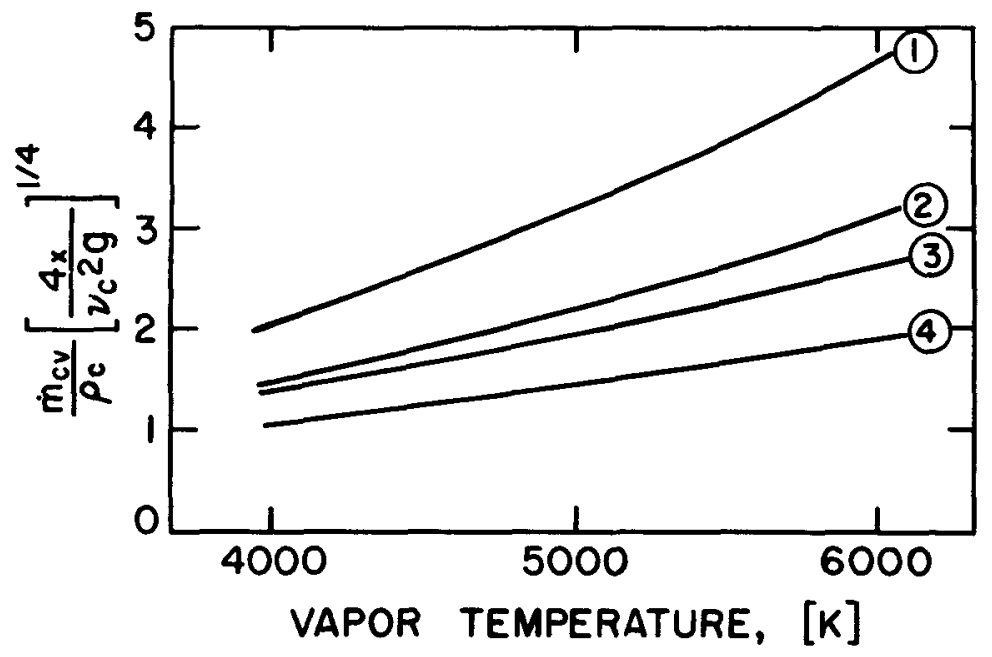

(a)

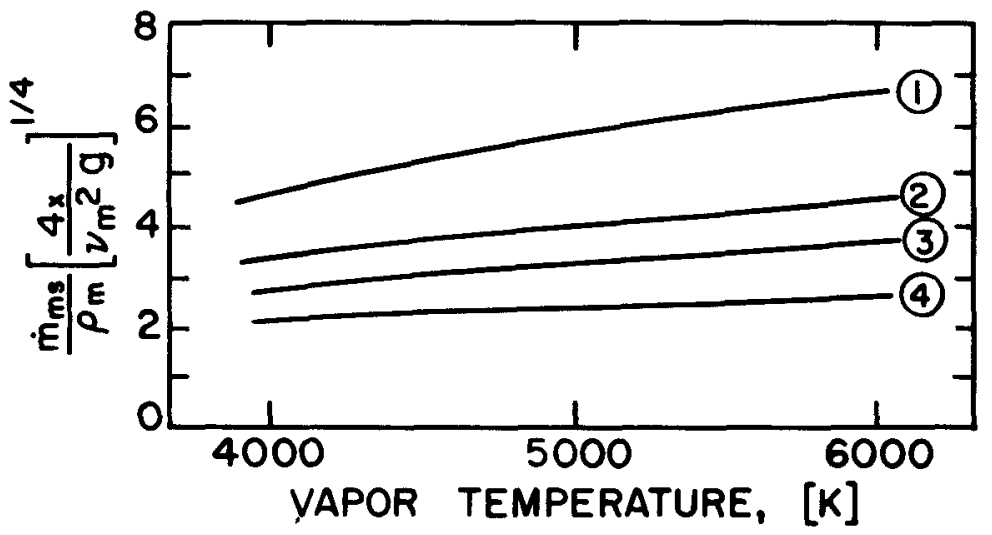

(b)

\begin{tabular}{l|l|c|c}
$\begin{array}{l}\text { LEGEND } \\
\text { CURVE }\end{array}$ & $\epsilon$ & $(\vec{u} \cdot \vec{\nabla}) T$ & $(\vec{u} \cdot \vec{\nabla}) u$ \\
\hline 1 & 0 & 0 & 0 \\
\hline 2 & 1 & 0 & 0 \\
\hline 3 & 1 & 0 & 0 \\
\hline 4 & 1 & 10 & 10
\end{tabular}

Figure 2-7. Steady-state (a) fuel condensation and (b) steel melting mass fluxes as a function of vapor temperature showing the effect of vapor shear and convective terms.

(Stagnant vapor, vertical steel with $\mathrm{T}_{\mathrm{o}, \mathrm{ms}}=300 \mathrm{~K}$. ) 
A final result to be presented for the upward flowing vapor case is the relative importance of the two shear stress terms given in Equation 2.1-1. The ratio of the two terms is given in Table 2-2 for two different vapor velocities ${ }^{*}$ and were calculated based on the film surface velocities obtained from the two-film problem with the shear stress due only to the excess momentum flux. The frictional shear component utilized a Reynolds number based on the hydraulic diameter associated with the intact pin geometry of the CRBR core $40 \quad(2.6 \mathrm{~mm})$ and saturated vapor properties. The frictional shear stress is found to be less than $10 \%$ of the excess momentum flux shear for the low vapor speeds ( 0 to $10 \mathrm{~m} / \mathrm{s}$ ) and substrates $1 \mathrm{~m}$ long. The frictional component of the shear stress is most important for large relative velocities between the vapor and the condensate film surface (i.e., high vapor velocity and positions far down the substrate) and also for high vapor temperatures (primarily due to the vapor density). Neglecting the frictional component in the current work was a reasonable approximation.

\subsection{Inclusion of Condensate Solidification (Infinite Viscosity)}

The calculational models presented in Sections 2.2 and 2.3 did not allow the condensed fuel to solidify. The calculated results, however, do indicate that the interface temperature between the steel melt and the fuel condensate is below the fuel melting point

\footnotetext{
* The value $31.6(=\sqrt{1000})$ was used since it allows actual results to be obtained easily from the dimensionless results.
} 
TABLE 2-2

Local Ratio of the Frictional Shear Stress to the Excess Momentum Flux Shear Stress for the Steady-State Condensation of Upward-Flowing Fuel onto Melting Steel with $\mathrm{T}_{\mathrm{o}, \mathrm{ms}}=800 \mathrm{~K}$

\begin{tabular}{|l|c|c|c|c|c|c|}
\hline$T_{c V}[K]$ & \multicolumn{2}{|c|}{4000} & \multicolumn{2}{c|}{5000} & \multicolumn{2}{c|}{6000} \\
\hline$u_{\infty}[\mathrm{m} / \mathrm{s}]$ & -1 & -31.6 & -1 & -31.6 & -1 & -31.6 \\
\hline$\underline{x}[\mathrm{~m}]$ & & & & & & \\
0 & 0.007 & 0.038 & 0.006 & 0.091 & 0.006 & 0.155 \\
0.1 & 0.018 & 0.041 & 0.017 & 0.104 & 0.018 & 0.178 \\
1 & 0.031 & 0.048 & 0.034 & 0.136 & 0.065 & 0.237 \\
10 & 0.055 & 0.066 & 0.138 & 0.255 & 0.262 & 0.461 \\
\hline
\end{tabular}


$(3138 \mathrm{~K})$ for most cases of interest. This is illustrated in Table 2-3 for two steady-state condensation models. Part a of the table is for the stagnant-vapor/vertical substrate situation, ${ }^{13}$ and part $b$ is for the flowing-vapor/horizontal-substrate situation ${ }^{14}$ (and neglected convective terms). The temperature at the interface between the fuel and steel films is not a function of position along the length of the substrate for either model. The interface temperature is a function of axial position for the flowing-vapor/vertical-substrate situation (Section 2.2); the average interface temperatures would, ceteris paribus, be lower than those in Table 2-3 (a) for low vapor speeds and slightly higher than those in Table 2-3 (b) for very high vapor speeds. Part a of the table, therefore, is more representative of the situations of current interest. The numbers in part a indicate that the fuel condensate would actually solidify except for the combination of very high fuel vapor temperature and high steel substrate temperature. Solidification will not occur over most of the temperature ranges of interest if the calculations are performed for the flowing-vapor/horizontal-substrate situation as evidenced by the results shown in part $\underline{b}$ of the table.

There are two major effects which could be expected from condensate solidification. The latent heat of fusion released during solidification is an extra amount of energy introduced into the system. This energy could result in increased substrate melting rates. Additionally, the properties of the solidified material are different from those of the condensate. One normally thinks of the low thermal 
TABLE 2-3

Interface Temperature Following Contact of Fuel Vapor and Solid Steel

a) Stagnant-Vapor/Vertical-Substrate

\begin{tabular}{|c|c|c|c|}
\hline $\mathrm{T}_{\mathrm{O}, \mathrm{ms}}[\mathrm{K}]$ & & & \\
\hline 800 & 4000 & 5000 & 6000 \\
\hline 1200 & 2505 & 2748 & 2969 \\
\hline 1700 & 2565 & 2816 & 3042 \\
\hline
\end{tabular}

b) Flowing-Vapor/Horizonta1-Substrate

\begin{tabular}{|c|c|c|c|}
\hline $\mathrm{T}_{\mathrm{O}, \mathrm{ms}}[\mathrm{K}]$ & & & \\
\hline 800 & 4000 & 5000 & 6000 \\
\hline 1200 & 2923 & 3344 & 3679 \\
\hline 1700 & 3099 & 3595 & 4000 \\
\hline
\end{tabular}


conductivity of solid fuel, but after properties have been evaluated at average temperatures the difference between the conductivities of the solid and the liquid is not very big (cf. Appendix A).

Previous treatment of condensate solidification has only been performed within the context of a transient conduction calculation ${ }^{12}$. The work in this section and the next will examine the importance of condensate solidification within the steady-state film condensation problem. In this section the solid will be treated as an infinitely viscous fluid. The next section will treat the solid as being rigid for comparison.

Treating the solid as a viscous fluid presents the picture of rigidity in the y direction. Velocity gradients do exist, however, in the axial direction. The solid is supported locally at each $\mathrm{x}$ location by the difference in shear stresses across the solid. This corresponds also to the case in which a rigid solid is segmented axially rather than being one continuous piece. The importance of solidification will be examined within the stagnant vapor situation. This allows the use of a similarity transform. The additional difficulties introduced by considering a flowing vapor situation are not worth the additional modeling effort (order of magnitude) in view of the sma11 vapor speed effects (50\%) found in Section 2.2

The problem geometry is illustrated in Figure 2-8. The symbol normally used for the thickness of the melt $f i l m, \delta_{m}$, is a negative quantity in this particular model.

The conservation equations for the three regions are the equations 


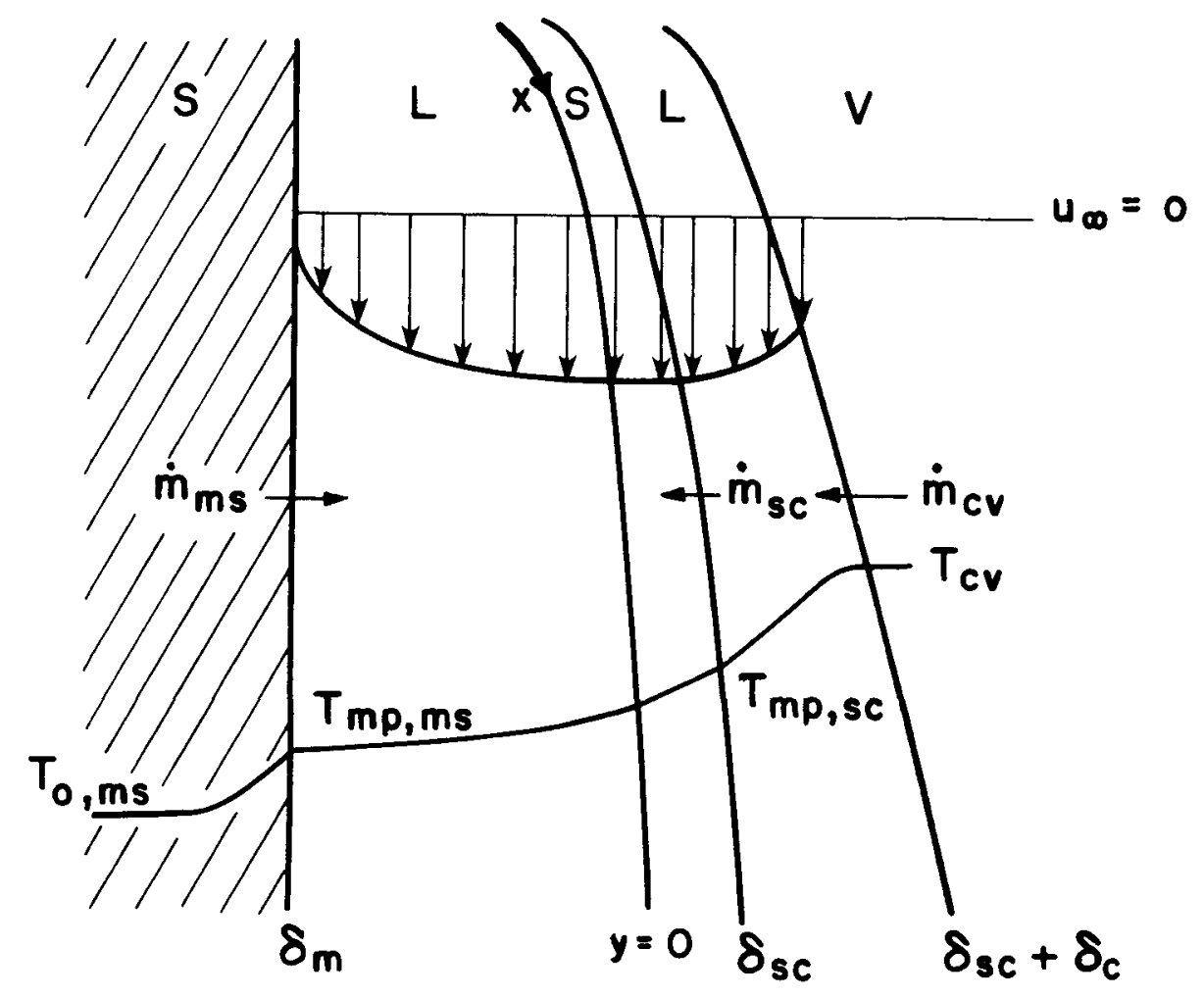

Figure 2-3. Schematic of the geometry used to analyze the steady state condensation and solidification of stagnant fuel onto a vertical steel substrate when the solidified condensate is treated as an infinitely viscous fluid. 
which were presented in Section.2.1 except for the momentum equation to be used in the solidified condensate region:

$$
\begin{array}{cl}
\frac{\partial u_{1}}{\partial x}+\frac{\partial v_{i}}{\partial y}=0 & i=m, s c, c \\
u_{i} \frac{\partial u_{i}}{\partial x}+v_{i} \frac{\partial u_{i}}{\partial y}=g+v_{i} \frac{\partial^{2} u_{i}}{\partial y^{2}} & i=m, c \\
u_{i} \frac{\partial T_{i}}{\partial x}+v_{i} \frac{\partial T_{i}}{\partial y}=\alpha \alpha_{i} \frac{\partial^{2} T_{i}}{\partial y^{2}} & i=m, s c, c
\end{array}
$$

The limiting form of the momentum equation for an infinitely viscous fluid is given by

$$
0=\frac{\partial^{2} u s c}{\partial y^{2}}
$$

Treating the solidified condensate as an infinitely viscous fluid results in the $\mathrm{u}$ component of velocity being independent of $\mathrm{y}$ at any axia1 location, or

$$
\frac{\partial u s c}{\partial y}=0
$$

The latter of these two equations implies the former equation

The boundary conditions associated with this problem are

$$
\begin{aligned}
& \mathrm{y}=\delta_{\mathrm{m}} ; \quad \mathrm{u}_{\mathrm{m}}=0 \\
& \mathrm{~T}_{\mathrm{m}}=\mathrm{T}_{\mathrm{mp}, \mathrm{ms}} \\
& \dot{\mathrm{m}}_{\mathrm{ms}} \mathrm{L}_{\mathrm{ms}}^{*}=\mathrm{k}_{\mathrm{m}} \frac{\partial \mathrm{T}_{\mathrm{m}}}{\partial \mathrm{y}} \\
& (2.4-6 a, 13 a) \\
& \text { (2. 4-14a) } \\
& y=0: \\
& \mathrm{u}_{\mathrm{m}}=\mathrm{u}_{\mathrm{sc}} \\
& \mathrm{T}_{\mathrm{m}}=\mathrm{T}_{\mathrm{sc}} \\
& (2.4-7 a, 15 a) \\
& \mathrm{v}_{\mathrm{m}}=\mathrm{v}_{\mathrm{sc}}=0 \\
& k_{m} \frac{\partial T_{m}}{\partial y}=k_{s c} \frac{\partial T s c}{\partial y} \\
& (2.4-8 a, 9 a, 16 a)
\end{aligned}
$$




$$
\begin{aligned}
& y=\delta_{s c}: \\
& \mathrm{u}_{\mathrm{sc}}=\mathrm{u}_{\mathrm{c}}, \quad \mathrm{T}_{\mathrm{sc}}=\mathrm{T}_{\mathrm{c}}=\mathrm{T}_{\mathrm{mp}, \mathrm{sc}} \\
& v_{s c}=v_{c}, \quad k_{s c} \frac{\partial T_{s c}}{\partial y}=k_{c} \frac{\partial T_{c}}{\partial y}+\dot{m}_{s c} L_{s c}(2 \cdot 4-11 a, 19 a) \\
& y=\delta_{s c}+\delta_{c} \\
& \mathrm{~T}_{\mathrm{c}}=\mathrm{T}_{\mathrm{cV}} \\
& \mu_{c} \frac{\partial u_{c}}{\partial y}=-\dot{m}_{c} u_{c}, \quad k_{c} \frac{\partial T_{c}}{\partial y}=\dot{m}_{c v} L_{c v} \quad(2.4-12 a, 21 a)
\end{aligned}
$$

Most of these conditions have been discussed in Section 2.2 and in Reference 13. An additional condition needed to describe the shear stress balance across the solidified condensate layer is given by

$$
\left.\mu_{\mathrm{m}} \frac{\partial \mathrm{u}_{\mathrm{m}}}{\partial \mathrm{y}}\right|_{\mathrm{y}=0}-\left.\mu_{\mathrm{c}} \frac{\partial \mathrm{u}_{\epsilon}}{\partial \mathrm{y}}\right|_{\mathrm{y}=\delta \mathrm{sc}}=\rho_{\mathrm{sc}} g \delta \mathrm{sc}
$$

This equation reflects the concept that the solidified condensate is supported locally.

The mass balances on the films are obtained from equations similar to Equations $2.2-23$ and $2.2-24$ and result in defining

$$
\begin{aligned}
& \dot{\mathrm{m}}_{\mathrm{ms}}=\left.\rho_{\mathrm{m}} \mathrm{v}_{\mathrm{m}}\right|_{\mathrm{y}}=\delta_{\mathrm{m}} \\
& \dot{\mathrm{m}}_{\mathrm{sc}}=\left.\rho_{\mathrm{sc}}\left[\mathrm{u}_{\mathrm{sc}} \frac{\mathrm{d} \delta_{\mathrm{sc}}}{\mathrm{dx}}-\mathrm{v}_{\mathrm{sc}}\right]\right|_{\mathrm{y}}=\delta_{\mathrm{sc}} \\
& \dot{\mathrm{m}}_{\mathrm{cv}}-\dot{\mathrm{m}}_{\mathrm{sc}}=\rho_{\mathrm{c}}\left\{\left.\left[\mathrm{u}_{\mathrm{c}} \frac{\mathrm{d}}{\mathrm{dx}}\left(\delta_{\mathrm{sc}}+\delta_{\mathrm{c}}\right)-\mathrm{v}_{\mathrm{c}}\right]\right|_{\mathrm{y}=\delta_{\mathrm{sc}}}+\delta_{\mathrm{c}}\right. \\
& \left.-\left.\left[u_{c} \frac{d \delta}{d x}-v_{c}\right]\right|_{y=\delta_{s c}}\right\}
\end{aligned}
$$

The conservation equations can be reduced to ordinary differential equations through a similarity transform.* The transform to be

\footnotetext{
* The reader is referred to Hansen ${ }^{41}$ for background theory on similarity transforms.
} 
utilized is very close to the one which was used by Koh et al. 38 and employs the following definitions:

$$
\begin{aligned}
& \eta_{i}=\left[\frac{g}{4 v_{i}^{2} x}\right]^{\frac{1}{4}} y \\
& u_{i}=2(g x)^{\frac{1}{2}} F_{i}^{\prime} \\
& v_{i}=\left[\frac{v_{i}{ }^{2} g}{4 x}\right]^{\frac{1}{4}}\left(\eta_{i} F_{i}^{\prime}-3 F_{i}\right) \\
& \theta_{i}=\frac{T_{i}-T_{m p}, m s}{T_{c v}-T_{m p}, m s}
\end{aligned}
$$

for each region $i=m$, $s c$, and $c$. The prime denotes differentiation with respect to $n_{i}$. In the above and what follows, occurrences of $v_{s c}$ (including the occurrences in $\mathrm{Pr}{ }_{s c}$ ) should be replaced with $\nu_{c}$ due to $\mu_{s c}$ being infinite throughout the derivation. The above transform satisfies the continuity equation identically. The remaining conservation equations are as follows:

$$
\begin{array}{ll}
F_{i}^{\prime \prime \prime}+3 F_{i} F_{i}^{\prime \prime}-2\left(F_{i}^{\prime}\right)^{2}+1=0 & , i=m, c \\
F_{s c}^{\prime \prime \prime}=0 & \\
F_{s c}^{\prime \prime}=0 & , i=m, s c, c \\
\theta_{i}^{\prime \prime}+3 \operatorname{Pr}_{i} F_{i} \theta_{i}^{\prime}=0 & \quad, i=0
\end{array}
$$

The film mass balances are transformed to

$$
\frac{\dot{\mathrm{m}}_{\mathrm{ms}}}{\rho_{\mathrm{m}}}\left[\frac{4 \mathrm{x}}{\nu_{\mathrm{m}}{ }^{2} \mathrm{~g}}\right]^{\frac{1}{4}}=-3 \mathrm{~F}_{\mathrm{m}}\left(n_{\delta_{\mathrm{m}}}\right)
$$




$$
\begin{aligned}
& \frac{\dot{\mathrm{m}}_{\mathrm{SC}}}{\rho_{c}}\left(\frac{4 \mathrm{x}}{v_{c}{ }^{2} g}\right)^{\frac{1}{4}}=3 \mathrm{RF}_{\mathrm{Sc}}\left(\eta_{\delta_{S c}}\right) \\
& \frac{\dot{\mathrm{m}}_{\mathrm{CV}_{V}}}{\rho_{c}}\left(\frac{4 \mathrm{x}}{v_{c}^{2} g}\right)^{\frac{1}{4}}=3\left[\mathrm{~F}_{c}\left(n_{\delta_{s c}}+n_{\delta_{c}}\right)+(R-1) F_{c}\left(n_{\delta s c}\right)\right]
\end{aligned}
$$

where

$$
\eta_{\delta_{i}} \equiv \eta_{i}\left(x, \delta_{i}\right)=\left(\frac{g}{4 \nu_{i}{ }^{2} x}\right)^{\frac{1}{4}} \delta_{i}
$$

and $n_{\delta_{i}}$ is not a function of $x$ by nature of the similarity transform. The velocity and temperature boundary conditions become

$$
\begin{aligned}
& \mathrm{F}_{\mathrm{m}}^{\prime}\left(\eta_{\delta_{\mathrm{m}}}\right)=0 \\
& \theta_{\mathrm{m}}\left(n_{\delta_{\mathrm{m}}}\right)=0 \\
& -3 \operatorname{Pr}_{\mathrm{m} m} \mathrm{~F}_{\mathrm{m}}\left(\eta_{\delta_{\mathrm{m}}}\right)=\mathrm{N}_{\mathrm{m}} \Theta_{\mathrm{m}}^{\prime}\left(\eta_{\delta}\right) \\
& F_{\mathrm{m}}^{\prime}(0)=\mathrm{F}_{\mathrm{Sc}}^{\prime}(0) \text {, } \\
& \theta_{\mathrm{m}}(0)=\theta_{\mathrm{sc}}(0) \\
& F_{m}(0)=F_{s c}(0)=0, \quad b K \theta_{m}^{\prime}(0)=\theta_{s c}^{\prime}(0) \\
& \mathrm{F}_{\mathrm{sc}}^{\prime}\left(n_{\delta}\right)=\mathrm{F}_{\mathrm{cc}}^{\prime}\left(n_{\delta}\right), \quad \theta_{\mathrm{sc}}\left(n_{\delta}\right)=\theta_{\mathrm{sc}}\left(n_{\delta}\right)=\theta_{\mathrm{mp}}, \mathrm{sc}(2.4-10 \mathrm{~b}, 17 \mathrm{~b},
\end{aligned}
$$

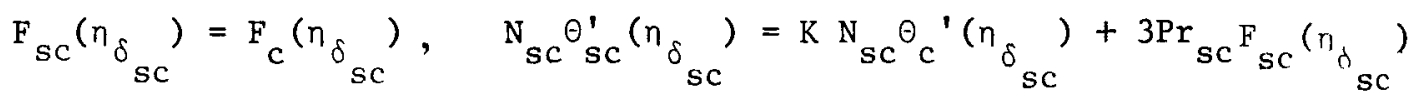

$$
\begin{aligned}
& (2.4-11 b, 19 b) \\
& F_{c}^{\prime \prime}\left(n_{\delta}+n_{\delta c}\right)=-3 F_{c}^{\prime}\left(n_{\delta}+n_{\delta c}\right)\left[F_{c}\left(n_{\delta_{s c}}+n_{\delta_{c}}\right)+(R-1) F_{c}\left(n_{\delta}\right)\right](2.4-12 b) \\
& \theta_{c}\left(n_{\delta c}+n_{\delta}\right)=1
\end{aligned}
$$

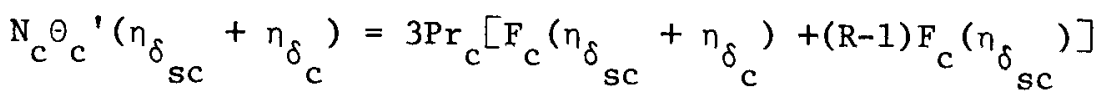


along with the transition condition

$$
F_{m}^{\prime \prime}(0)=a\left[F_{c}^{\prime \prime}\left(\eta_{\delta}\right)+R \eta_{\delta c}\right]
$$

where

$$
\begin{aligned}
& a \equiv\left(\frac{\rho_{c}^{\mu} c}{\rho_{m}^{\mu}}\right)^{\frac{1}{2}} \\
& \mathrm{~b} \equiv \frac{\mathrm{k}_{\mathrm{m}}}{\mathrm{k}_{\mathrm{c}}}\left(\frac{\nu_{c}}{\nu_{\mathrm{m}}}\right)^{\frac{1}{2}} \\
& \mathrm{~K} \equiv \frac{\mathrm{k}_{\mathrm{c}}}{\mathrm{k} \mathrm{sc}} \\
& \mathrm{N}_{\mathrm{c}} \equiv \frac{\mathrm{c}_{\mathrm{c}}\left(\mathrm{T}_{\mathrm{cV}}-\mathrm{T}_{\mathrm{mp}, \mathrm{ms}}\right)}{\mathrm{L}_{\mathrm{cv}}} \\
& \mathrm{N}_{\mathrm{m}} \equiv \frac{\mathrm{c}_{\mathrm{m}}\left(\mathrm{T}_{\mathrm{cv}}-\mathrm{T}_{\mathrm{mp}, \mathrm{ms}}\right)}{\mathrm{L}_{\mathrm{ms}}^{*}} \\
& \mathrm{~N}_{\mathrm{sc}} \equiv \frac{\mathrm{c}_{\mathrm{sc}}\left(\mathrm{T}_{\mathrm{cv}}-\mathrm{T}_{\mathrm{mp}, \mathrm{ms}}\right)}{\mathrm{L}_{\mathrm{sc}}} \\
& \mathrm{R} \equiv \frac{\rho_{\mathrm{sc}}}{\rho_{\mathrm{c}}} \\
& \theta_{m p, s c} \equiv \frac{T_{m p, s c}-T_{m p, m s}}{T_{c v}-T_{m p, m s}}
\end{aligned}
$$

Even after having performed the transformation, Equations 2.4-2b through $5 b$ and the associated boundary conditions still represent a rather complicated set of ordinary differential equations. The 
integral approximation was employed to simplify the system further.* This procedure has been used many times in boundary layer flows and has been shown to compare very well with more exact solutions. ${ }^{39}$ In the integral approximation, the conservation equations are required to be satisfied after they have been integrated across each region thickness (integrals with respect to y or with respect to $\eta$ at a constant $x$ ). Analytical forms (polynomials in $\eta_{i}$ ) are postulated for $F_{i}$ and $\theta_{i}$ in order to perform the integrations. This reduces the system of ordinary differential equations to a set of nonlinear algebraic equations to be solved for the coefficients in $\mathrm{F}_{i}$ and $\theta_{i}$.

The number of equations available allows postulation of stream functions and temperature profiles having the following forms:

$$
\begin{array}{ll}
F_{i}\left(n_{i}\right)=A_{i}+B_{i} n_{i}+D_{i} n_{i}^{2}+E_{i} n_{i}^{3} & , i=m, s c, c \\
\theta_{i}\left(n_{i}\right)=G_{i}+H_{i} n_{i}+J_{i} n_{i}^{2} & , i=m, s c, c
\end{array}
$$

Substitution of the stream function and temperature profile forms into the integrated conservation equations and boundary conditions results in a system of 24 equations to be solved for the following unknowns:

$$
\left(A, B, D, E, G, H, J \text {, and } \eta_{\delta}\right)_{i} \quad i=m, s c, c
$$

After performing the required algebraic manipulation, the resulting

\footnotetext{
* The momentum equation analogue for the solidified condensate region, Equations $2.4-4 \mathrm{~b}$ and $5 \mathrm{~b}$, will be satisfied pointwise rather than integrally.
} 
system of equations (cf. Appendix B) was solved numerically using a Newton-Raphson iterative technique. ${ }^{34}$ The solution converged to six significant figures in less than ten iterations based on an input guess at the solution. If more than ten iterations were required, the iterative process was, typically, divergent, and a new guess was selected.

A summary of the results calculated with this model is presented in Table 2-4. The numbers in parentheses are the results one obtains if solidification is neglected and were obtained using the model described in Reference 13. The allowance for fuel solidification is seen to have little effect on the results. The biggest discrepancies are at a combination of low fuel vapor temperature and low steel temperature. This is due to the large fraction $(-40 \%)$ of condensate which solidifies. The biggest difference seen is in the total thickness of the fuel region. The actual mass in this region is in closer agreement than the film thicknesses due to the solid having a higher density than the liquid. The solidification has only a very minor effect on the more important mass transfer rates. The biggest discrepancy is about $4 \%$ in the steel melting rate at low temperatures. Allowance for fuel solidification has only a limited impact on the steel melting rate since the additional amount of energy imparted to the system by the release of the heat of fusion during solidification, when combined with the relatively small mass of fuel solidifying, is a small contribution to the energy balance relative to the energy coming into the system from condensation. 
TABLE 2-4

Effect of Fuel Condensate Solidification during the Steady-State Condensation of Stagnant Fuel onto Vertical Steel

\begin{tabular}{|c|c|c|c|c|c|c|}
\hline $\mathrm{T}_{\mathrm{cV}}[\mathrm{K}]$ & 400 & & 50 & & 60 & \\
\hline $\mathrm{T}_{\mathrm{o}, \mathrm{ms}}[\mathrm{K}]$ & 800 & 1200 & 800 & 1200 & 800 & 1200 \\
\hline$\left[\frac{g}{4 v_{m}^{2} x}\right]^{\frac{1}{4}}\left|\delta_{m}\right|$ & $\begin{array}{c}2.038 \\
(2.000)\end{array}$ & $\begin{array}{c}2.350 \\
(2.312)\end{array}$ & $\begin{array}{c}2.195 \\
(2.192)\end{array}$ & $\begin{array}{c}2.518 \\
(2.514)\end{array}$ & $\begin{array}{c}2.333 \\
(2.338)\end{array}$ & $\begin{array}{c}2.662 \\
(2.664)\end{array}$ \\
\hline$\frac{\delta_{s c}}{\delta_{c}}$ & $\begin{array}{c}0.4893 \\
(0)\end{array}$ & $\begin{array}{c}0.4434 \\
(0)\end{array}$ & $\begin{array}{c}0.1413 \\
(0)\end{array}$ & $\begin{array}{c}0.1170 \\
(0)\end{array}$ & $\begin{array}{c}0.0396 \\
(0)\end{array}$ & $\begin{array}{c}0.0225 \\
(0)\end{array}$ \\
\hline$\left[\frac{g}{4 \nu_{c}^{2} x}\right]^{\frac{1}{4}}\left(\delta_{s c}+\delta_{c}\right)$ & $\begin{array}{c}0.6887 \\
(0.7980)\end{array}$ & $\begin{array}{c}0.6789 \\
(0.7795)\end{array}$ & $\begin{array}{c}1.042 \\
(1.099)\end{array}$ & $\begin{array}{c}1.033 \\
(1.082)\end{array}$ & $\begin{array}{c}1.388 \\
(1.411)\end{array}$ & $\begin{array}{c}1.381 \\
(1.394)\end{array}$ \\
\hline$\frac{\dot{\mathrm{m}}_{\mathrm{ms}}}{\rho_{\mathrm{m}}}\left[\frac{4 \mathrm{x}}{v_{\mathrm{m}}{ }^{2} \mathrm{~g}}\right]^{\frac{1}{4}}$ & $\begin{array}{c}2.156 \\
(2.084)\end{array}$ & $\begin{array}{c}2.566 \\
(2.498)\end{array}$ & $\begin{array}{c}2.379 \\
(2.353)\end{array}$ & $\begin{array}{c}2.798 \\
(2.778)\end{array}$ & $\begin{array}{c}2.562 \\
(2.557)\end{array}$ & $\begin{array}{c}2.987 \\
(2.985)\end{array}$ \\
\hline$\frac{\dot{\mathrm{m}}_{\mathrm{sc}}}{\dot{\mathrm{m}}_{\mathrm{cV}}}$ & $\begin{array}{c}0.3853 \\
(0)\end{array}$ & $\begin{array}{c}0.3648 \\
(0)\end{array}$ & $\begin{array}{c}0.1761 \\
(0)\end{array}$ & $\begin{array}{c}0.1504 \\
(0)\end{array}$ & $\begin{array}{c}0.0600 \\
(0)\end{array}$ & $\begin{array}{c}0.0348 \\
(0)\end{array}$ \\
\hline$\frac{\dot{\mathrm{m}}_{\mathrm{cv}}}{\rho_{\mathrm{c}}}\left[\frac{4 \mathrm{x}}{v_{c}{ }^{2} g}\right]^{\frac{1}{4}}$ & $\begin{array}{c}1.105 \\
(1.081)\end{array}$ & $\begin{array}{c}1.087 \\
(1.066)\end{array}$ & $\begin{array}{c}1.480 \\
(1.467)\end{array}$ & $\begin{array}{c}1.463 \\
(1.452)\end{array}$ & $\begin{array}{c}1.861 \\
(1.856)\end{array}$ & $\begin{array}{c}1.844 \\
(1.842)\end{array}$ \\
\hline
\end{tabular}

Legend for results groupings:

Include condensate solidifj.cation--Section 2.4

(Neglect condensate solidification--Reference 13) 
These results indicate that fuel solidification has little impact on the analysis of condensation and suggests that analyses which neglect the solidification would not be in serious error. This is encouraging since each region which must be considered in a problem such as this is an added complication to the problem and it is always nice to be able to find reasonable approximations and simplifications which can be employed. The actual presence of the solidified fuel layer may be an important factor to consider when analyzing the stability of the films in the condensation/melting problem; however, film stability will not be addressed in the present work.

The steady-state condensation and melting rates obtained using the model which was derived in this section may be approximated by the following relationships;

$$
\mathrm{Nu}_{\mathrm{x}}^{*}=4.144 \operatorname{Pr}_{\mathrm{c}}{ }^{2}\left(\mathrm{Gr}_{\mathrm{x}}^{*} \mathrm{Pr}_{\mathrm{c}}\right)^{\frac{1}{4}}
$$

and

$$
\frac{\dot{\mathrm{m}}_{\mathrm{ms}}}{\dot{\mathrm{m}}_{\mathrm{cv}}}=1.4\left[1+10^{-4}\left(5000-\mathrm{T}_{\mathrm{cv}}\right)\right]\left[1+1.8 \times 10^{-5}\left(\mathrm{~T}_{\mathrm{o}, \mathrm{ms}}-400\right)^{1.5}\right]
$$

where

$$
\begin{aligned}
& \mathrm{Nu}_{\mathrm{x}}^{*} \equiv \frac{\mathrm{h}_{\mathrm{cv}}^{*} \mathrm{x}}{\mathrm{k}_{\mathrm{c}}} \\
& \text { [Nusselt number] (2.4-42) } \\
& \mathrm{Gr}_{\mathrm{x}}^{*} \equiv \frac{\mathrm{gx}}{4 \mathrm{v}_{\mathrm{c}}^{2}} \\
& \text { [Grashoff number] (2.4-43) } \\
& h_{c v}{ }^{*} \equiv \frac{\dot{\mathrm{m}}_{c V} \mathrm{~L}_{c V}}{\mathrm{~T}_{\mathrm{cv}}-\mathrm{T}_{\mathrm{mp}, \mathrm{ms}}}
\end{aligned}
$$

and $\mathrm{T}$ is in Kelvins. 
An asterisk superscript denotes that the definition of the quantity may differ somewhat from the usual definition. Specifically, the bouyancy term in the Grashoff number is unity in the current work, and the melting temperature rather than $\mathrm{T}_{\mathrm{o}}, \mathrm{ms}$ has been used in the condensation heat transfer coefficient. The completely dimensionless form used in Equation 2.4-40 should not be construed as applying to any system other than the fuel/steel system currently being studied. Both of the above correlations are valid over the temperature ranges $\mathrm{T}_{\mathrm{C}_{v}} \varepsilon(4000,6000 \mathrm{~K})$ and $\mathrm{T}_{\mathrm{O}, \mathrm{ms}} \varepsilon(800,1700 \mathrm{~K})$.

Equation 2.4-40 approximates the calculated results within $\pm 2 \%$ over the stated temperature range and is based on the result that the condensation heat flux $\left(q_{c v}^{\prime \prime} \equiv \dot{m}_{c v} L_{c v}\right)$ is a very weak function of both boundary temperatures. This heat flux may be approximated within $\pm 6 \%$ using the following simple expression

$$
q_{c v}^{\prime \prime}=13.09 x^{-\frac{1}{4}}
$$

where $\mathrm{q}_{\mathrm{Cv}}^{\prime \prime}$ is in $\mathrm{MW} / \mathrm{m}^{2}$ and $\mathrm{x}$ is in metres.

Equation 2.4-41 approximates the calculated melting rate results within $\pm 4 \%$ over the majority of the temperature range; however, it does underestimate the melting rate by $8 \%$ in the $10 \mathrm{w} \mathrm{T}_{\mathrm{cv}} /$ high $\mathrm{T}_{\mathrm{o}}, \mathrm{ms}$ portion of the range. The above forms should be simple enough to be of use in future work.

The major results in this section are:

- the occurrance of fuel solidification has only a minor effect on the condensation/melting rates and, thus, need not be modeled explicitly; and

- the condensation and melting rates may be approximated using 
reasonably simple correlations which facilitates the inclusion of these phenomena in other analyses.

The actual technique used to treat the solidified condensate (as an infinitely viscous fluid) has not been demonstrated to be a realistic treatment. For this reason, a second method of treating this region will be examined in the next section.

\subsection{Alternate Treatment of Solidified Condensate (Rigid)}

The actual stability or form of the fuel which solidifies during a CDA has received attention only very recently. ${ }^{42}$ The treatment of solid (i.e. infinite viscosity) presented in the preceding section was at the extreme of a mushy or broken up solid which was supported locally. The solid could also be treated as being rigid and being supported in a bulk fashion. This is the situation considered in this section.

The velocity of the solid region is now a function of neither space coordinate due to the rigid nature of the solid. This renders the similarity transform used in Section 2.4 useless since it results in axial velocities proportional to $\mathrm{x}^{\frac{1}{2}}$. The convective terms will, thus, be neglected in the conservation equations in this section in order to obtain a speedy solution. While these terms were found to be important in Section 2.3, it is felt that the terms can be neglected when looking at other effects if comparisons are then made with other models that also neglected the convective terms. The stagnant vapor case will be considered for the same reason of simplicity. The geometry of the problem is illustrated in Figure 2-9. 


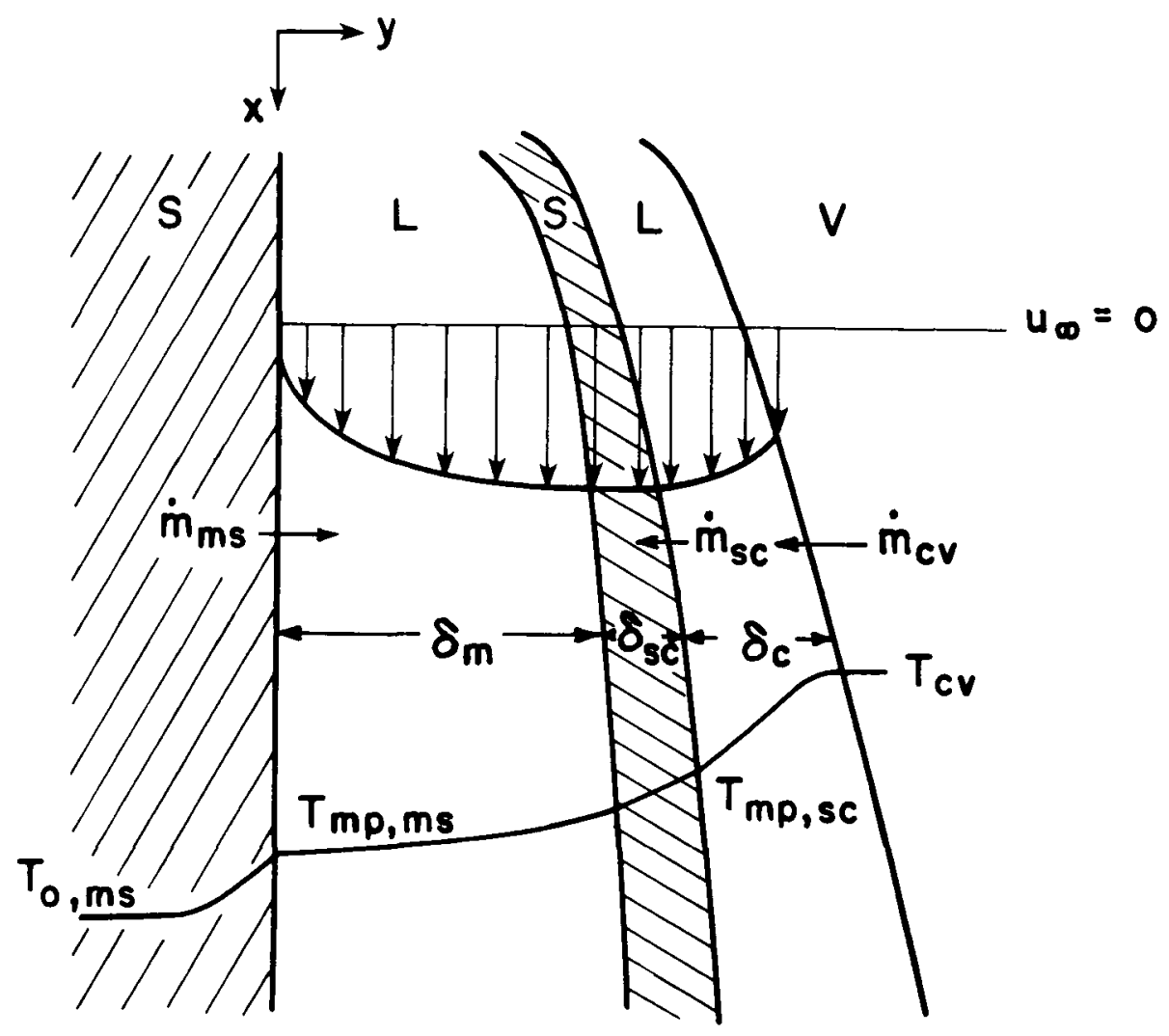

Figure 2-9. Schematic of the geometry used to analyze the steady-state condensation and solidification of stagnant fuel onto a vertical steel substrate when the solidified condensate is treated as rigid. 
The conservation equations are given by

$$
\begin{aligned}
& \frac{\partial u_{i}}{\partial x}+\frac{\partial v_{i}}{\partial y}=0 \\
& 0=g+v_{i} \frac{\partial^{2} u_{i}}{\partial y^{2}} \\
& 0=\frac{\partial^{2} T_{i}}{\partial y^{2}}
\end{aligned}
$$

for $i=m, s c$, and $c$ except that no momentum equation $(2.5-2)$ is needed for the solidified condensate.

The boundary conditions are very similar to those used in Section 2.4 with two exceptions; the conditions on $v$ are not needed when convective terms are neglected and the shear transmittal condition, Equation 2.4-8, will receive special treatment. Since the coordinate system has shifted slightly the conditions are restated here:

$\underline{y}=0$

$$
\mathrm{u}_{\mathrm{m}}=0
$$

$$
\mathrm{T}_{\mathrm{m}}=\mathrm{T}_{\mathrm{mp}, \mathrm{ms}}
$$

$$
\dot{\mathrm{m}}_{\mathrm{ms}} \mathrm{L}_{\mathrm{ms}}^{*}=\mathrm{k}_{\mathrm{m}} \frac{\partial \mathrm{T}}{\partial \mathrm{y}}
$$

$y=\delta m$

$$
u_{\mathrm{m}}=\mathrm{u}_{\mathrm{sC}}
$$$$
\mathrm{T}_{\mathrm{m}}=\mathrm{T}_{\mathrm{sc}}
$$

$$
k_{m} \frac{\partial T_{m}}{\partial y}=k_{s c} \frac{\partial T_{s c}}{\partial y}
$$

$\mathrm{y}=\delta_{\mathrm{m}}+\delta_{\mathrm{sc}}$

$$
u_{s c}=u_{c}
$$

$$
\begin{gathered}
\mathrm{T}_{s c}=\mathrm{T}_{c}=\mathrm{T}_{\mathrm{mp}, s c} \\
\mathrm{k}_{\mathrm{sc}} \frac{\partial \mathrm{T}_{\mathrm{sc}}}{\partial \mathrm{y}}=\mathrm{k}_{\mathrm{c}} \frac{\partial \mathrm{T}_{\mathrm{c}}}{\partial \mathrm{y}}+\dot{\mathrm{m}}_{\mathrm{sc}} \mathrm{L}_{\mathrm{sc}}
\end{gathered}
$$$$
(2.5-6 a, 12 a, 13 a)
$$ 


$$
\mathrm{y}=\delta_{\mathrm{m}}+\delta_{\mathrm{sc}}+\delta_{\mathrm{c}}
$$

$$
\mu_{c} \frac{\partial u_{c}}{\partial y}=-\dot{\mathrm{m}}_{c v} u_{c} \quad k_{c} \frac{\partial T_{c}}{\partial y}=\dot{m}_{c v} L_{c v}
$$

$$
T_{c}=T_{c v}
$$

Rather than satisfying the shear stress transmittal condition (Equation 2.4-21a) pointwise, it will be satisfied in an integral fashion over the axial length of substrate $x_{L_{2}}$, being considered: $\int_{0}^{x_{L}}\left[\left.\mu_{m} \frac{\partial u_{m}}{\partial y}\right|_{y=\delta_{m}}-\left.\mu_{c} \frac{\partial u_{c}}{\partial y}\right|_{y=\delta_{m}}+\delta_{s c} \quad\right] d x=\int_{0}^{x_{L} \rho_{s c}} g \delta_{s c} d x \quad(2.5-17)$

The solid layer turns out to be supported primarily from the top where the difference in the two shear stress terms is much larger than the weight of the thin solid region.

The velocity of the solidified condensate, $u_{s c}$, must be thought of as a "known" in the derivation effectively replacing $x_{L}$ which will be an unknown. This will be discussed in greater detail following the derivation.

Integration of the conservation equations twice with respect to $\mathrm{y}$ shows that the velocity and temperature profiles have the same functional forms as in Section 2.2:

$$
\begin{aligned}
& u_{i}(x, y)=a_{i}(x)+b_{i}(x) y-\frac{g}{2 v_{i}} y^{2} \\
& T_{i}(x, y)=d_{i}(x)+f_{i}(x) y
\end{aligned}
$$

Application of the boundary conditions given by Equations 2.5-8a, $10 a, 11 a, 12 a, 13 a$ and $15 a$ determines the coefficients of $y$ in the temperature profiles: 


$$
\begin{aligned}
& \mathrm{d}_{\mathrm{m}}=\mathrm{T}_{\mathrm{mp}, \mathrm{ms}} \\
& \mathrm{f}_{\mathrm{m}}=\frac{\mathrm{k}_{\mathrm{sc}}}{\mathrm{k}_{\mathrm{m}}} \mathrm{f}_{\mathrm{sc}} \\
& \mathrm{d}_{\mathrm{sc}}=\mathrm{T}_{\mathrm{mp}, \mathrm{sc}}-\left(\delta_{\mathrm{m}}+\delta_{\mathrm{sc}}\right) \mathrm{f}_{\mathrm{sc}} \\
& \mathrm{f}_{\mathrm{sc}}=\frac{\mathrm{T}_{\mathrm{mp}, \mathrm{sc}}-\mathrm{T}_{\mathrm{mp}, \mathrm{ms}}}{\mathrm{k}_{\mathrm{sc}}} \delta_{\mathrm{m}}+\delta_{\mathrm{sc}} \\
& \mathrm{d}_{\mathrm{c}}=\mathrm{T}_{\mathrm{mp}, \mathrm{sc}}-\left(\delta_{\mathrm{m}}+\delta_{\mathrm{sc}}\right) \mathrm{f}_{\mathrm{c}} \\
& \mathrm{f}_{\mathrm{c}}=\frac{\mathrm{T}_{\mathrm{cv}}-\mathrm{T}_{\mathrm{mp}, \mathrm{sc}}}{\delta_{\mathrm{c}}}
\end{aligned}
$$

Equations 2.5-9a, 14a, 15a may be used to find the following relationships:

$$
\begin{aligned}
& \dot{\mathrm{m}}_{\mathrm{ms}} \delta_{\mathrm{m}}\left[1+\frac{\mathrm{k}_{\mathrm{m}}}{\mathrm{k}_{\mathrm{sc}}} \frac{\dot{\mathrm{sc}}_{\delta}}{\delta_{\mathrm{m}}}=\mu_{\mathrm{m}} \frac{\mathrm{N}_{\mathrm{m}}}{\mathrm{Pr}} \neq F(\mathrm{x})\right. \\
& \dot{\mathrm{m}}_{\mathrm{ms}} \mathrm{L}_{\mathrm{ms}}^{*}=\dot{\mathrm{m}}_{\mathrm{sc}}{ }_{\mathrm{s} c}+\dot{\mathrm{m}}_{\mathrm{cv}} \mathrm{L}_{\mathrm{cv}} \\
& \dot{\mathrm{m}}_{\mathrm{cv}{ }_{\mathrm{c}}}=\mu_{\mathrm{c}} \frac{\mathrm{N}_{\mathrm{c}}}{\mathrm{Pr}_{\mathrm{c}}} \neq F(\mathrm{x})
\end{aligned}
$$

where

$$
\begin{aligned}
& \mathrm{N}_{\mathrm{c}}=\frac{{ }_{c}\left(\mathrm{~T}_{c v}-\mathrm{T}_{\mathrm{mp}, \mathrm{sc}}\right)}{\mathrm{L}_{\mathrm{cv}}} \\
& \mathrm{N}_{\mathrm{m}}=\frac{{ }_{\mathrm{m}}\left(\mathrm{T}_{\mathrm{mp}, \mathrm{sc}}-\mathrm{T}_{\mathrm{mp}, \mathrm{ms}}\right)}{\mathrm{L}_{\mathrm{ms}}^{*}}
\end{aligned}
$$

Use of Equations 2.5-4a,5a,6a, and 7a, along with Equation 2.5-16b to eliminate $\dot{\mathrm{m}}_{\mathrm{cv}}$, will determine the coefficients of $\mathrm{y}$ in the velocity profiles: 


$$
\begin{aligned}
& a_{m}=0 \\
& b_{m}=\frac{1}{\delta_{m}}\left[u_{s c}+\frac{g \delta_{m}^{2}}{2 v_{m}}\right] \\
& a_{c}=u_{s c}-\left(\delta_{m}+\delta_{s c}\right) b_{c}+\frac{g\left(\delta_{m}+\delta_{s c}\right)^{2}}{2 \nu_{c}} \\
& b_{c}=\frac{-\frac{N_{c}}{P r_{c}} \frac{u_{s c}}{\delta_{c}}-\frac{N_{c}}{P r} \frac{g \delta_{c}}{2 v_{c}}+\left(1+\frac{N}{P r}\right) \frac{g\left(\delta_{m}+\delta_{s c}+\delta_{c}\right)}{v_{c}}}{1+\frac{N_{c}}{P r}}
\end{aligned}
$$

The film mass balance equations are similar to those used in previous sections and are given by

$$
\begin{aligned}
& \dot{\mathrm{m}}_{\mathrm{ms}}=\frac{\mathrm{d}}{\mathrm{dx}} \int_{0}^{\delta} \mathrm{m} \rho_{\mathrm{m}} \mathrm{u}_{\mathrm{m}}(\mathrm{x}, \mathrm{y}) \mathrm{dy} \\
& \dot{\mathrm{m}}_{\mathrm{sc}}=\frac{\mathrm{d}}{\mathrm{dx}} \int_{\delta}^{\delta}{ }^{\delta}+{ }_{\mathrm{m}}^{\delta} \mathrm{sc} \rho_{\mathrm{sc}} \mathrm{u}_{\mathrm{sc}} \mathrm{dy} \\
& \dot{\mathrm{m}}_{\mathrm{cv}}-\dot{\mathrm{m}}_{\mathrm{sc}}=\frac{\mathrm{d}}{\mathrm{dx}} \int_{\delta_{\mathrm{m}}}^{\delta}+\delta_{\mathrm{sc}}+\delta_{\mathrm{c}} \rho_{\rho_{c} \mathrm{u}_{\mathrm{c}}(\mathrm{x}, \mathrm{y}) \mathrm{dy}}
\end{aligned}
$$

After substituting the velocity profiles, performing the integrals, and using the definitions of the coefficients of $y$ in the velocity profiles and Equations $2.5-9 b, 14 b$, and $16 \mathrm{~b}$, these equations may be written as

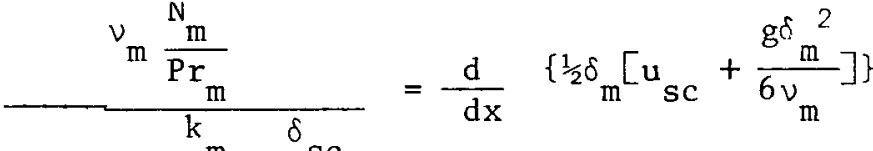

$$
\begin{aligned}
& \delta_{m}\left[1+\frac{m}{k s c} \frac{s c}{\delta_{m}}\right]
\end{aligned}
$$




$$
\begin{aligned}
& \frac{\rho_{\mathrm{m}} \mathrm{L}_{\mathrm{ms}}^{*}}{\rho_{\mathrm{sc}} \mathrm{L}_{\mathrm{sc}}} \frac{\nu_{\mathrm{m}} \frac{\mathrm{N}_{\mathrm{m}}}{\mathrm{Pr}_{\mathrm{m}}}}{\delta_{\mathrm{m}}\left[1+\frac{\mathrm{m}}{\mathrm{k}}-\frac{\delta_{\mathrm{sc}}}{\delta_{\mathrm{m}}}\right]}-\frac{\rho_{c} \mathrm{~L}_{\mathrm{cv}}}{\rho_{\mathrm{sc}} \mathrm{L}_{\mathrm{sc}}} \frac{\nu_{\mathrm{c}} \frac{\mathrm{N}_{\mathrm{c}}}{\mathrm{Pr}_{\mathrm{c}}}}{\delta_{\mathrm{c}}}=\frac{\mathrm{d}}{\mathrm{dx}}\left\{\delta_{\mathrm{sc}} \mathrm{u}_{\mathrm{sc}}\right\} \\
& \frac{\nu_{c} \frac{{ }_{c}}{\mathrm{Pr}_{c}}}{\delta_{c}}=\frac{\rho_{s c}}{\rho_{c}} \frac{d}{d x}\left\{\delta_{s c} u_{s c}\right\}+\frac{d}{d x}\left\{\frac { \delta _ { c } } { 1 + \frac { N _ { c } } { P r _ { c } } } \left[\left(1+\frac{1}{2} \frac{{ }_{c}}{P r_{c}}\right) u_{s c}\right.\right. \\
& \left.\left.+\left(2+\frac{1}{2} \frac{\mathrm{N}_{c}}{\operatorname{Pr}{ }_{c}}\right) \frac{g \delta_{c}^{2}}{6 v_{c}}\right]\right\}
\end{aligned}
$$

After performing the indicated differentiations and rearranging, these equations may be written as

$$
\begin{aligned}
& \frac{\mathrm{d} \delta}{\mathrm{m}}=\frac{2 \frac{\mathrm{N}_{\mathrm{m}}}{\mathrm{Pr}_{\mathrm{m}}} \frac{\nu_{\mathrm{m}}}{\delta_{\mathrm{m}}}}{\left[1+\frac{\mathrm{m}}{\mathrm{k}} \frac{\delta_{\mathrm{sc}}}{\delta_{\mathrm{m}}}\right]\left[\mathrm{u}_{\mathrm{sc}}+\frac{\mathrm{g}_{\mathrm{m}}^{2}}{2 \nu_{\mathrm{m}}^{2}}\right]} \\
& \frac{\mathrm{d} \delta}{\mathrm{dx}}=\frac{1}{u_{s c}}\left\{\frac{\rho_{\mathrm{m}} \mathrm{L}_{\mathrm{ms}}^{*}}{\rho_{s c} \mathrm{~L}_{\mathrm{sc}}} \frac{\frac{\mathrm{N}_{\mathrm{m}}}{\mathrm{Pr}_{\mathrm{m}}} \frac{\nu_{\mathrm{m}}}{\delta_{\mathrm{m}}}}{\left[1+\frac{\mathrm{k}_{\mathrm{m}}}{\mathrm{k}_{\mathrm{sc}}} \frac{\left.\delta_{\mathrm{sc}}\right]}{\delta_{\mathrm{m}}}\right.}-\frac{\rho_{c} \mathrm{~L}_{c v}}{\rho_{s c} \mathrm{~L}_{s c}} \frac{\mathrm{N}_{c}}{\operatorname{Pr}_{c}} \frac{{ }_{c}}{\delta_{c}}\right\} \\
& \frac{\mathrm{d} \delta_{\mathrm{c}}}{\mathrm{dx}}=\frac{\left(I+\frac{\mathrm{N}_{\mathrm{c}}}{\mathrm{Pr}}\right)\left[\frac{\mathrm{N}_{\mathrm{c}}}{\mathrm{Pr}} \frac{\nu_{c}}{\delta_{c}}-\frac{\rho_{\mathrm{sc}}}{\rho_{c}} u_{s c} \frac{\mathrm{d} \delta_{\mathrm{sc}}}{\mathrm{dx}}\right]}{\left(1+\frac{1}{2} \frac{\mathrm{N}_{\mathrm{c}}}{\mathrm{Pr}}\right) \mathrm{u}_{\mathrm{c} c}+\left(2+\frac{1}{2} \frac{\mathrm{N}_{\mathrm{c}}}{\mathrm{Pr}}\right) \frac{\mathrm{g} \delta_{c}}{2 \nu_{c}}}
\end{aligned}
$$

These 3 equations must be integrated with respect to $x$ in order to find the $3 \mathrm{film}$ thicknesses. The mass transfer rates may then be found from Equations $2.5-9 \mathrm{~b}, 14 \mathrm{~b}$, and $16 \mathrm{~b}$. 
While the differential equations are only of first order, the coupling between the equations is such that the integration must be performed numerically. This is due, primarily, to the ratios of the various film thicknesses being a function of $\mathrm{x}$ (as was also the case for the flowing vapor problem examined in Section 2.2). A computer subroutine based on the method of Bulirsch and Stoer ${ }^{31}$ was used to perform the integrations.

The integration procedure is started by specifying a set of film thicknesses which are near the desired actual condition $\delta_{m}=\delta_{s c}=\delta_{c}=0$ at $x=0$. This must be done in order to avoid the singularity in the derivatives at the location $x=0$. A value must also be specified for the velocity of the solidified condensate region. The integration proceeds down the substrate, and the problem is stopped when the shear-stress/film-weight balance expressed by Equation $2.5-17$ is satisfied. The spatial location where this occurs determines the substrate length, $x_{L}$, which is appropriate to the selected value of $u_{s C}$. This length will usually not correspond to the actual substrate length of interest, and some adjusting must be done. Conceptually cases must be run with different values for $\mathrm{u}_{\mathrm{sc}}$ until the desired value for $\mathrm{x}_{\mathrm{L}}$ is obtained. Fortunately, the results do scale with $u_{s c}$ in a convenient fashion, and it is only necessary to run a single case. The following dimensionless results will be identical among cases run using different $\mathbf{u}_{\mathbf{s c}}$ :

$$
\Delta=\left[\frac{\mathrm{g}}{v \mathrm{u}_{\mathrm{SC}}}\right]^{\frac{1}{2} \delta}
$$




$$
\begin{aligned}
& \dot{M}=\frac{\dot{\mathrm{m}}}{\rho}\left[\frac{\mathrm{u}_{s c}}{v g}\right]^{\frac{1}{2}} \\
& U=\frac{u}{u_{s c}}
\end{aligned}
$$

as a function of

$$
\mathrm{x}=\frac{\mathrm{gx}}{\mathbf{u}^{2} \mathrm{sc}}
$$

where $\rho_{c}$ and $\nu_{c}$ should be used in forming $\Delta_{s c}$ and ${ }_{s c}$.

The average mass transfer fluxes over the length of the substrate may be found using the average film velocity method (similar to the method used in Section 2.2). In dimensionless form, these average phase change rates are given by

$$
\begin{aligned}
& \hat{\dot{M}}_{\mathrm{ms}}=\frac{\Delta_{\mathrm{m}} \overline{\mathrm{U}}_{\mathrm{m}}}{\mathrm{X}} \\
& \hat{\dot{M}}_{\mathrm{sc}}=\frac{\rho_{\mathrm{sc}}}{\rho_{\mathrm{c}}} \frac{\Delta_{\mathrm{sc}}}{\mathrm{X}} \\
& \hat{\dot{M}}_{\mathrm{cV}}=\frac{\Delta_{\mathrm{c}} \overline{\mathrm{U}}_{\mathrm{c}}}{\mathrm{X}}+\hat{\dot{M}}_{\mathrm{sc}}
\end{aligned}
$$

where all quantities are evaluated at $\mathrm{X}=\mathrm{X}_{\mathrm{L}}$.

The results of applying this model to the fuel/steel system are given in Table 2-5. The results are presented specifically for $x_{L}=1.2 m$ rather than leaving the results in dimensionless form. A direct comparison of these results with those obtained from the model presented in Section 2.4 (infinitely viscous solid) would not only show the effect of how the solid is treated but would, to a greater 
TABLE 2-5

Phase Change Mass Fluxes and Velocity of the Solidified Condensate Averaged over an Axial Length of $1.2 \mathrm{~m}$ for the Steady State Condensation of Stagnant Fuel onto Vertical Steel with $\mathrm{T}_{0, \mathrm{~ms}}=800 \mathrm{~K}$.

\begin{tabular}{|c|c|c|c|}
\hline $\mathrm{T}_{\mathrm{cV}},[\mathrm{K}]$ & 4000 & 5000 & 6000 \\
\hline$\hat{\dot{m}}_{\mathrm{ms}},\left[\mathrm{kg} / \mathrm{m}^{2} \cdot \mathrm{s}\right]$ & $\begin{array}{c}28.05 \\
(27.44) \\
{[26.37]}\end{array}$ & $\begin{array}{c}32.98 \\
(32.31) \\
{[31.43]}\end{array}$ & $\begin{array}{c}36.71 \\
(35.85) \\
{[35.23]}\end{array}$ \\
\hline$\hat{\dot{\mathrm{m}}}_{\mathrm{sc}},\left[\mathrm{kg} / \mathrm{m}^{2} \cdot \mathrm{s}\right]$ & $\begin{array}{c}5.412 \\
(4.920) \\
{[0]}\end{array}$ & $\begin{array}{c}3.438 \\
(3.057) \\
{[0]}\end{array}$ & $\begin{array}{c}2.162 \\
(1.919) \\
{[0]}\end{array}$ \\
\hline$\hat{\dot{\mathrm{m}}}_{\mathrm{cv}},\left[\mathrm{kg} / \mathrm{m}^{2} \cdot \mathrm{s}\right]$ & $\begin{array}{c}12.86 \\
(12.64) \\
{[12.92]}\end{array}$ & $\begin{array}{c}17.74 \\
(17.42) \\
{[17.50]}\end{array}$ & $\begin{array}{c}23.34 \\
(22.83) \\
{[22.85]}\end{array}$ \\
\hline$\hat{u}_{\mathrm{sc}},[\mathrm{m} / \mathrm{s}]$ & $\begin{array}{c}4.098 \\
(4.047) \\
{[4.204]}\end{array}$ & $\begin{array}{c}4.869 \\
(4.826) \\
{[4.884]}\end{array}$ & $\begin{array}{c}5.554 \\
(5.598) \\
{[6.355]}\end{array}$ \\
\hline
\end{tabular}

Regular entries are for rigid solidified condensate.

(Numbers in parentheses are for infinitely viscous solidified condensate.) [Number in square brackets do not include effects of condensate solidification.] 
extent, be showing the effects of the convective transport terms in the conservation equations. In order to make a valid comparison between the two treatments of the solidified region, the convective terms must be neglected in the viscous solid treatment. Reduction of the model of Section 2.4 to this case is presented in Appendix C, and the calculated results are shown in parentheses in Table 2-5. An additional comparison of interest is the effect of neglecting condensate solidification when the convective transport terms are also neglected. These results were presented previously under the " $\varepsilon=1,(\overrightarrow{\mathrm{u}} \cdot \vec{\nabla}) \mathrm{u}=0,(\overrightarrow{\mathrm{u}} \cdot \vec{\nabla}) \mathrm{T}=0$ " heading in Table 2-1 and are shown in square brackets in Table 2-5.

Addressing the treatment of the solid first, the biggest difference between a rigid and a viscous treatment is approximately $10 \%$ in the solidification mass flux. The condensation and melting mass fluxes differ by only $2 \%$. The velocity assigned to the rigid solid is within $1 \%$ of the average (over $x$ ) velocity of the viscous solid. A second comparison which can be drawn from the numbers in this table is the importance of including the solid using either treatment. The differences between with and without condensate solidification are on the order of $2 \%$ difference in the condensation rate and $5 \%$ difference in the melting rate. The average velocity of the solid (or the velocity of the interface separating the condensate and melt films when the solid is neglected) shows differences as high as $15 \%$, but this quantity is not very important. The results shown in this table reinforce the conclusion made 
at the end of Section 2.4: fuel condensate solidification may be neglected without incurring serious errors in the steady-state condensation and melting rates. Additionally, if condensate solidification is to be included in a particular model, it appears that the actual characteristics of the solid, i.e. rigid versus viscous or broken up, has little bearing on the results. 


\section{SECTION 3}

\section{TRANSIENT ANALYSIS -- SINGLE FILM}

Most situations in which condensation of fuel will be of interest are transient in nature. Fuel vapor enters the condensing region at temperatures and velocities which are functions of time. Even if the fuel vapor conditions were constant, the condensation process might never reach a steady state due to the possibility of melting through the entire substrate thickness. Examination of the complete problem mechanistically would require a modeling effort equal to that already existing in the SIMMER code. ${ }^{5}$ The results of the modeling would no longer serve the purpose of developing relationships for condensation coefficients; instead, the results would be solutions to very specific situations from which it would be difficult to obtain very many meaningful conclusions suitable for extrapolation to different sets of conditions.

The transient situation is more difficult to analyze than the steady-state situation in the general case. since there is the additional independent variable. The only multi-region, multimaterial, transient treatment of condensation onto a melting substrate was presented by Epstein and Cho ${ }^{12}$. This analysis* assumed that heat was only transferred by one-dimensional conduction and did not allow for any material flows; this effectively corresponds to the

\footnotetext{
*A summary of the derivation of the model presented in Reference 12 and the results of applying the model to the $\mathrm{UO}_{2} /$ steel system are presented in Appendix D.
} 
condensation of stagnant vapor onto a horizontal substrate. The soild substrate and the vapor space were both of semi-infinite extent .

When material flows are modeled in the transient situation, the equations quickly become unmanageable for most practical purposes. An exception to this is when a single fluid film separates the solid substrate from the vapor -- i.e. a 3 region, 1 material situation. A transient solution to a problem of this type was presented by Contreras and Thorsen ${ }^{11}$. The situation considered and approximations involved will be explored in Section 3.1, which presents the derivation of an improved version of the Contreras-Thorsen model.

A prefacing word of caution is in order. The intent of the present section is not to demonstrate that the fuel-condensate and the steel-melt films can be represented by a single film; nevertheless, with a relatively straightforward averaging of film properties, the single-film results are within a factor of 2 of the multiple-film results. The real purpose of the present section is to illustrate the complexities of a transient situation when only a single film is considered; each additional film considered approximately doubles the complexity of the derivation and solution methods. An additional point discovered while examining this single-film problem is that a total transient solution can be well represented by the combination of the solutions to two simpler problems: a transient, conductiononly model for short times and a steady-state, flowing-film model for long times. This combination of solutions is presented in Section 3.2. 


\subsection{Full Transient Solution}

The problem geometry being considered is shown in Figure 3-1. The coordinate system used in this problem is fixed rather than moving with the film. Stagnant vapor condenses onto a vertical substrate of the same material which melts. A single liquid film forms and flows under the influence of gravity. This motion is resisted by the shear stresses at the substrate /film and the film/vapor interfaces. The latter of these shear stresses was neglected in the analysis ${ }^{*}$ presented by Contreras and Thorsen ${ }^{11}$. Stagnant rather than flowing vapor is considered for the reasons stated in Section 2.3. Strictly speaking, the substrate must be at the melting temperature for the following analysis to be correct since a spatial energy equation will not be used in ithe solid. The effective heat of fusion (Equation 2.2-14) will be used to simulate the subcooled nature of the substrate ${ }^{\dagger}$.

The film is treated as a smooth, laminar, boundary layer as was done in Section 2. The inertia terms in the momentum equations are neglected $\left[i \cdot e \cdot \frac{\partial u}{\partial t}+(\vec{u} \cdot \vec{\nabla}) u=0\right]$; this forces the velocity within the films to follow the steady-state profile associated with the current value of the film thickness at any time rather than having to approach this profile transiently. This assumption results in allowing the differential equations to be uncoupled. The assumption made by

\footnotetext{
* There are numerous typographical errors in Reference 11 , especially in the later equations. One error in the theory is noted later in this report under Equation 3.1-29 on page 86.

${ }^{\dagger}$ A11 calculations in Section 3 will assume $\gamma=1$; Appendix D discusses the actual value of $\gamma$ for transient situations.
} 


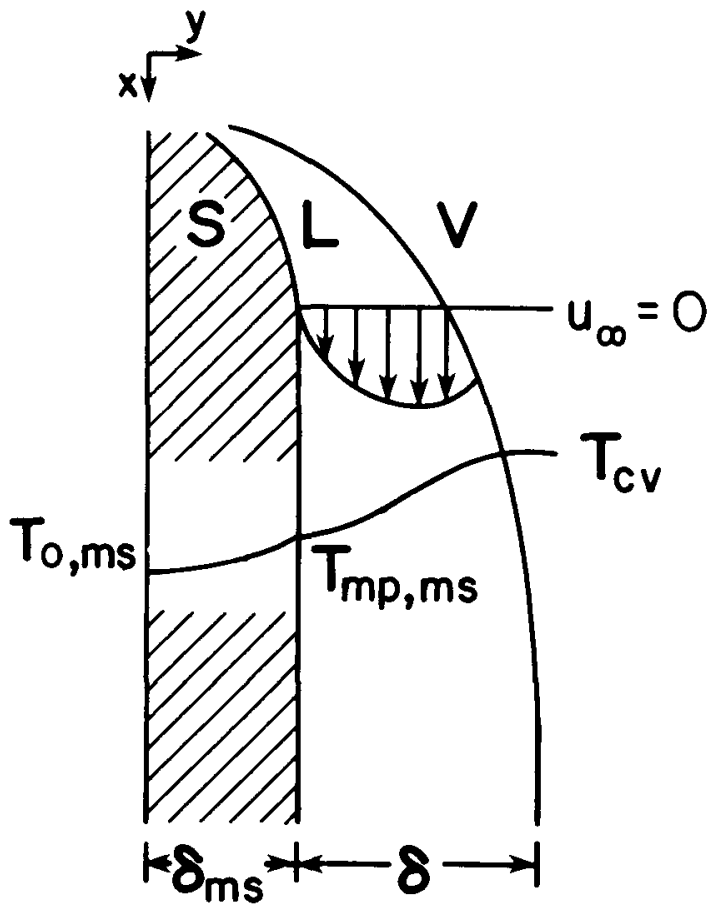

Figure 3-1. Schematic of geometry used for analyzing transient condensation of a stagnant vapor onto a substrate of the same material. 
Contreras and Thorsen concerning the negligible curvature of the solid $\partial \delta$ $\left(\frac{\mathrm{ms}}{\partial \mathrm{x}} \rightarrow 0\right)$ is, mathematically, not necessary; the idea conveyed is, however, implicit in having decided to treat the film as a boundary layer.

With the above assumptions, the conservation equations for the film are given by

$$
\begin{gathered}
\frac{\partial u}{\partial x}+\frac{\partial v}{\partial y}=0 \\
0=g+v \frac{\partial^{2} u}{\partial y^{2}} \\
\frac{\partial T}{\partial t}+u \frac{\partial T}{\partial x}+v \frac{\partial T}{\partial y}=x \frac{\partial^{2} T}{\partial y^{2}}
\end{gathered}
$$

The boundary conditions are very similar to those used throughout Section 2 and are given by

$y=\delta_{m s}:$

$$
\begin{aligned}
\mathrm{u}=0 & \mathrm{~T}_{\mathrm{mp}, \mathrm{ms}} \\
\mathrm{v}=\left[\frac{\rho_{\mathrm{ms}}}{\rho}-1\right] \frac{\dot{\mathrm{m}}_{\mathrm{ms}}}{\rho_{\mathrm{ms}}} & \dot{\mathrm{m}}_{\mathrm{ms}}{ }^{*}{ }_{\mathrm{ms}}=\mathrm{k} \frac{\partial \mathrm{T}}{\partial \mathrm{y}} \\
\delta_{\mathrm{ms}}+\delta: & \mathrm{T}=\mathrm{T}_{\mathrm{cv}} \\
\mu \frac{\partial \mathrm{u}}{\partial \mathrm{y}}=-\varepsilon_{\mathrm{cv}}^{\mathrm{th}} \mathrm{k} & \frac{\partial \mathrm{T}}{\partial \mathrm{y}}=\dot{\mathrm{m}}_{\mathrm{cv}}{ }^{\mathrm{L}} \mathrm{cv}
\end{aligned}
$$

The nomenclature is the same used in Section 2 with the following exception: film properties are unsubscripted. (A subscript "ms" denotes substrate properties.) The present derivation includes the shear at the condensate/vapor interface $(\varepsilon=1) ; \varepsilon=0$ is the case considered in Reference 11. The condition given by Equation 3.1-5a may 
seem new but is equivalent, for example, to the combination of Equations 2.4-8a and 2.4-23a where a moving coordinate system was used. Equation 3.1-5a subtracts out the velocity at which the melting interface is progressing into the solid,

$$
\frac{\partial \delta_{\mathrm{ms}}}{\partial \mathrm{t}}=-\frac{\dot{\mathrm{m}}_{\mathrm{ms}}}{\rho_{\mathrm{ms}}}
$$

in order to obtain the transverse velocity induced in the film due to any density difference associated with melting.

The initial conditions for the problem are

$$
t=0:
$$

$$
\begin{aligned}
\delta_{\mathrm{ms}} & =\delta_{\mathrm{ms}, \mathrm{o}} \\
\delta & =0
\end{aligned}
$$

The mass balance on the film is similar to those used in Section 2 except that a mass storage term must be included:

$$
\dot{\mathrm{m}}_{\mathrm{ms}}+\dot{\mathrm{m}}_{\mathrm{cv}}=\rho \frac{\partial \delta}{\partial t}+\frac{\partial}{\partial \mathrm{x}} \int_{\delta_{\mathrm{ms}}}^{\delta_{\mathrm{ms}}+\delta} \rho \mathrm{u}(\mathrm{x}, \mathrm{y}, \mathrm{t}) \mathrm{dy},
$$

After using Leibnitz's rule for differentiation of an integral and Equations $3.1-1,4 a, 5 a$, and 11 , Equation $3.1-14 a$ may be written as

$$
\frac{\mathrm{m}_{\mathrm{cv}}}{\rho}=\frac{\partial}{\partial \mathrm{t}}\left(\delta_{\mathrm{ms}}+\delta\right)+\left.\left[\mathrm{u} \frac{\partial}{\partial \mathrm{x}}\left(\delta_{\mathrm{ms}}+\delta\right)-\mathrm{v}\right]\right|_{\mathrm{y}=\delta_{\mathrm{ms}}}+\delta
$$

The solution technique is identical to that used by Contreras and Thorsen. The momentum equation will be satisfied pointwise. Equation 3.1-2 is integrated twice with respect to $y$ to obtain

$$
u(x, y, t)=a+b \xi-\frac{g \delta^{2}}{2 v} \xi^{2}
$$


where a dimensionless space variable $\xi$, given by

$$
\xi \equiv \frac{\mathrm{y}-\delta_{\mathrm{ms}}(\mathrm{x}, \mathrm{t})}{\delta(\mathrm{x}, \mathrm{t})},
$$

has been introduced to replace the normally occuring $y$ to simplify future equations. The integral approximation will be used for the energy equation. The following temperature profile is assumed:

$$
\Theta=A+B \xi+C \xi^{2}
$$

where

$$
\theta=\frac{T(x, y, t)-T_{m p, m s}}{T_{c v}-T_{m p, m s}}
$$

The coefficients $a, b, A, B$, and $C$ in the above profiles are, in the general case, functions of $x$ and $t$.

Two of the coefficients in the temperature profile may be determined by using the boundary conditions given by Equations 3.1-7a and $9 a$ :

$$
\begin{aligned}
& A=0 \\
& B=1-C
\end{aligned}
$$

The third coefficient, $\mathrm{C}$, is determined in conjunction with finding the differential equation which governs the substrate thickness by using the boundary condition given by Equation 3.1-8a and requiring the energy euqation to be satisfied at the location $y=\delta_{m s}(x, t)$. While this latter step has not been used previously in the present report, it is a very common requirement when the integral approximation is used in analyses of boundary layer flows. The equation to be satisfied is: 


$$
\left.\left[\frac{\partial \theta}{\partial t}+u \frac{\partial \Theta}{\partial x}+v \frac{\partial \theta}{\partial y}\right]\right|_{y=\delta}=\left.\alpha \frac{\partial^{2} \theta}{\partial y^{2}}\right|_{y=\delta_{m s}}
$$

A total derivative of the general temperature field when evaluated at $y=\delta_{\mathrm{ms}}(\mathrm{x}, \mathrm{t})$ shows that

$$
\left.\frac{\partial \Theta}{\partial t}\right|_{y=\delta}=-\left.\frac{\partial \Theta}{\partial y}\right|_{y=\delta} \frac{\partial \delta_{m s}}{\partial t}
$$

Use of this condition along with Equations 3.1-4a, 5a, and 11 reduces Equation 3.1-19a to:

$$
-\left.\frac{\rho_{\mathrm{ms}}}{\rho} \frac{\partial \delta_{\mathrm{ms}}}{\partial t} \frac{\partial \Theta}{\partial y}\right|_{\mathrm{y}=\delta_{\mathrm{ms}}}=\left.\alpha \frac{\partial^{2} \Theta}{\partial \mathrm{y}^{2}}\right|_{\mathrm{y}=\delta_{\mathrm{ms}}}
$$

The temperature profile, Equation 3.1-17 with Equations $3.1-7 \mathrm{~b}$ and $3.1-9 b$, is substituted into this equation, and the derivatives are evaluated to yield

$$
\frac{\partial \delta \mathrm{ms}}{\partial t}=-M \frac{\alpha}{\delta}
$$

where

$$
\mathrm{M}=\frac{\rho}{\rho_{\mathrm{ms}}} \frac{2 \mathrm{C}}{1-\mathrm{C}}
$$

Equation $3.1-19 c$ governs the melting of the substrate.

Equations 3.1-11 and 19c, along with the temperature profile, are then used in the boundary condition given by Equation 3.1-8a to determine an equation in which $\mathrm{C}$ is the only unknown:

$$
c^{2}-2\left(1+\frac{L^{*}}{L_{c v}} \frac{1}{N}\right) C+1=0
$$

where

$$
\mathrm{N}=\frac{\mathrm{c}\left(\mathrm{T}_{\mathrm{cv}}-\mathrm{T}_{\mathrm{mp}, \mathrm{ms}}\right)}{\mathrm{L}_{\mathrm{cv}}}
$$


The quadratic formula is used to find $\mathrm{C}$ from Equation $3.1-8 \mathrm{~b}$ and shows

$$
C=\left(1+\frac{L_{m s}^{*}}{L_{c v}} \frac{1}{N}\right)-\sqrt{\left(1+\frac{L_{m s}^{*}}{L_{c v}^{*}} \frac{1}{N}\right)^{2}-1}
$$

where the sign in front of the radical has been selected in such a way that $\frac{\partial \delta \mathrm{ms}}{\partial \mathrm{t}}$ (as given by Equation $3.1-19 \mathrm{c}$ ) is negative.

The remaining temperature boundary condition, Equation 3.1-10a, may be used to show

$$
\dot{\mathrm{m}}_{\mathrm{cV}} \delta=\mu \frac{\mathrm{N}}{\mathrm{Pr}}(1+\mathrm{C}) \neq F(\mathrm{x})
$$

Requiring the velocity profile to satisfy the boundary conditions given by Equations $3.1-4 a$ and $3.1-6 a$ shows

$$
a=0
$$

and

$$
\mathrm{b}=\frac{2+\varepsilon \frac{\mathrm{N}}{\mathrm{Pr}}(1+\mathrm{C})}{1+\varepsilon \frac{\mathrm{N}}{\mathrm{Pr}}(1+\mathrm{C})} \frac{\mathrm{g} \delta^{2}}{2 \nu}
$$

This completes the determination of the coefficients in the velocity and temperature profiles as functions of the two unknowns $\delta$ ms and $\delta$. The differential equation which governs the film thickness is obtained by integrating the energy euqation across the thickness of the film:

$$
\int_{\delta \mathrm{ms}}^{\delta}+\delta\left[\frac{\partial \theta}{\partial t}+u \frac{\partial \theta}{\partial x}+v \frac{\partial \theta}{\partial y}\right] d y=\int_{\delta}^{\delta} \mathrm{ms}+\delta \alpha \frac{\partial^{2} \theta}{\partial y^{2}} d y
$$

After use of Leibnitz's rule. Equations 3.1-1. 4a, 6a, 10a and 14b, and transforming y to $\xi$, this may be written as

$$
\frac{\partial}{\partial t}\left\{\delta f_{0}^{1} \theta d \xi\right\}+\frac{\partial}{\partial x}\left\{\delta f_{0}^{1}(u \Theta) d \xi\right\}=\frac{\alpha}{\delta}\left\{\left.(1+N) \frac{\partial \Theta}{\partial \xi}\right|_{\xi=1}-\left.\frac{\partial \Theta}{\partial \xi}\right|_{\xi=0}\right\}
$$


After substitution of the velocity and temperature profiles into this equation and performing the integrations and differentiations indicated, this equation become

$$
G \delta \frac{\partial \delta}{\partial t}+H \frac{g \delta^{3}}{2 \nu} \frac{\partial \delta}{\partial x}=\alpha J
$$

where the dimensionless, constant coefficients are

$$
\begin{aligned}
& G=\frac{1}{2}\left[1-\frac{1}{3} C\right] \\
& H=\left\{\frac{2+\varepsilon \frac{N}{\operatorname{Pr}}(1+C)}{1+\varepsilon \frac{N}{\operatorname{Pr}}(1+C)}-\frac{3}{4}-\frac{1}{4}\left[\frac{2+\varepsilon \frac{N}{\operatorname{Pr}}(1+C)}{1+\varepsilon \frac{N}{\operatorname{Pr}}(1+C)}-\frac{3}{5}\right] C\right\} \\
& J=\{N(1+C)+2 C\} .
\end{aligned}
$$

The equation governing the film thickness, Equation 3.1-23, does not involve the (unknown) thickness of the substrate. This equation is a quasi-linear, parabolic, partial differential equation of first order. The equation was solved using the method of characteristics as discussed by Hildebrand. ${ }^{43}$ The solution is given by

$$
\begin{aligned}
& \delta\left[x, t>t_{s s}(x)\right]=\left[\frac{2 J}{\operatorname{PrH}} \frac{4 v^{2} x}{g}\right]^{\frac{1}{4}} \\
& \delta\left[x, t<t_{s s}(x)\right]=\left[\frac{2 J}{G} a t\right]^{\frac{1}{2}}
\end{aligned}
$$

where $t_{s s}(x)$ is given by the intersection of the two solutions

$$
t_{S S}(x)=G\left[\frac{2 P r}{J H} \frac{x}{g}\right]^{\frac{1}{2}}
$$

Knowing the film thickness, the mass transfer rates may be calculated using Equation 3.1-10b $\left(\dot{\mathrm{m}}_{\mathrm{cv}}\right)$ and Equations 3.1-11 and $19 \mathrm{c}$ 
$\left(\dot{\mathrm{m}}_{\mathrm{ms}}\right)$. These mass fluxes are independent of the substrate thickness. Mass transfer rates at any time $t$ in the solution may be averaged over the substrate length $x_{L}$; however, the integrals must be split into the two pieces:

$$
\begin{aligned}
& \text { 1) } 0<x<x_{s s}(t) \\
& \text { 2) } x_{s s}(t)<x<x_{L}
\end{aligned}
$$

where $x_{s s}(t)$ is found by solving Equation 3.1-28 for $x$.

These expressions for the film thickness may now be substituted into Equation $3 \cdot 1-19 \mathrm{c}$ and the resulting equations solved for the substrate thickness ${ }^{\star}$ :

$$
\begin{aligned}
& \delta_{m s}\left[x, t>t_{s s}(x)\right]=\delta_{m s, o}-\frac{1}{2} \frac{M G}{J} \delta\left[x, t>t_{s s}(x)\right]-M \frac{\alpha t}{\delta\left[x, t>t_{s s}(x)\right]} \\
& \left.\delta_{m s}\left[x, t<t_{s s}(x)\right]=\delta_{m s, o}-2 M \frac{a t}{\delta\left[x, t<t_{s s}(x)\right.}\right]
\end{aligned}
$$

The character of this solution is very interesting. The progression of the problem in time is illustrated in Figure 3-2. At any time $t$, the film has reached a steady-state thickness over a certain region of the substrate $0<x<x_{s s}(t)$, and the thickness of the film in this region is proportional to $x^{\frac{1}{4}}$; this spatial scaling is the same as was found for the steady-state/stagnant-vapor problems examined in Section 2.3. The substrate is continuing to melt in this * Contreras and Thorsen appear to have made an error in determining their
Equation 56 which is the analogue of the present Equation $3.1-29 \mathrm{a}$. Their
integration started from $t=0$ and $\delta_{\mathrm{ms}}=\delta_{\mathrm{ms}, \mathrm{o}}$, whereas it must be started
at $\mathrm{t}=\mathrm{t} \mathrm{ss}(\mathrm{x})$ and $\delta_{\mathrm{ms}}=\delta_{\mathrm{ms}}[\mathrm{x}, \mathrm{t}=\mathrm{t} \mathrm{ss}(\mathrm{x})]$ from Equations $3.1-29 \mathrm{~b}$. Their
technique results in the thickness of the solid in their derivation being
discontinuous at $\mathrm{t}=\mathrm{t} \mathrm{ss}(\mathrm{x})$. 


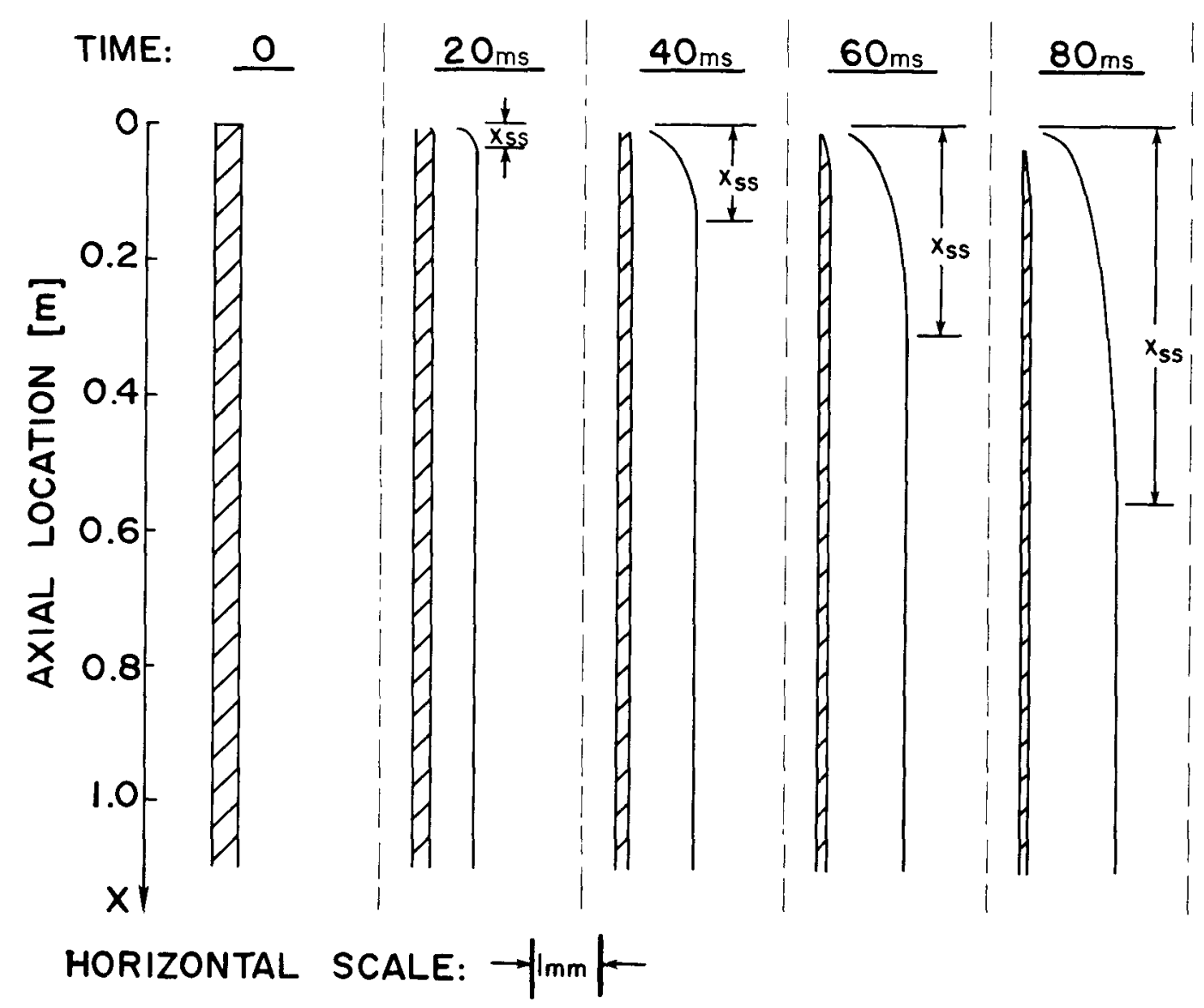

Figure 3-2. Transient film buildup and substrate meltaway during condensation of a stagnant vapor onto its solid. (The horizontal scale has been expanded by a factor of 100 over the vertical scale. Case identification: $\mathrm{T}_{\mathrm{cv}}=5000 \mathrm{~K}$, $\mathrm{T}_{\mathrm{o}, \mathrm{ms}}=800 \mathrm{~K}, \rho_{\mathrm{ms}} / \rho=1, \gamma=1, \varepsilon=1$, average fuel/steel properties). 
region, but melting and condensation are occurring at constant rates. In the region $x>x_{s s}(t)$ the thicknesses of the solid and the film are not functions of $x$. Melting and condensation are proceeding at rates proportional to $t^{-\frac{1}{2}}$; this behavior is characteristic of conduction heat transfer solutions for problems involving a phase change. 44

An unfortunate aspect of the solution is that it does not recognize that anything special occurs when complete melt-through of the substrate occurs $\left(i . e ., \delta_{m s}<0\right)$. This occurs instantaneously $\left(t=0^{+}\right)$at the location $x=0$ as the melting interface receedes to $\delta_{\mathrm{ms}}=-\infty$. This should not be a major problem unless substrate melt through should occur over a significant portion of the solid on a time scale which is short compared with the timescale of the overall condensation process which one is trying to analyze.

Some results calculated with this model will be presented in Section 3.2.3 following a brief discussion of two additional models.

\subsection{Simulation of Transient}

The analytical forms of the results found in Section 3.1 lead one to ask the following question: How well would the combination of 1) a transient, conduction-only analysis and 2) a steady-state film analysis represent the full transient film condensation and melting processes? This section will derive the two models needed in order to make this comparison for the single-film condensationinduced melting problem. The two problems will be addressed within the same modeling assumptions and solution techniques as used in 
deriving the full transient solution (Section 3.1 ) so that a valid comparison can be made. This is an important point because the two individual problems can each be easily solved with a higher degree of sophistication than can the full transient problem. Thus the two solutions to be presented are not the best solutions to the respective problems.

\subsubsection{Solution for Short Times}

The transient portion of the problem will be solved assuming that the heat transfer is only by a one-dimensional conduction process which is described by

$$
\frac{\partial T}{\partial t}=\alpha \frac{\partial^{2} T}{\partial y^{2}}
$$

The geometry for this portion of the analysis is illustrated in Figure 3-3. The density change on melting is ignored for it introduces a material velocity which is not included in the conduction equation.

The boundary and initial conditions are identical to those used in Section 3.1 but they are restated here due to the shift in the location of $y=0$ :

$y=-\delta_{\mathrm{ms}}$

$$
\begin{array}{rl}
\mathrm{T} & =\mathrm{T}_{\mathrm{mp}, \mathrm{ms}} \\
\rho \frac{\mathrm{d} \delta}{\mathrm{ms}} & \mathrm{L}_{\mathrm{ms}}^{\star} \\
\mathrm{dt} & \mathrm{k} \frac{\partial \mathrm{T}}{\partial \mathrm{y}} \\
\mathrm{T} & =\mathrm{T}_{\mathrm{cv}}
\end{array}
$$$$
y=\delta_{c v}:
$$ 


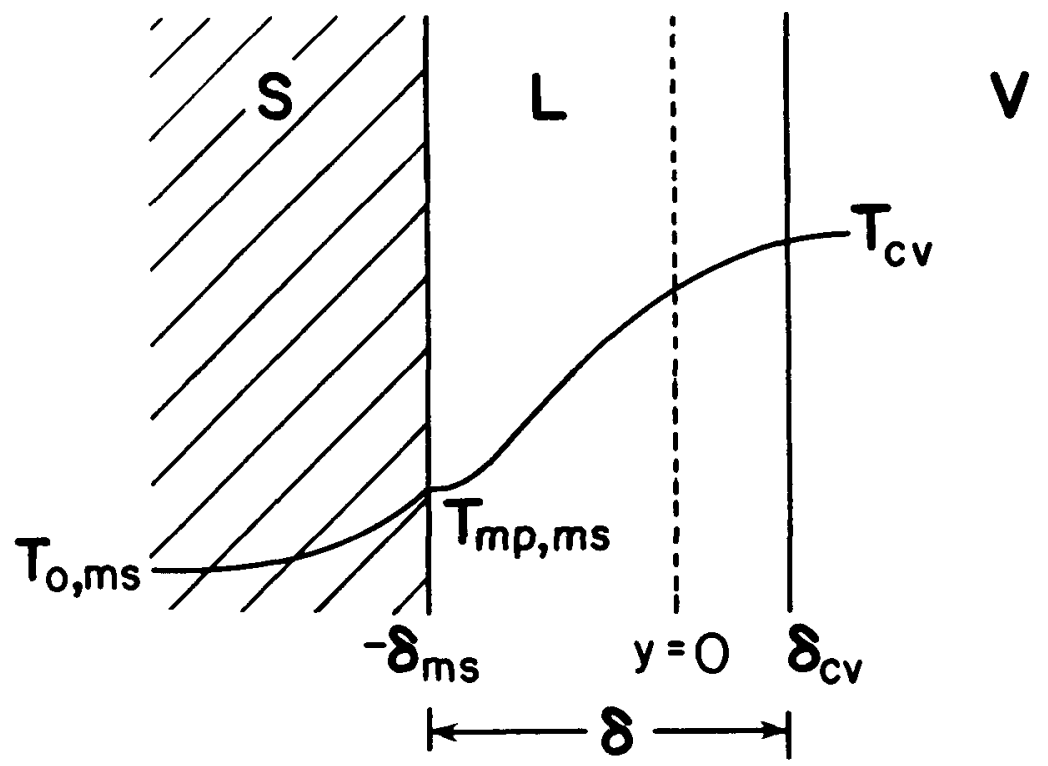

Figure 3-3. Schematic of geometry used for the short-time (conduction-only) solution of a condensationinduced melting problem. 


$$
\mathrm{k} \frac{\partial \mathrm{T}}{\partial \mathrm{y}}=\rho \frac{\mathrm{d} \delta}{\mathrm{dt}} \mathrm{L}_{\mathrm{cv}}
$$

$\underline{t}=0$ :

$$
\begin{aligned}
& \delta_{\mathrm{ms}}=0 \\
& \delta_{\mathrm{cV}}=0
\end{aligned}
$$

The effective heat of fusion concept has been utilized to account for the temperature in the substrate being different from the melting temperature (cf. Equation 2.2-14 with $\gamma=1$ ).

The conduction equation will be satisfied in a integral manner as was done in Section 3.1. The following form is used for the temperature profile:

where

$$
\theta=A+B \xi+C \xi^{2}
$$

$$
\begin{aligned}
& \theta \equiv \frac{\mathrm{T}-\mathrm{T}_{\mathrm{mp}, \mathrm{ms}}}{\mathrm{T}_{\mathrm{cv}}-\mathrm{T}_{\mathrm{mp}, \mathrm{ms}}} \\
& \xi \equiv \frac{\delta_{\mathrm{ms}}+\mathrm{y}}{\delta} \\
& \delta \equiv \delta_{\mathrm{ms}}+\delta_{\mathrm{cv}}
\end{aligned}
$$

Requiring the temperature profile to satisfy the boundary conditions given by Equations $3 \cdot 2 \cdot 1-2 \mathrm{a}$ and $4 \mathrm{a}$ will show

$$
A=0
$$

and

$$
B=1-C
$$

These results allow the remaining two boundary conditions to be written as

$$
\frac{\mathrm{d} \delta_{\mathrm{ms}}}{\mathrm{dt}}=\mathrm{N}(1-\mathrm{C}) \frac{\mathrm{L}_{\mathrm{cv}}}{\mathrm{L}_{\mathrm{ms}}^{*}} \frac{\alpha}{\delta}
$$


and

$$
\frac{d \delta}{d t}=N(1+C) \frac{\alpha}{\delta}
$$

where

$$
\mathrm{N} \equiv \frac{c\left(\mathrm{~T}_{\mathrm{cv}}-\mathrm{T}_{\mathrm{mp}, \mathrm{ms}}\right)}{\mathrm{L}_{\mathrm{cv}}}
$$

A differential equation describing the growth of the liquid layer thickness, $\delta$, may be found by taking the derivatives with respect to time of Equation 3.2.1-11 and using the above results:

$$
\delta \frac{\mathrm{d} \delta}{\mathrm{dt}}=\mathrm{N}\left[\frac{\mathrm{L}_{\mathrm{cv}}}{\mathrm{L}_{\mathrm{ms}}^{*}}+1-\left(\frac{\mathrm{L}_{\mathrm{cv}}}{\mathrm{L}_{\mathrm{ms}}^{*}}-1\right) \mathrm{C}\right] \alpha
$$

This equation may be integrated from the initial condition (given by combining Equations 3.2.1-6a and 7)

$$
\delta(t=0)=0
$$

to find that

$$
\delta=\left\{2 \mathrm{~N}\left[\frac{\mathrm{L}_{\mathrm{cv}}}{\mathrm{L}_{\mathrm{ms}}^{\star}}+1-\left(\frac{\mathrm{L}}{\mathrm{L}_{\mathrm{ms}}^{*}}-1\right) \mathrm{C}\right] \alpha t\right\}^{\frac{1}{2}}
$$

The quantity $C$ has not been specified at this point but has been assumed to be independent of time.

A second equation for $\delta$ may be found by requiring the energy equation to be satisfied integrally:

$$
\int_{-\delta}^{\delta} \mathrm{cv} \frac{\partial \mathrm{T}}{\partial \mathrm{t}} \mathrm{dy}=\int_{-\delta \mathrm{ms}}^{\delta} \mathrm{cv} \alpha \frac{\partial^{2} \mathrm{~T}}{\partial \mathrm{y}^{2}} \mathrm{dy}
$$

\footnotetext{
This assumption was not required in Section 3.1; however, the derivation showed $C$ was not a function of either $x$ or $t$ in Section 3.1.
} 
After using Leibnitz's rule and several of the boundary conditions this may be written as

$$
\frac{\mathrm{d}}{\mathrm{dt}}\left\{\delta \int_{0}^{1} \theta \mathrm{d} \xi\right\}=\frac{\alpha}{\delta} \quad\left[\left.(1+\mathrm{N}) \frac{\partial \Theta}{\partial \xi}\right|_{\xi=1}-\left.\frac{\partial \Theta}{\partial \xi}\right|_{\xi=0}\right]
$$

Substitution of the temperature profile and performing the indicated calculus leads to the expression

$$
\frac{1}{2}\left(1-\frac{1}{3} \mathrm{C}\right) \delta \frac{\mathrm{d} \delta}{\mathrm{dt}}=\alpha[\mathrm{N}(1+\mathrm{C})+2 \mathrm{C}]
$$

This equation is solved subject to the initial condition given in Equation $3.2 .1-6 \mathrm{~b}$ to find

$$
\delta=2\left[\frac{N(1+C)+2 C}{\left(1-\frac{1}{3} C\right)} \alpha t\right]^{\frac{1}{2}}
$$

The expression for $C$ is now determined by requiring the two expressions for $\delta$, Equations $3 \cdot 2 \cdot 1-13 b$ and 1 , be identical at all time $t$. This requirement shows that $C$ is given by

$$
C=2\left\{\beta+\kappa \sqrt{\beta^{2}-3 / 4}\right\}
$$

where

$$
B \equiv \frac{\frac{\mathrm{L}_{\mathrm{cv}}}{\mathrm{L}_{\mathrm{ms}}^{*}}+1+\frac{3}{\mathrm{~N}}}{\frac{\mathrm{L}_{\mathrm{cv}}}{\mathrm{L}_{\mathrm{ms}}^{*}}-1}
$$

and

$$
K \equiv \begin{cases}+1 & \text { for } \beta<0 \\ -1 & \text { for } \beta>0\end{cases}
$$

The sign selection on the radical (i.e. the definition of $k$ ) is based on the condition that $\frac{\mathrm{d} \delta_{\mathrm{ms}}}{\mathrm{dt}}$ and $\frac{\mathrm{d} \delta_{\mathrm{cv}}}{\mathrm{dt}}$ are both positive. 
The solution is now complete. Mass transfer rates may be evaluated by definitions similar to Equation 3.1-11 and using Equations $3 \cdot 2 \cdot 1-3 b$ and $3 \cdot 2 \cdot 1-5 b$. The results calculated using this formulation will be presented and discussed in Section 3.2.3.

\subsubsection{Solution for Long Times}

The steady-state portion of the problem will be modeled using a flowing-film approach. The problem geometry is illustrated in Figure 3-4. A moving coordinate system will be employed as was done in Section 2. The liquid in the film is allowed to flow, and the shear at the condensate/vapor interface is included, but the vapor is stagnant. The convective transport terms will be neglected in the momentum equation and retained in the energy equation as was done in Section 3.1.

The conservation equations are

$$
\begin{aligned}
\frac{\partial u}{\partial x}+\frac{\partial v}{\partial y} & =0 \\
0 & =g+v \frac{\partial^{2} u}{\partial y^{2}} \\
u \frac{\partial T}{\partial x}+v \frac{\partial T}{\partial y} & =\alpha \frac{\partial^{2} T}{\partial y^{2}}
\end{aligned}
$$

Most of the boundary conditions are identical to those used in Section 3.1:

$\mathrm{y}=0$ :

$$
\begin{aligned}
& u=0 \\
& \mathrm{v}=\frac{\stackrel{\grave{\mathrm{m}}}{\mathrm{p}}}{\mathrm{m}} \\
& \mathrm{T}=\mathrm{T}_{\mathrm{mp}, \mathrm{ms}} \\
& \dot{\mathrm{m}}_{\mathrm{ms}} \mathrm{L}_{\mathrm{ms}}^{*}=\mathrm{k} \frac{\partial \mathrm{T}}{\partial \mathrm{y}}
\end{aligned}
$$




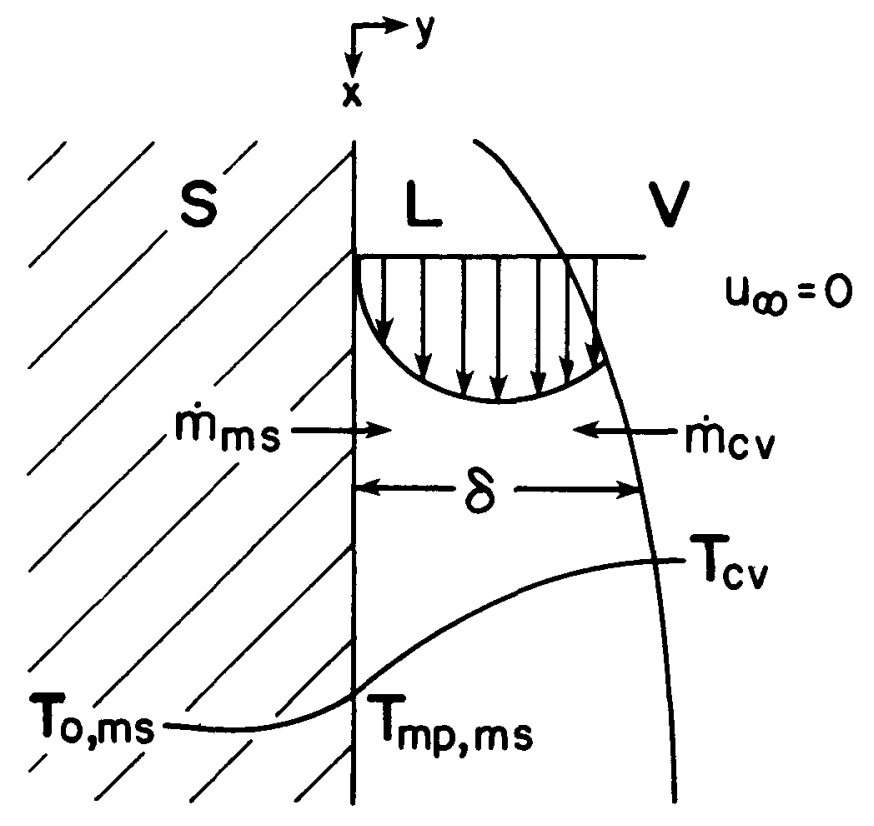

Figure 3-4. Schematic of the geometry used for the long-time (flowing-film) solution of a condensation-induced melting problem. 
$y=\delta:$$$
T=T_{c V}
$$
$\mu \frac{\partial u}{\partial y}=-\varepsilon \dot{\mathrm{m}}_{\mathrm{cV}} \mathrm{u}$
$\mathrm{k} \frac{\partial \mathrm{T}}{\partial \mathrm{y}}=\dot{\mathrm{m}}_{\mathrm{cv}} \mathrm{L}_{\mathrm{cv}}$
$(3.2 .2-6 a, 10 a)$

The translational velocity of the melting interface has been deleted in obtaining Equation 3.2.2-5a from Equation 3.1-5a since the coordinate system is now moving rather than stationary.

The mass balance on the film is given by

$$
\dot{\mathrm{m}}_{\mathrm{ms}}+\dot{\mathrm{m}}_{\mathrm{cv}}=\frac{\mathrm{d}}{\mathrm{dx}} \quad \int_{0}^{\delta} \rho \mathrm{u}(\mathrm{x}, \mathrm{y}) \mathrm{dy}
$$

which may be rewritten as

$$
\frac{\dot{\mathrm{m}}_{\mathrm{cv}}}{\rho}=\left.\left[u \frac{\mathrm{d} \delta}{\mathrm{dx}}-\mathrm{v}\right]\right|_{\mathrm{y}=\delta}
$$

The similarity transform which was used in Section 2.4 will again be used. The following definitions are needed:

$$
\begin{aligned}
& n=\left(\frac{g}{4 v^{2} x}\right)^{\frac{1}{4}} y \\
& u=2(g x)^{\frac{1}{2}} F^{\prime} \\
& v=\left(\frac{\nu^{2} g}{4 x}\right)^{\frac{1}{4}}\left(n F^{\prime}-3 F\right) \\
& \theta=\frac{T-T_{m p, m s}}{T_{c v}-T_{m p}, m s}
\end{aligned}
$$

After applying this transform, the conservation equations may be written as

$$
\begin{aligned}
& F^{\prime \prime \prime}+1=0 \\
& \Theta^{\prime \prime}+3 \operatorname{Pr} F \Theta^{\prime}=0
\end{aligned}
$$


The mass transfer fluxes are now defined by

$$
\begin{aligned}
& \frac{\dot{\mathrm{m}}_{\mathrm{ms}}}{\rho}\left(\frac{4 \mathrm{x}}{v^{2} \mathrm{~g}}\right)^{\frac{1}{4}}=-3 \mathrm{~F}(0) \\
& \frac{\dot{\mathrm{m}}_{\mathrm{cv}}}{\rho}\left(\frac{4 \mathrm{x}}{v^{2} g}\right)^{\frac{1}{4}}=3 \mathrm{~F}\left(n_{\delta}\right)
\end{aligned}
$$

The boundary conditions are transformed to the following:

$\underline{n}=0:$

$$
F^{\prime}(0)=0 \quad \theta(0)=0
$$

$$
-3 F(0)=\frac{L_{c v}}{L_{m s}^{*}} \frac{N}{\operatorname{Pr}} \theta^{\prime}(0)
$$

$\mathrm{n}=n_{\delta}$

$$
\theta\left(n_{\delta}\right)=1
$$

$F^{\prime \prime}\left(n_{\delta}\right)=-\varepsilon 3 F^{\prime}\left(n_{\delta}\right) F\left(n_{\delta}\right) \quad \frac{N}{\operatorname{Pr}} \theta^{\prime}\left(n_{\delta}\right)=3 F\left(n_{\delta}\right)$

where $N$ is given by Equation 3.2.1-12 and $n_{\delta}$ is $n[x, \delta(x)]$.

The momentum equation is satisfied pointwise. Integration of Equation $3.2 .2-2 b$ shows

$$
\mathrm{F}(n)=\mathrm{A}+\mathrm{B} n+\mathrm{D} \eta^{2}+\mathrm{E} \eta^{3}
$$

where

$$
E=-1 / 6
$$

and $A, B$, and $D$ are to be determined from the boundary conditions.

The energy equation will be satisfied integrally:

$$
\int_{0}^{n} \delta\left[\theta^{\prime \prime}+3 \operatorname{Pr} F \theta^{\prime}\right] \mathrm{dn}=0
$$


A temperature profile of the form

$$
\Theta=\mathrm{G}+\mathrm{Hn}+\mathrm{Jn}^{2}
$$

is used. After performing the integral in Equation 3.2.2-17, a system of 7 nonlinear algebraic equations (3.2.2-4b, $6 \mathrm{~b}$ through $10 \mathrm{~b}$, and 17) are available for solution to find the coefficients $A, B, D, G, H$, and $J$ and the dimensionless film thickness, $n_{\delta}$. The final forms of these equations are given in Appendix E. The system was solved using a Newton-Raphson ${ }^{34}$ iterative technique. Some typical results calculated using this model will be presented in Section 3.2.3.

\subsubsection{Combination and Comparison with Full Transient}

The following procedure is proposed for combining the transient, conduction-only model (Section 3.2.1) with the steady-state flowing-

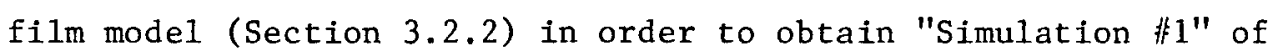
transient film condensation. Following initial contact of the vapor and substrate, the condensation rate is high, and the conduction model is used. The condensation rate decreases as the film thickness increases. When the condensation rate at any axial location decreases to the value associated with the steady-state condensation/melting model, the conduction model is abandoned in favor of the steady-state flowing-film model. Setting the condensation rates obtained from these two models equal to each other results in defining the switchover time as a function of location; this is analogous to the quantity $t_{s s}(x)$ which was used in Section 3.1. Quantities other than the condensation rate will not, in general, be continuous at the switchover time; for example, the condensation rates for the two model portions are 
different functions of the film thickness. This is in contrast to the full transient model of Section 3.1; all quantities in that model are continuous at the effective switchover time since only a single model formulation is involved.

As mentioned previously, the models presented in Sections 3.2.1 and 3.2.2 are not the best available descriptions of the individual portions of the problem; rather, these models were intentionally derived using the same modeling approximations used in the full transient model derived in Section 3.1. The best description of the transient, conduction-only portion is given in Carslaw and Jaeger ${ }^{45}$; the energy equation is satisfied pointwise in both the liquid (rather than integrally) and the solid (rather than using the effective heatof-fusion concept) regions. The best available description of the steady-state portion is given by Epstein and $\mathrm{Cho}^{13}$; the convective momentum terms are retained and the momentum equation is satisfied integrally in this analysis.

Table 3-1 presents the results obtained using the three modeling approaches: full transient (Section 3.1), simulation (非) of full transient (Sections 3.2.1 and 3.2.3), and a simulation (非) using the better individual models (References 45 and 13). The thermophysical properties used to obtain the values snown in Table 3-1 are given in Appendix A. The vapor has properties $\left(\mathrm{T}_{\mathrm{cV}}, \mathrm{L}_{\mathrm{cV}}\right)$ of $\mathrm{UO}_{2}$ fuel, the substrate has steel properties $\left(T_{m p, m s}, L_{m s}, c_{m s}\right.$, but $\left.\rho_{m s}=\rho\right)$, and the film has an average of fuel and steel properties $(\rho, c, k, \mu)$. The comparison between the Ful1 Transient and Simulation $\|_{1}$ 
TABLE $\quad 3-1$

Comparison of Full and Simulated Transient Solutions* of CondensationInduced Melting in Vertical Orientation $\left(\mathrm{T}_{\mathrm{o}, \mathrm{ms}}=800 \mathrm{~K}, \gamma=1, \rho_{\mathrm{ms}}=\rho\right.$,
$\varepsilon=1 ; \mathrm{x}$ in $[\mathrm{m}], \mathrm{t}$ in $[\mathrm{s}])$

\begin{tabular}{|c|c|c|c|}
\hline $\mathrm{T}_{\mathrm{cV}},[\mathrm{K}]$ & 4000 & 5000 & 6000 \\
\hline$t_{s s}(x),[s]$ & $\begin{array}{c}0.1220 \mathrm{x}^{\frac{1}{2}} \\
\left(0.1520 \mathrm{x}^{\frac{1}{2}}\right) \\
{\left[0.2882 \mathrm{x}^{\frac{1}{2}}\right]}\end{array}$ & $\begin{array}{l}0.1076 \mathrm{x}^{\frac{1}{2}} \\
\left(0.1336 \mathrm{x}^{\frac{1}{2}}\right) \\
{\left[0.2361 \mathrm{x}^{\frac{1}{2}}\right]}\end{array}$ & $\begin{array}{l}0.0947 x^{\frac{1}{2}} \\
\left(0.1195 x^{\frac{1}{2}}\right) \\
{\left[0.2049 x^{\frac{1}{2}}\right]}\end{array}$ \\
\hline \multicolumn{4}{|l|}{$t<t_{S S}(x)$} \\
\hline$\delta,[\mathrm{mm}]$ & $\begin{array}{l}3.838 t^{\frac{1}{2}} \\
\left(2.936 t^{\frac{1}{2}}\right) \\
{\left[2.122 t^{\frac{1}{2}}\right]}\end{array}$ & $\begin{array}{l}4.763 t^{\frac{1}{2}} \\
\left(3.607 t^{\frac{1}{2}}\right) \\
{\left[2.652 t^{\frac{1}{2}}\right]}\end{array}$ & $\begin{array}{l}5.749 \mathrm{t}^{\frac{1}{2}} \\
\left(4.266 \mathrm{t}^{\frac{1}{2}}\right) \\
{\left[3.114 \mathrm{t}^{\frac{1}{2}}\right]}\end{array}$ \\
\hline$\dot{\mathrm{m}}_{\mathrm{cv}},\left[\mathrm{kg} / \mathrm{m}^{2} \cdot \mathrm{s}\right]$ & $\begin{array}{l}3.823 \mathrm{t}^{-\frac{1}{2}} \\
\left(4.108 \mathrm{t}^{-\frac{1}{2}}\right) \\
{\left[4.328 \mathrm{t}^{-\frac{1}{2}}\right]}\end{array}$ & $\begin{array}{l}5.253 \mathrm{t}^{-\frac{1}{2}} \\
\left(5.457 \mathrm{t}^{-\frac{1}{2}}\right) \\
{\left[5.255 \mathrm{t}^{-\frac{1}{2}}\right]}\end{array}$ & $\begin{array}{l}6.813 \mathrm{t}^{\mathrm{t}-\frac{1}{2}} \\
\left(6.885 \mathrm{t}^{-\frac{1}{2}}\right) \\
{\left[6.196 \mathrm{t}^{-\frac{1}{2}}\right]}\end{array}$ \\
\hline$\dot{\mathrm{m}}_{\mathrm{ms}},\left[\mathrm{kg} / \mathrm{m}^{2} \cdot \mathrm{s}\right]$ & $\begin{array}{l}3.621 \mathrm{t}^{-\frac{1}{2}} \\
\left(6.553 \mathrm{t}^{-\frac{1}{2}}\right) \\
{\left[3.377 \mathrm{t}^{-\frac{1}{2}}\right]}\end{array}$ & $\begin{array}{l}3.779 \mathrm{t}^{-\frac{1}{2}} \\
\left(7.644 \mathrm{t}^{-\frac{1}{2}}\right) \\
{\left[4.374 \mathrm{t}^{-\frac{1}{2}}\right]} \\
\end{array}$ & $\begin{array}{l}3.757 \mathrm{t}^{-\frac{1}{2}} \\
\left(8.605 \mathrm{t}^{-\frac{1}{2}}\right) \\
{\left[5.112 \mathrm{t}^{-\frac{1}{2}}\right]}\end{array}$ \\
\hline \multicolumn{4}{|l|}{$t>t_{\text {ss }}(x)$} \\
\hline$\delta,[\mathrm{mm}]$ & $\begin{array}{l}1.341 \mathrm{x}^{\frac{1}{4}} \\
\left(1.188 \mathrm{x}^{\frac{1}{4}}\right) \\
{\left[1.552 \mathrm{x}^{\frac{1}{4}}\right]}\end{array}$ & $\begin{array}{l}1.562 x^{\frac{1}{4}} \\
\left(1.364 x^{\frac{1}{4}}\right) \\
{\left[1.883 x^{\frac{1}{4}}\right]}\end{array}$ & $\begin{array}{l}1.770 x^{\frac{1}{4}} \\
\left(1.520 x^{\frac{1}{4}}\right) \\
{\left[2.212 x^{\frac{1}{4}}\right]}\end{array}$ \\
\hline$\dot{\mathrm{m}}_{\mathrm{cv}},\left[\mathrm{kg} / \mathrm{m}^{2} \cdot \mathrm{s}\right]$ & $\begin{array}{l}10.94 \mathrm{x}^{-\frac{1}{4}} \\
\left(10.54 \mathrm{x}^{-\frac{1}{4}}\right) \\
{\left[8.06 \mathrm{x}^{-\frac{1}{4}}\right]}\end{array}$ & $\begin{array}{l}16.02 \mathrm{x}^{-\frac{1}{4}} \\
\left(14.93 \mathrm{x}^{-\frac{1}{4}}\right) \\
{\left[10.82 \mathrm{x}^{-\frac{1}{4}}\right]}\end{array}$ & $\begin{array}{l}22.13 \mathrm{x}^{-\frac{1}{4}} \\
\left(19.92 \mathrm{x}^{-\frac{1}{4}}\right) \\
{\left[13.69 \mathrm{x}^{-\frac{1}{4}}\right]}\end{array}$ \\
\hline$\dot{\mathrm{m}}_{\mathrm{ms}},\left[\mathrm{kg} / \mathrm{m}^{2} \cdot \mathrm{s}\right]$ & $\begin{array}{l}10.36 \mathrm{x}^{-\frac{1}{4}} \\
\left(15.42 \mathrm{x}^{-\frac{1}{4}}\right) \\
{\left[11.80 \mathrm{x}^{-\frac{1}{4}}\right]}\end{array}$ & $\begin{array}{l}11.52 \mathrm{x}^{-\frac{1}{4}} \\
\left(19.32 \mathrm{x}^{-\frac{1}{4}}\right) \\
{\left[14.00 \mathrm{x}^{-\frac{1}{4}}\right]}\end{array}$ & $\begin{array}{l}12.21 \mathrm{x}^{-\frac{1}{4}} \\
\left(23.24 \mathrm{x}^{-\frac{1}{4}}\right) \\
{\left[15.97 \mathrm{x}^{-\frac{1}{4}}\right]}\end{array}$ \\
\hline
\end{tabular}

*Legend for results groupings:

Fu11 Transient--Section 3.1

(Simulated Transient 非1--Sections 3.2.1 and 3.2.2)

[Simulated Transient \#2--References 45 and 13.] 
(the first two results shown for each quantity in Table 3-1) will be discussed first. The switchover times obtained from Simulation $\|_{1}$ are on1y 25\% larger than those predicted by the Full Transient solution. The film thicknesses agree within $15 \%$ in steady-state portion and $30 \%$ in the transient portion. For each portion of the solutions, the condensation rates are in the best agreement (within $\simeq 10 \%$ ), and the melting rates show the least agreement (as bad as a factor of 2). No portion of the temperature range shows a better overall comparison than any other.

The cause of the reasonably large disagreement in the melting rate is not understood. A possible explanation is that the model of Section 3.1 satisfied an additional boundary condition not satisfied in Section 3.2 by requiring the liquid energy equation to be satisfied at $y=\delta_{m s}$ (in addition to the integral satisfaction). There are two additional modeling differences which may be important factors in understanding the differences between the results. The momentum equation used in Section 3.1 is not exactly equivalent to that used in Section 3.2.2; Equation 3.1-2 would need a $\frac{\partial u}{\partial t}$ term on the left side; this term would not only allow the velocity profile to develop in time but is also needed once the profile has attained the steadystate value to account for the film translating into the substrate relative to the fixed coordinate system being used in Section 3.1. A second consideration is that the fluid in the film is flowing in all portions of the full transient solution; fluid flow is only allowed in the steady-state region, $0<x<x_{s s}(t)$, in the simulated transient 
model; the energy convection effects associated with this flow could be significant.

The next item to be examined is the comparison of the full transient solution with the simulated transient solution composed of the best available models (first and third results shown for each quantity in Table 3-1). This simulation is a poorer representation of the full transient than was the simulation examined in the previous paragraphs. This is not totally surprising based on the effects seen in Section 2.3, since the modeling approximations are quite different in the solution techniques being compared. The biggest discrepancies in the results are in the switchover time and in the liquid region thickness for $t<t s(x)$. Surprisingly, the melting rate obtained from this simulation is a closer representation of the full transient solution than the melting rate obtained from Simulation 1 . 1 . This may be a result of the full transient solution imposing an extra boundary condition (Equation 3.1-19a) over those used in Simulation \#1 which forces the solution closer to the more sophisticated treatment in Simulation $\#^{2}$.

If the model-portion switchover time, $t_{s s}(x)$, in either of the simulated transient solutions had been based on matching liquid-region thickness rather than matching condensation rates, the switchover times between the full- and simulated - transient solutions would differ by $\simeq 35 \%$ for Simulation $\# 1$ and a factor of 5 for Simulation $\# 2$. While the film-thickness-based switchover time would seem to be the formal approach used in Section 3.1, the formulation in that 
section is such that the condensation rate and all other quantities are continuous at the effective switchover time. The present work has used the condensation-rate-based switchover time since this leads to a better overall agreement between the full transient solution and its simulation.

The results of this section indicate that a full transient solution to a condensation-induced melting problem in vertical orientation can be approximated by the results obtained from the combination of a transient conduction-only model and a steady-state flowing-film model when the same modeling approximations are employed in the several models. The postulate at this point is that this approach can be extended in order to say that the best simulation of the actual transient problem is obtained by combining the best available transient conduction-only model with the best available steady-state flowing-film model. The postulate is not provable at this time since the model presented in Section 3.1 has not been extended to include the inertia and convective momentum terms to provide the basis needed for evaluation of Simulation \#2. 


\section{SECTION 4}

\section{TRANSIENT ANALYSIS -- MULTIPLE FILMS}

Transient film condensation of one material onto a melting substrate of a second material has received no treatment in the literature. Indeed, the one-material problem has only been solved in an approximate manner (cf. § 3.1). When even a second film is added to this problem, a straightforward solution is hindered by an inability to uncouple the partial differential equations (this uncoupling was possible in the one-film problem). Rather than studying the multiplefilm problem by solving the full set of transient conservation equations, a composite solution is postulated as an approximate solution suitable for the current purposes.

The transient solution of a one-film problem was found, in Section 3 , to be well approximated by the combination of a transient, conductiononly solution and a steady-state, flowing-film solution when the same assumptions were employed within the several models. The idea to be advanced here is that this result can be extrapolated to apply to the multiple-film problem. The approach is to use the best available solution for each portion of the composite solution. This will consist of using the transient, conduction-only solution presented by Epstein and $\mathrm{Cho}^{12}$ for short times and the steady-state film-condensation solution presented in Section 2.4 for long times. The switchover between the two solutions occurs when the condensation rate obtained from the transient, conduction-only solution decreases to the rate obtained from the steady-state solution. As in Section 3.2.3, the 
switchover time is a function of axial location.

The two portions of the solution have a number of assumptions in common; these include neglection of noncondensable gas and sodium. consideration of semi-infinite vapor space and substrate thickness, and the requirement of smooth liquid regions. Both models include condensate solidification and allow the temperature of the substrate to be below its melting temperature.

In the short-time solution, the conduction equation is satisfied pointwise within all regions of the problem. A summary of the important equations in this model is presented in Appendix D.

In the long-time solution, the solidified condensate is treated as an infinitely viscous fluid. This region and the two liquid regions are treated as smooth, laminar boundary layers. The conservation equations are satisfied in an integral manner within each region. The shear stress at the condensate/vapor interface is modeled although the bulk vapor velocity is zero in this model.

The condensation heat fluxes and the switchover times for this composite solution are given in Table 4-1. (A switchover time based on condensation heat flux is identical to the switchover time based on condensation mass flux.) As noted previously, the transient and steadystate heat fluxes are both relatively weak functions of $\mathrm{T}_{\mathrm{cV}}$ and $\mathrm{T}_{\mathrm{o}}, \mathrm{ms}$. This results in the model switchover time being insensitive to these two temperatures,

The only quantity which is continuous at the switchover time is the condensation rate. Some of the discontinuities encountered when 
TABLE $\quad 4-1$

Simulation of Transient Condensation of Stagnant Fuel onto Vertical Melting Steel ( $x$ is in $[\mathrm{m}], t$ is in $[s]$ )

\begin{tabular}{|c|c|c|c|c|c|c|}
\hline $\mathrm{T}_{\mathrm{cV}},[\mathrm{K}]$ & \multicolumn{2}{|c|}{4000} & \multicolumn{2}{|c|}{5000} & \multicolumn{2}{|c|}{6000} \\
\hline $\mathrm{T}_{\mathrm{o}, \mathrm{ms}},[\mathrm{K}]$ & 800 & 1200 & 800 & 1200 & 800 & 1200 \\
\hline$t_{s s}(x),[s]$ & $0.2394 x^{\frac{1}{2}}$ & $0.2242 \mathrm{x}^{\frac{1}{2}}$ & $0.2462 x^{\frac{1}{2}}$ & $0.2360 x^{\frac{1}{2}}$ & $0.2492 \mathrm{x}^{\frac{1}{2}}$ & $0.2419 x^{\frac{1}{2}}$ \\
\hline$\stackrel{t}{t}<s(x):$ & & & & & & \\
\hline $\mathrm{q}_{\mathrm{cV}}^{\prime \prime}(\mathrm{t}),\left[\mathrm{MW} / \mathrm{m}^{2}\right]$ & $6.309 \mathrm{t}^{-\frac{1}{2}}$ & $6.009 \mathrm{t}^{-\frac{1}{2}}$ & $6,840 t^{-\frac{1}{2}}$ & $6.621 \mathrm{t}^{-\frac{1}{2}}$ & $6.863 \mathrm{t}^{-\frac{1}{2}}$ & $6.703 \mathrm{t}^{-\frac{1}{2}}$ \\
\hline$t>t_{S S}(x):$ & & & & & & \\
\hline $\mathrm{q}_{\mathrm{cV}}^{\prime \prime}(\mathrm{x}),\left[\mathrm{MW} / \mathrm{m}^{2}\right]$ & $12,90 x^{-\frac{1}{4}}$ & $12.69 \mathrm{x}^{-\frac{1}{4}}$ & $13.79 \mathrm{x}^{-\frac{1}{4}}$ & $13.63 \mathrm{x}^{-\frac{1}{4}}$ & $13.75 \mathrm{x}^{-\frac{1}{4}}$ & $13.63 \mathrm{x}^{-\frac{1}{4}}$ \\
\hline
\end{tabular}


switching models at a given axial location are as follows:

- total fuel region thickness decreases by 2 to $20 \%$

- steel region thickness increases by 35 to $140 \%$

- total film thickness increases by 20 to $65 \%$

- steel melting rate increases by 15 to $90 \%$

The biggest differences are observed for the low-vapor-temperature and low-substrate-temperature cases. The large discontinuities in quantities associated with the steel melt are due to the large differences in the effective heat of fusion, $\mathrm{L}_{\mathrm{ms}}^{*}$, between the two portions of the problem (cf. Appendix D).

The spatially averaged, time-dependent, condensation heat transfer coefficients obtained from this simulated transient analysis are shown in Figure 4-1. These numbers were obtained using the averaging process described in Section 3.1 and are a function of the $1.2 \mathrm{~m}$ averaging length used. The coefficients retain the $t^{-\frac{1}{2}}$ dependence for approximately $50 \mathrm{~ms}$. The dependence is gradually reduced to $t^{0}$ by $270 \mathrm{~ms}$ at which time steady state is achieved over the $1.2 \mathrm{~m}$ length. All the curves in this figure should be lowered by 8 to $10 \%$ for $\mathrm{T}_{\mathrm{o}} \mathrm{ms}=$ 1200K.

The average condensation heat flux may be represented by using the approximations developed for the transient, conduction-only (Equation $\mathbf{D = 1 8}$ ) and steady-state (Equation 2.4-45) portions of the composite mode1. This average heat flux is given by 


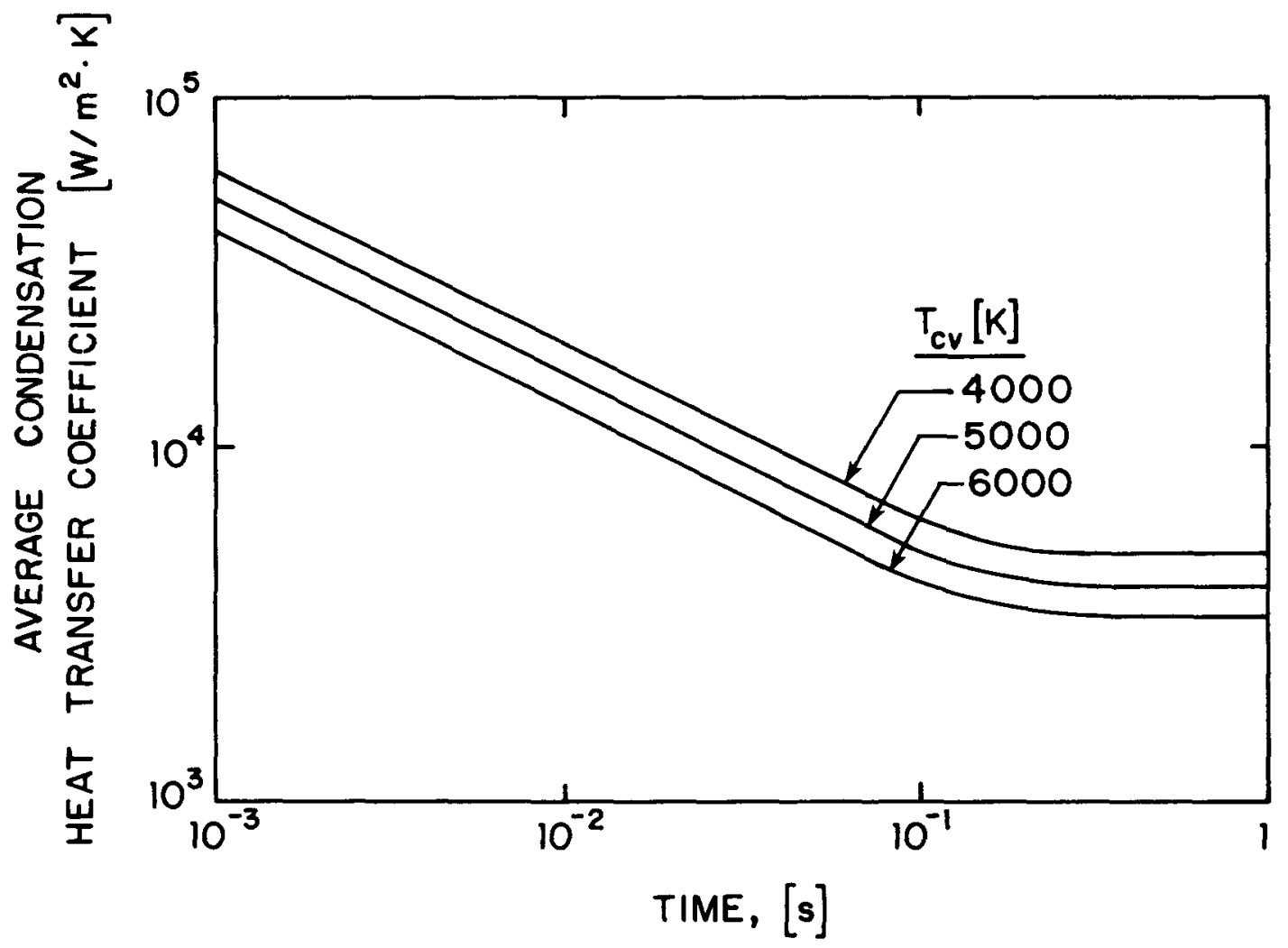

Figure 4-1. Spatially averaged condensation heat transfer coefficients as a function of time for stagnant fuel condensing onto vertical steel $\left(\mathrm{x}_{\mathrm{L}}=1.2 \mathrm{~m}, \mathrm{~T}_{\mathrm{o}}, \mathrm{ms}=300 \mathrm{~K}\right)$. 


$$
\left.\hat{q}_{c v}^{\prime \prime}\right|_{x_{L}}= \begin{cases}{\left[6.457+36.35 \frac{t^{2}}{x_{L}}\right] t^{-\frac{1}{2}}} & , t<0.2433 x_{L}^{\frac{1}{2}} \\ 17.45 x_{L}^{-\frac{1}{4}} & , t>0.2433 x_{L}^{\frac{1}{2}}\end{cases}
$$

where $t$ is in $s$ and $x_{L}$ is in $m$ to give $\hat{q}_{\mathrm{cv}}^{\prime \prime}$ in $M W / \mathrm{m}^{2}$. This expression represents the composite solution within $\pm 7 \%$ over the temperature ranges $\mathrm{T}_{\mathrm{CV}} \in(4000,6000 \mathrm{~K})$ and $\mathrm{T}_{\mathrm{o}, \mathrm{ms}} \in(800,1200 \mathrm{~K})$. The average heat flux calculated from this expression is shown in Figure 4-2 as a function of time for several substrate lengths. The heat flux is independent of $x_{L}$ for short times. For longer times, the steady-state value and the time required to attain this value are both functions of $\mathrm{x}_{\mathrm{L}}$.

The steel melting rate associate with this fuel condensation rate is not easily correlated; however, approximate forms have been given in Section 2.4 and Appendix $D$ for the two portions of the composite model and are not repeated here.

The effect of an upward vapor velocity on these results is rather complicated. This will not be addressed analytically; however, a few comments on this effect are presented. The current model used for the short time solution does not allow for any material flows; however, early in the transient, the flowing vapor should be able to maintain the relatively thin film in an upflow condition. As the thickness of the film increases at a given location, it will be increasingly difficult to maintain the upflow condition. Portions of the film will switch to a draining situation as the film grows sufficiently thick. Surface waves will undoubtedly be present during the switch from flooding to draining in the films, and this is an effect which is not 


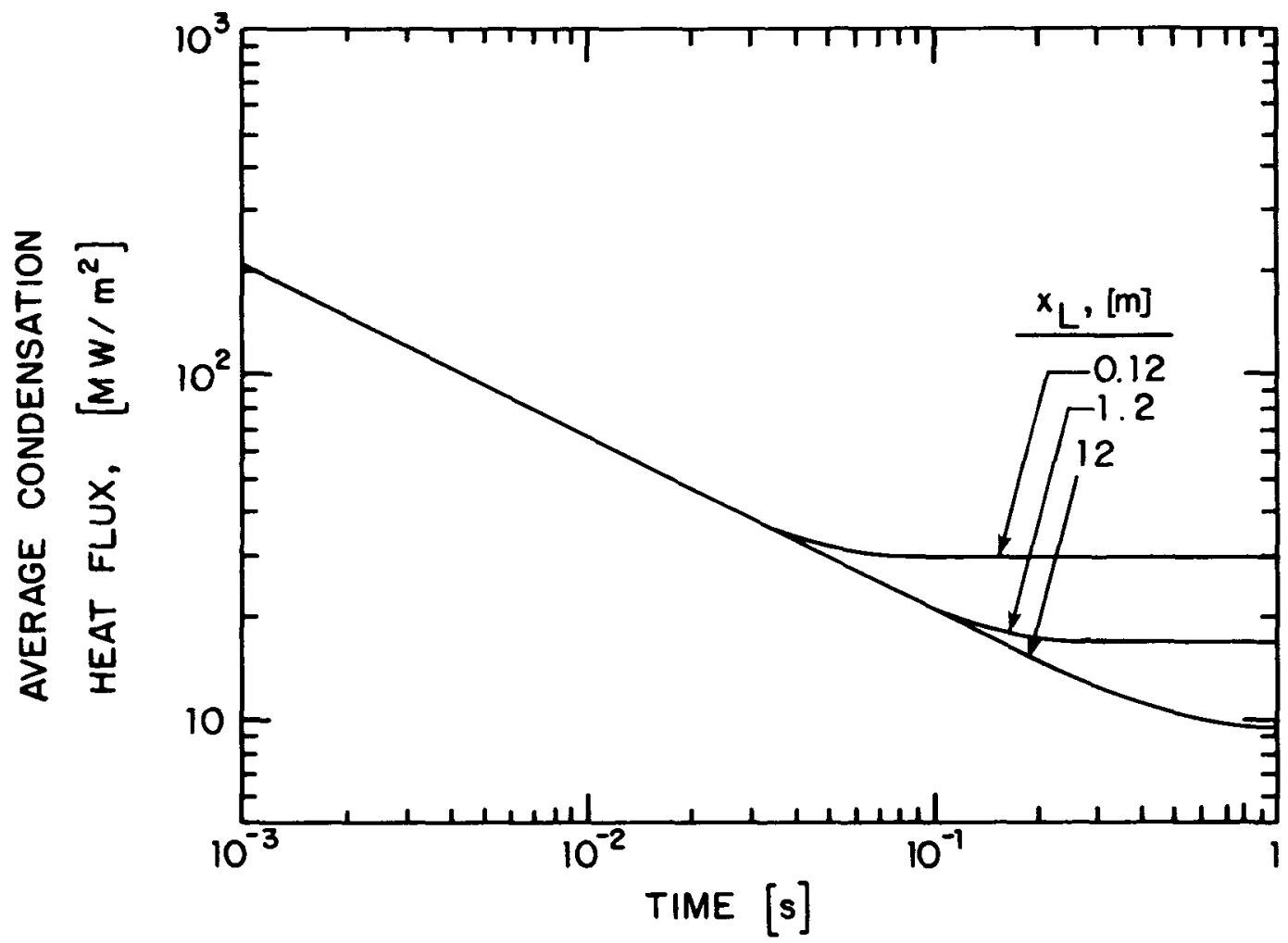

Figure 4-2. Spatially averaged condensation heat flux as a function of time and substrate length for stagnant fuel condensing onto vertical steel. 
included in any of the models presented in this report. Even if surface waves were neglected, the model presented in Section 2.4 would have to be extended (or the convective terms included in the model presented in Section 2.2) to obtain the steady-state portion of the composite model for flowing vapor cases. 
SECTION 5

CONCLUDING SUMMARY AND RECOMMENDATIONS

Condensation of fuel onto melting steel has been examined for both transient and steady-state situations, with emphasis on the latter. This section will summarize the important results found in this study and also recommend areas for further work.

Within the steady-state analyses, the fuel condensate and steel melt were assumed to flow side-by-side as smooth films which could be treated as boundary layers. Specific results found are as follows:

- A portion of the fuel condensate will actually solidify. This solidification may be neglected within the current work without seriously affecting the calculated fuelcondensation and steel-melting rates. The presence of this solid layer between the two liquid films may, however, be an important factor when trying to assess the stability of the films.

- The shear stress at the condensate/vapor interface and the convective momentum and energy terms in the conservation equations are important. Neglection of any of these terms simplifies the analysis but results in overestimating the condensation and melting rates.

- The films are thickened and the phase-change rates are reduced if the vapor is flowing upward at low velocities rather than being stagnant. For sufficiently high (upward) vapor velocities the phase change rates may actually be 
higher than the rates associated with stagnant vapor.

- The condensation rates are most easily correlated in terms of the condensation heat flux, since this quantity is relatively insensitive to the vapor and substrate temperatures. Transient condensation-induced melting was only examined for stagnant-vapor situations. The transient problem was first examined for the situation in which only a single material was involved. This analysis indicated that the full transient solution could be approximated by using a transient, conduction-only model for short times and a steady-state, flowing-film model for long times. The switchover between the two model portions occurs, as a function of axial location, when the condensation rate obtained from the conduction-only mode1 decreases to the local condensation rate obtained from the flowing film model. This concept was extrapolated to the two-material situation to provide a simulated transient solution describing fuel condensation onto steel. The spatially averaged condensation heat fluxes obtained from this simulation of the transient were found to be primarily a function of the substrate length (and time) and very weak functions of the temperatures of the vapor and substrate.

There are several items which would be interesting topics for follow-on studies to the present work. These include further examination of

- the ability of the postulated composite solution to simulate the full transient solution (for both the one- and two-material cases) 


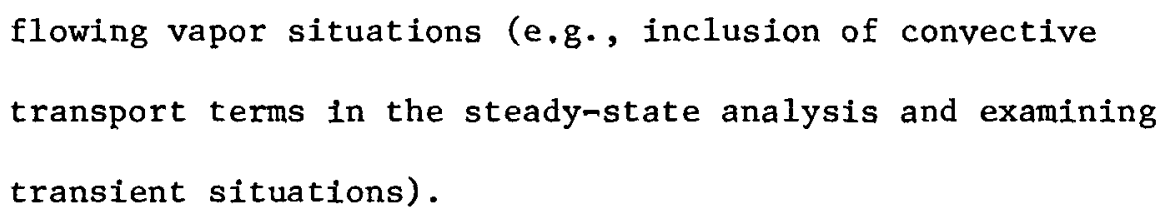

These problems may be primarily of academic interest since they would still be investigations of the condensation-induced melting problem within a number of approximations which may inhibit the direct use of the results in LMFBR accident-analysis work. The results of these followmon studies should provide valuable information to clarify modeling uncertanties and to indicate the trends of the various effects.

There are a number of assumptions in the present work which must be examined and possibly removed in order to produce models which will be directly applicable to LMFBR accident analysis projects. The following items are expected to be important:

- effects of noncondensable gas mixed with the fuel vapor

- effect of sodium in the condensing region

- development of surface waves on the film

- allowing for turbulent flow in the films

The potential effects of these items were discussed in Section 2.1. The only discussion to be added here is in connection with the first two items. When a second gas species is present in the primary condensing vapor, the surface temperature of any condensed film is no longer necessarily the temperature of the vapor space. The potential for radiation heat transfer from the vapor (or droplets within the vapor) to the film surface must be assessed in this situation. 46 
The final topic to be discussed in this section is the substrate melt-through times predicted from the current analysis. The primary substrate of interest in the CDA situation is the fuel-pin cladding $(0.381 \mathrm{~mm}$ thickness) in the fission-gas-plenum region ( $1.2 \mathrm{~m}$ length) above the reactor core. Direct use of the results in Table D-2 shows that the melt front would progress through the substrate thickness in $^{+} 26$ to $137 \mathrm{~ms}$. (Substrate melt-through may be determined using this transient conduction-only model since only 1 to $30 \%$ of the $1.2 \mathrm{~m}$ condensing region length has reached steady state at the melt-through times just stated.) This particular calculation, however, has been performed assuming that there is an infinite thickness of substrate available; a large portion of the energy entering the substrate at the melting boundary has been transmitted past the physical thickness of the actual substrate.

There are two approximate ways of correcting for this loss of energy from the physical substrate which will avoid having to actually perform the calculation using a finite substrate thickness. The first method would entail performing the calculation with the substrate at the melting temperature but with the latent heat of fusion increased by the amount of sensible heat needed to raise the substrate from its actual initial temperature up to the melting temperature (i.e., $\left.c\left[\mathrm{~T}_{\mathrm{mp}, \mathrm{ms}}-\mathrm{T}_{\mathrm{o}, \mathrm{ms}}\right]\right)$. The melt-through times predicted by this

TIn this paragraph and the next, the first number in each pair is for $\mathrm{T}_{\mathrm{cV}}=6000 \mathrm{~K}$ and $\mathrm{T}_{\mathrm{o}, \mathrm{ms}}=1200 \mathrm{~K}$; the second number is for $\mathrm{T}_{\mathrm{cv}}=4000 \mathrm{~K}$ and $\mathrm{T}_{\mathrm{o}, \mathrm{ms}}=800 \mathrm{~K}$. 
calculation are 17 to $35 \mathrm{~ms}$. A second method of correcting for the finiteness of the substrate would use the heat flux into the melting solid, rather than the melt-front progression rates, given by the information in Tables $\mathrm{D}-1$ and $\mathrm{D}-2$; melt-through occurs when the integrated heat flux into the solid equals the original sensibleplus latent-heat content of the substrate. This technique predicts that melt-through will occur in 11 to $19 \mathrm{~ms}$. The melt-through times obtained from these latter two techniques should be more realistic than the melt-through times obtained from using the melt-front progression rates from Table D-2 directly.

These calculations indicate that fuel-pin-cladding me1t-through would occur very rapidly; in fact, less than $2 \%$ of the $1.2 \mathrm{~m}$ length would have achieved a steady-state configuration during this time. Thus, future work on condensation models for LMFBR accident-analysis work should be concentrated on transient aspects of the problem. There are two qualifiers on this recommendation. Steady-state condensation rates may be used in a conservative calculation since the steady-state rates are less than the transient rates. (Transient melting rates must be used to obtain a conservative estimate of substrate melt-through times.) A second condensing surface, the $3.05 \mathrm{~mm}$-thick fuel-assembly wall, is available; the melt-through times associated with this substrate are a factor of $64 \quad(=[3.05 /$ $0.381]^{2}$ ) longer than those associated with fuel-pin-cladding meltthrough and would allow time for a steady-state situation to be attained. 


\section{REFERENCES}

1. J.F. Meyer, L. Lois, J.L. Carter, and T.P. Speis, An Analysis and Evaluation of the Clinch River Breeder Reactor Core Disruptive Accident Energetics, NUREG-0122, U.S. Nuclear Regulatory Commission (March 1977).

2. J.A. Gieseke, R.C. Behn. R.L. Ritzman, and J.M. Genco, Aeroso1 Source Term for Fast Reactor Safety Analysis, (Final Report) BMI-x-637, Batte1le Columbus Laboratories (August 11, 1972).

3. P.L. Garner and C.A. Erdman, "Dynamics of Fue1 Expansion into the Sodium Pool," Bubble Behavior in LMFBR Core Disruptive Accidents (Annual Report), NUREG-0114, University of Virginia, pp. 39-58 (September 1976).

4. Radiological Assessment Models (Fifth Quarterly Report), GEAP14034-5, Genera1 E1ectric Company, pp. 2-1 through 2-3 (Dec. 1975).

5. C.R. Be11, P.B. Bleiweis, J.E. Boudreau, F.R. Parker, and L.L. Smith, SIMMER-I: An $S_{n}$, Implicit, Multifield, Multicomponent Eulerian, Recriticality Code for LMFBR Disrupted Core Analysis, LA-NUREG-6467-MS, Los Alamos Scientific Laboratory (January 1977).

6. T.S. Kress, G.W. Parker and M.H. Fontana, Work Plan: Transient Release from LMFBR Fuel, ORNL-TM-4875, Oak Ridge National Laboratory (September 1975).

7. W. Nusse1t, "Die Oberflachenkondensation des Wasserdampfes," Zeitschrift des Vereines Deutscher Ingenieure, 60, 541-546 and 569-575 (1916).

8. Stefan, Ann. Phys. u. Chem. (Wiedmann) N.F., 42, 269-286 (1891)

9. Chi Tien and Y.C. Yen, "Condensation-Melting Heat Transfer," Convective and Interfacial Heat Transfer, A.I.Ch.E., Chemica1 Engineering Progress Symposium Series, No, 113, 67, 1-9 (1971).

10. D.H. Cho and M. Epstein, "Laminar Film Condensation of Flowing Vapor on a Horizontal Melting Surface," Int, J. Heat Mass Transfer, 20(1), 23-30 (January 1977).

11. W. Contreras and R.S. Thorsen, "Transient Melting of a Solid Heated by a Condensing Saturated Vapor - Case 1: Negligible Interface Curvature," J. Heat Transfer, Trans. ASME, C, 97(4), 570-575(November 1975). 
12. M. Epstein and D.H. Cho, "Melting of Stainless Steel by UO Vapor", Reactor Development Program Progress Report, ANL-RDP-27, Argonne National Laboratory, 7.9-7.12, (April 1974).

13. M. Epstein and D.H. Cho, "Laminar Film Condensation on a Vertical Melting Surface", J. Heat Transfer, Trans. ASME, C, 98(1), 108-113 (February 1976).

14. D.H. Cho and M. Epstein, "Melting of Steel Structure by Flowing Fuel or Stee1 Vapor," Reactor Development Program Progress Report, ANL-RDP-46, Argonne National Laboratory, 7.19-7.21 (December 1975).

15. E.M. Sparrow and S.H. Lin, "Condensation Heat Transfer in the Presence of a Noncondensable Gas," J. Heat Transfer, Trans. ASME, C, $86(3), 430-436$ (August 1964).

16. E.M. Sparrow, W.J. Minkowycz, and M. Saddy, "Forced Convection Condensation in the Presence of Noncondensables and Interfacial Resistance," Int. J. Heat Mass Transfer, 10(12), 1829-1845, (December 1967).

17. Yin-Chao Yen, Anthony Zehnder, Stephen Zavoluk, and Chi Tien, "Condensation-Melting Heat Transfer in the Presence of Air," Heat Transfer: Fundamentals and Industrial Applications, Chemical Engineering Progress Symposium Series, 69(131), A.I.Ch.E., 23-29 (1973).

18. I.G. Shekriladze and V.I. Gomelauri, "Theoretical Study of Laminar Film Condensation of Flowing Vapor," Int. J. Heat Mass Transfer, 9(6), 581-591 (June 1966).

19. V.E. Denny and A.F. Mills, "Nonsimilar Solutions for Laminar Film Condensation on a Vertical Surface," Int. J. Heat Mass Transfer, 12(8), 965-979 (August 1969).

20. M.F. Kennedy, C.A. Erdman, P.L. Garner, A.B. Reynolds, and A. E. Waltar, "A First-Generation Model to Predict Particle-Size Distributions for Condensed UO 2 Vapor," Trans. Am. Nucl. Soc., 26, 339-340 (June 1977).

21. D.H. Cho, M. Epstein, H.K. Fauske, "Work Potential Resulting from a Voided-Core Disassembly," Trans. Am. Nuc1. Soc., 18, 220 (June 1974).

22. Susumu Kotake, "Gas-Liquid Laminar Boundary-Layer Flows with a Wavy Phase-Changing Interface," Int. J. Heat Mass Transfer, $17(8)$, 885-897 (August 1974).

23. S. George Bankoff, "Stability of Liquid Flow Down a Heated Inclined P1ane," Int. J. Heat Mass Transfer, 14(3), 377-385 (March 1971). 
24. E.M. Sparrow and J.L. Gregg, "A Boundary-Layer Treatment of Laminar-Film Condensation," J. Heat Transfer, Trans. ASME, C, 81, 13-18 (February 1959).

25. D.H. Cho and M. Epstein, "Film Condensation of Fuel Vapor with Heat Generation," Reactor Development Program Progress Report, ANL-RDP-29, Argonne National Laboratory, 7.5-7.8 (June 1974).

26. A.P. Colburn, "Note on the Calculation of Condensation When a Portion of the Condensate Layer is in Turbulent Motion," Trans. AIChE, 30, 187-193 (1933-34).

27. R.A. Seban, "Remarks on Film Condensation with Turbulent Flow," Trans. ASME, 76, 299-303 (1954).

28. W.M. Rosenhow, J.H, Weber, and A.T. Ling, "Effect of Vapor Velocity on Laminar and Turbulent Film Condensation," Trans. ASME, 78, 1637-1643 (November 1956).

29. E.R.G. Eckert and Robert M. Drake, Jr., Analysis of Heat and Mass Transfer, McGraw-Hil1 Book Company, New York, 275, 278 (1972).

30. Ibid. ,234-236.

31. Roland Bulirsh and Josef Stoer, "Numerical Treatment of Ordinary Differential Equations by Extrapolation Methods," Numerische Mathematik, 8, 1-13 (1966).

32. Max Jakob, Heat Transfer, I, John Wiley \& Sons, Inc., New York, 675-680 (1949).

33. V.E. Denny and A.F. Mills, Op. cit. (Reference 19), 977-978 (Appendix A).

34. R. Schappelle, NONLIN-Solution of a System of Nonlinear Equations by Newton-Raphson Method, LIB-C029, Computing Center, University of Virginia (November 1976).

35. M. Ishii and M.A. Grolmes, "Inception Criteria for Droplet Entrainment in Two-Phase Concurrent Film Flow," AIChE Journa1, 21(2), 308-318 (March 1975).

36. S.S. Kutateladze and V.M. Borishanskii, A Concise Encyclopedia of Heat Transfer, Pergamon Press, Oxford, $1 \overline{81}$ (1966).

37. W.M. Rosenhow, "Heat Transfer and Temperature Distribution in Laminar-Film Condensation," Trans. ASME, 78, 1645-1648 (Nov. 1956). 
38. J.C.Y. Koh, E.M. Sparrow, and J.P. Hartnett, "The Two Phase Boundary Layer in Laminar Film Condensation," Int. J. Heat Mass Transfer, 2(1/2), 69-82 (March 1961).

39. J.C.Y. Koh, "An Integral Treatment of Two-Phase Boundary Layer in Film Condensation," J. Heat Transfer, Trans. ASME, $\mathrm{C}, 83(3)$, 359-362 (August 1961).

40. Preliminary Safety Analysis Report for the Clinch River Breeder Reactor Plant, Project Management Corporation.

41. Arthur G. Hansen, Similarity Analyses of Boundary Valve Problems in Engineering, Prentice-Hall, Inc., Englewood Cliffs, N.J. (1964).

42. M. Epstein, R.P. Anderson, and D.R. Armstrong, "Stability of a Submerged UO ${ }_{2}$ Fuel Crust," Trans. Am. Nuc1. Soc., 24, 255-256 (November 1976).

43. F.B. Hildebrand, Advanced Calculus for Engineers, Prentice-Hall, Inc., Englewood Cliffs, N.J. 368-378 (1949).

44. H.S. Carslaw and J.C. Jaeger, Conduction of Heat in Solids, second edition, Oxford University Press, London, Chapter XI (1959).

45. Ibid., 290 .

46. D.W. Condiff and S.H. Chan, "Studies of Radiation-Controlled Fog Formation," Reactor Development Program Progress Report, ANL-RDP39, Argonne National Laboratory, 7.31-7.34 (April 1975),

47. L. Leibowitz (editor), Properties for LMFBR Safety Analysis, ANL-CEN-RSD-76-1, Argonne National Laboratory (April 1976).

48. Op. cit. (Reference 40), F6.2-37.

49. P.B. Bleiweis and C.R. Bell, "SIMMER Hydrodynamics Improvements," Reactor Safety and Technology Quarterly Progress Report for January 1 through March 31 1976, LAPR-NUREG-6317, Los Alamos Scientific Laboratory, 48-49 (1976).

50. R. Byron Bird, Warren E. Stewart, and Edwin N. Lightfoot, Transport Phenomena, John Wiley \& Sons, New York, 15-19 (1963).

51. D.C. Menzies, The Equation of State of Uranium Dioxide at High Temperatures and Pressures, TRG Report 1119(D) (1966). 


\section{APPENDIX A}

FUEL AND STEEL PROPERTIES

The fuel and steel properties used in this analysis are given in Table A-1 for several representative temperatures. All properties were obtained from Reference 47 with the following exceptions or qualifiers:

- Fuel properties are for $\mathrm{UO}_{2}$ (not $\mathrm{UO}_{2}-\mathrm{PuO}_{2}$ ).

- The latent heat of condensation for fuel was calculated using the Clapeyron equation using the saturation pressure and saturated liquid specific volume in Reference 47 and using a saturated vapor specific volume obtained from the ideal gas law. (Reference 47 gives only a single value for $\mathrm{L}_{\mathrm{cv}}$ but notes that the quantity should be temperature dependent.)

- The conductivity of liquid fuel was taken to be that of the solid at the melting temperature. (This is the approach used in Reference 48. Reference 47 does not state any values for this property.)

- The fuel vapor viscosity was calculated using the theoretical approach outlined in References 49 and 50 . The critical point 51 of fuel was assumed to be given by $8000 \mathrm{~K}$ and $200 \mathrm{MPa}$.

- Stee1 properties are for Type 316. The properties were evaluated at average region temperatures as indicated in each section of the table. 
TABLE A-1

Summary of Fuel and Steel Properties

Fuel Vapor $(=c v)^{a}$

\begin{tabular}{|ll|l|l|l|}
\hline $\mathrm{T}$ & {$[\mathrm{K}]$} & 4000 & 5000 & 6000 \\
\hline$\rho$ & {$\left[\mathrm{kg} / \mathrm{m}^{3}\right]$} & 2.017 & 21.81 & 82.92 \\
$\mu$ & {$\left[\mathrm{mN} \cdot \mathrm{s} / \mathrm{m}^{2}\right]$} & 0.1010 & 0.1263 & 0.1516 \\
$\mathrm{~L}$ & {$[\mathrm{MJ} / \mathrm{kg}]$} & 1.696 & 1.492 & 1.281 \\
\hline
\end{tabular}

${ }^{a}$ Evaluated at $\mathrm{T}_{\mathrm{cv}}$

Fue1 Liquid $(=c)^{b}$

\begin{tabular}{|l|c|c|c|}
\hline $\mathrm{T}[\mathrm{K}]$ & 4000 & 5000 & 6000 \\
\hline$\rho\left[\mathrm{Mg} / \mathrm{m}^{3}\right]$ & 8.396 & 8.108 & 7.838 \\
$\mathrm{c}[\mathrm{kJ} / \mathrm{kg} \cdot \mathrm{K}]$ & 0.5036 & 0.5036 & 0.5036 \\
$\mathrm{k}[\mathrm{W} / \mathrm{m} \cdot \mathrm{K}]$ & 3.928 & 3.928 & 3.928 \\
$\mu\left[\mathrm{mN} \cdot \mathrm{s} / \mathrm{m}^{2}\right]$ & 3.606 & 3.073 & 2.712 \\
\hline
\end{tabular}

$\left.{ }_{\text {Evaluated at } \frac{1}{2}\left(\mathrm{~T}_{\mathrm{cv}}\right.}+\mathrm{T}_{\mathrm{mp}, \mathrm{sc}}\right)$

\begin{tabular}{|l|c|c|}
\hline & Solid Fuel $(=\mathrm{sc})^{\mathrm{c}}$ & Liquid Steel $(=\mathrm{m})^{\mathrm{d}}$ \\
\hline $\mathrm{T}_{\mathrm{mp}}[\mathrm{K}]$ & 3138 & 1700 \\
$\mathrm{~L}[\mathrm{MJ} / \mathrm{kg}]$ & 0.278 & 0.268 \\
$\rho\left[\mathrm{Mg} / \mathrm{m}^{3}\right]$ & 9.921 & 6.750 \\
$\mathrm{c}[\mathrm{kJ} / \mathrm{kg} \cdot \mathrm{K}]$ & 0.5957 & 0.7707 \\
$\mathrm{k}[\mathrm{W} / \mathrm{m} \cdot \mathrm{K}]$ & 3.305 & 19.16 \\
$\mu\left[\mathrm{mN} \cdot \mathrm{s} / \mathrm{m}^{2}\right]$ & $-\cdots$ & 3.650 \\
\hline
\end{tabular}

$\left.\left.{ }_{\text {Evaluated at } \frac{1}{2}\left[\frac{1}{2}\left(T_{m p, m s}\right.\right.}+T_{m p, s c}\right)+T_{m p, c v}\right]$

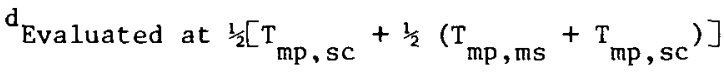

Solid Steel $(=m s)^{e}$

\begin{tabular}{|l|c|c|c|}
\hline $\mathrm{T}_{\mathrm{o}}[\mathrm{K}]$ & 800 & 1200 & 1700 \\
\hline $\mathrm{c}[\mathrm{kJ} / \mathrm{kg} \cdot \mathrm{K}]$ & 0.6254 & 0.6520 & 0.6852 \\
$\mathrm{k}[\mathrm{W} / \mathrm{m} \cdot \mathrm{K}]$ & 28.89 & 32.03 & 35.96 \\
\hline
\end{tabular}

$\left.e_{\text {Evaluated at } \frac{1}{2}\left(T_{o, m s}+T_{m p}, m s\right.}\right)$ 
An average set of fuel/steel properties was assembled for use in single film problems, that is where fuel condenses onto melting steel and the two liquids are treated as a single material ( $\$ 3$ ). The weighting of the properties was performed based on the film thicknesses obtained from a two-f $j 1 \mathrm{~m}$ analysis ( $\$ 2.3$ and Appendix $D$ ) as follows:

- same mass and same film thickness at any given axial location (determines $\rho)$.

- mass weight any "per unit mass" quantity (i,e., c, $\mu$ ).

- obtain $\mathrm{k}$ from equivalent thermal resistance

$$
\frac{\delta}{\mathrm{k}}=\frac{\delta_{\mathrm{c}}}{\mathrm{k}_{\mathrm{c}}}+\frac{\delta_{\mathrm{m}}}{\mathrm{k}_{\mathrm{m}}}
$$

The above properties were found as a function of $T_{c v}$ for both the steady-state and transient (conduction-only) model results, averaged over $T_{c v}$ within both steady-state and transient models, and then averaged between steady-state and transient models to obtain the following results for any $\mathrm{T}_{\mathrm{cv}}$ (with $\mathrm{T}_{\mathrm{o}, \mathrm{ms}}=800$ ):

$$
\begin{aligned}
& \rho=7.263 \mathrm{Mg} / \mathrm{m}^{3} \\
& c=0.6585 \mathrm{~kJ} / \mathrm{kg} \cdot \mathrm{K} \\
& \mathrm{k}=7.921 \mathrm{~W} / \mathrm{m} \cdot \mathrm{K} \\
& \mu=3.431 \mathrm{mN} \cdot \mathrm{s} / \mathrm{m}^{2}
\end{aligned}
$$

The normal values of $I_{c v}\left(a t T_{c v}\right.$ ) and the substrate properties (at $T_{0, m s}$ ) continue to be used in single-film analyses. 


\section{APPENDIX B}

EQUATION SUMMARY FOR INFINITE VISCOSITY TREATMENT OF SOLIDIFIED CONDENSATE

This appendix outlines the solution technique and presents the final equations associated with the model derived in Section 2.4 .

Substitution of the $F_{i}$ and $\theta_{i}$ profiles (Equations 2.4-38 and 39) into the various boundary conditions and into the integrated conservation equations results in a system of 24 nonlinear algebraic equations to be solved in order to find the 24 unknowns. After some algebraic manipulation this system can be reduced to a set of 18 definitions and 6 nonlinear equations.

The Newton-Raphson iterative procedure ${ }^{34}$ to be used to solve the system repeatedly calls a subroutine to evaluate the 6 functions to be zeroed based on the current values of the 6 "primary" unknowns at that point in the iteration. For this problem, the 6 primary unknowns are $B_{c}, D_{c}, E_{c}, \eta_{\delta_{m}}, \eta_{\delta_{s c}}$, and ${ }^{r_{1}} \delta_{c}$.

The following quantities are identically zero:

$$
\begin{aligned}
& \mathrm{E}_{s c}=0 \\
& \mathrm{D}_{\mathrm{sc}}=0 \\
& \mathrm{~A}_{\mathrm{sc}}=\mathrm{A}_{\mathrm{m}}=0
\end{aligned}
$$

For each call to the function evaluator, the following quantities

\footnotetext{
* The equation numbering pattern in this Appendix has been selected to correspond to that used in Section 2.4 in order to be able to show the equation match up.
} 
are calculated, in the order stated, based on the current iterated values of the 6 primary unknowns:

$$
A_{c}=-\left(D_{c}+2 E_{c} n_{\delta}\right) n_{\delta c}^{2}
$$

( $F_{C}$ and derivatives may be calculated at this point.)

$$
\begin{aligned}
& B_{s c}=F_{c}^{\prime}\left(\eta_{\delta}\right) \\
& B_{m}=B_{s c} \\
& D_{m}=\frac{1}{2} a\left[F_{c}^{\prime \prime}\left(\eta_{\delta}\right)+R n_{\delta c}\right] \\
& E_{m}=-\frac{1}{3 n_{\delta_{m}}}\left[2 D_{m}+\frac{1}{n_{\delta}} B_{m}\right]
\end{aligned}
$$

$\left(F_{m}, F_{s c}\right.$, and derivatives may be calculated at this point.)

$\mathrm{J}_{c}=\frac{1}{n_{\delta}}\left\{\frac{\Theta_{\mathrm{mp}, \mathrm{sc}}}{n_{\delta}}+3 \frac{\mathrm{Pr}}{\mathrm{N}_{\mathrm{c}}}\left[\mathrm{F}_{\mathrm{c}}\left(\eta_{\delta}+n_{\delta c}\right)+(\mathrm{R}-1) \mathrm{F}_{\mathrm{c}}\left(\eta_{\delta}\right)\right]\right\}$

$H_{c}=\frac{1-\theta_{m p, s c}}{n_{\delta_{c}}}-J_{c}\left(2 n_{\delta_{s c}}+n_{\delta_{c}}\right)$

$G_{c}=\theta_{m p, s c}-H_{c} n_{\delta s c}-J_{c} n_{\delta s c}^{2}$

$\left(\theta_{c}\right.$ and derivatives may be calculated at this point.)

$$
\begin{gathered}
G_{m}=\left\{-\frac{2}{n_{\delta}} \theta_{m p, s c}+K \theta_{c}^{\prime}\left(n_{\delta}\right)+3\left[\frac{P r_{s c}}{N_{s c}} F_{s c}\left(n_{\delta}\right)+b K \frac{P r_{m}}{N_{m}} F_{m}\left(n_{\delta}\right)\right]\right\} \div \\
\left\{2\left[\frac{b K}{n_{\delta}}-\frac{1}{n_{\delta}}\right]\right\}
\end{gathered}
$$

$$
H_{m}=-\frac{2}{n_{\delta_{m}}} G_{m}+3 \frac{P r_{m}}{N_{m}} F_{m}\left(n_{\delta_{m}}\right)
$$




$$
\begin{aligned}
& \mathrm{J}_{\mathrm{m}}=-\frac{1}{\eta_{\delta_{\mathrm{m}}}}\left[\frac{1}{\eta_{\delta_{\mathrm{m}}}} \mathrm{G}_{\mathrm{m}}+\mathrm{H}_{\mathrm{m}}\right] \\
& \mathrm{G}_{\mathrm{sc}}=\mathrm{G}_{\mathrm{m}} \\
& \mathrm{H}_{\mathrm{sc}}=\mathrm{bKH_{ \textrm {m } }} \\
& \mathrm{J}_{\mathrm{sc}}=\frac{1}{\eta_{\delta}}\left[\frac{\Theta_{\mathrm{mp}, \mathrm{sc}}-\mathrm{G}_{\mathrm{sc}}}{\eta_{\delta}}-\mathrm{H}_{\mathrm{sc}}\right]
\end{aligned}
$$

$\left(\Theta_{\mathrm{m}}, \Theta_{\mathrm{sc}}\right.$, and derivatives may be calculated at this point.)

The following 6 equations are to be zeroed (actually, the right side is evaluated and passed as a function value back to the NewtonRaphson iteration):

$0=F_{c}^{\prime \prime}\left(n_{\delta}+n_{\delta c}\right)+3 F_{c}^{\prime}\left(n_{\delta}+n_{\delta c}\right)\left[F_{c}\left(n_{\delta}+n_{\delta c}\right)+(R-1) F_{c}\left(n_{\delta}\right)\right]$

$\underline{i}=\mathrm{m}, \mathrm{c}:$

$$
\begin{aligned}
0 & =\left[F_{i}^{\prime \prime}(n)+3 F_{i}(n) F_{i}^{\prime}(n)-\left(5 B_{i}{ }^{2}-1\right) n-10 B_{i} D_{i} n^{2}\right. \\
& \left.-10\left(B_{i} E_{i}+\frac{2}{3} D_{i}{ }^{2}\right) n^{3}-15 D_{i} E_{i} n^{4}-9 E_{i}{ }^{2} n^{5}\right]\left.\right|_{n=\eta_{i, 1}} ^{n=n_{i, 2}}
\end{aligned}
$$

$i=m, s c, c:$

$$
\begin{aligned}
0 & =\left\{\theta_{i}^{\prime}(n)+3 \operatorname{Pr}_{i}\left[F_{i}(n) \theta_{i}(n)-B_{i} G_{i} \eta-\frac{1}{2}\left(B_{i} H_{i}+2 D_{i} G_{i}\right) n^{2}\right.\right. \\
& \left.\left.-\frac{1}{3}\left(B_{i} J_{i}+2 D_{i} H_{i}+3 E_{i} G_{i}\right) n^{3}-\frac{1}{4}\left(2 D_{i} J_{i}+3 E_{i} H_{i}\right) n^{4}-\frac{3}{5} E_{i} J_{i} n^{5}\right]\right\}\left.\right|_{\eta=n} ^{n=n_{i, 2}}
\end{aligned}
$$


where $n_{i, j}$ are given by

\begin{tabular}{|c|c|c|c|}
\hline$j$ & $j$ & $s c$ & $c$ \\
\hline 1 & $n_{\delta}$ & 0 & $n_{\delta}$ \\
\hline 2 & 0 & $n_{\delta}$ & $n_{\delta s c}+n_{\delta c}$ \\
\hline
\end{tabular}

These last 6 equations came from the shear stress balance at the condensate/vapor interface and the integrated momentum and energy equations. 
APPENDIX C

TREATMENT OF SOLIDIFIED CONDENSATE AS AN INFTNITELY VISCOUS FLUID WHEN CONVECTIVE TRANSPORT TERMS ARE NEGLECTED

The present treatment of the solid was needed so that the rigid solid results could be examined in the proper perspective. The problem geometry, nomenclature, and assumptions are identical to those set forth in Section 2.4 except in the present derivation the convective momentum and energy transport terms will be neglected, After applying the similarity transform*, the conservation equations become

$$
\begin{array}{lll}
F_{i}^{\prime \prime \prime}+1=0 & i=m, c & (C-2 a)^{\dagger} \\
\Theta_{i}^{\prime \prime}=0 & i=m, s c, c & (C-3 a) \\
F_{S c}^{\prime \prime}=0 & & (C-4 a) \\
F_{S C}^{\prime \prime}=0 &
\end{array}
$$

These equations will be satisfied pointwise rather than using the integral approximation used in Section 2.4 .

Multiple integrations of Equations $\mathrm{C}-2 \mathrm{a}$ thru $\mathrm{C}-4 \mathrm{a}$ result in showing that

$$
\begin{array}{ll}
F_{i}\left(n_{i}\right)=A_{i}+B_{i} n_{i}+D_{i} n_{i}^{2}-\frac{1}{6} n_{i}^{3} & , i=m, c \\
F_{s c}\left(n_{s c}\right)=A_{s c}+B_{s c} n_{s c} & , i=m, s c, c \\
\theta_{i}\left(n_{i}\right)=G_{i}+H_{i} n_{i} & , i=m
\end{array}
$$

\footnotetext{
* The similarity transform is not specifically needed to solve this problem, but its use does result in a compact derivation.

the equation numbering in this Appendix has been chosen to follow that used in Section 2.4 in order to show equation correspondences.
} 
In terms of the information in Section 2.4 and Appendix B, the above equations effectively show that

$$
\begin{aligned}
& E_{m}=E_{c}=-\frac{1}{6} \\
& D_{s c}=E_{s c}=0 \\
& J_{m}=J_{s c}=J_{c}=0
\end{aligned}
$$

The boundary conditions for the problem are identical (both before and after transformation) to those used in Section 2.4, and they are not repeated here.

The solution procedure is identical to that used in Appendix B. The three "primary" unknowns are the three film thicknesses, $n_{\delta_{i}}$. Application of the majority of the boundary conditions will result in equations for the remaining coefficients in $F_{i}$ and $\theta_{i}$ in terms of the three film thicknesses:

$$
\begin{aligned}
& \mathrm{A}_{\mathrm{m}}=0 \\
& A_{S C}=0 \\
& H_{c}=\frac{1-\theta_{m p, s c}}{n_{\delta_{c}}} \\
& G_{c}=1-H_{c}\left(n_{\delta}+n_{\delta c}\right) \\
& H_{m}=\frac{\theta_{m p, s c}}{b K n_{\delta s c}-n_{\delta_{m}}} \\
& \mathrm{G}_{\mathrm{m}}=-\mathrm{H}_{\mathrm{m}} \mathrm{n}_{\mathrm{m}} \\
& \mathrm{H}_{\mathrm{sC}}=\mathrm{bKH}_{\mathrm{m}}
\end{aligned}
$$




$$
\mathrm{G}_{\mathrm{sc}}=\theta_{\mathrm{mp}, \mathrm{sc}}-\mathrm{H}_{\mathrm{sc}} \mathrm{\eta}_{\delta \mathrm{sc}}
$$

$\left(\Theta_{i}\right.$ and derivatives may be calculated at this point.)

$$
\begin{aligned}
& D_{c}=\left\{-6 E_{c}\left(n_{\delta_{s c}}+n_{\delta_{c}}\right)-\frac{N_{c}}{P r_{c}} H_{c}\left[3 E_{c}\left(2 n_{\delta}+n_{\delta c}\right) n_{c}-3 E_{m} n_{\delta_{m}}^{2}-a\left(6 E_{c}+R\right)\right.\right. \\
& \left.\left.n_{\delta_{m}} n_{\delta c}\right]\right\}:\left\{2\left[1+\frac{N_{c}}{P r_{c}} H_{c}\left(n_{\delta_{c}}-a n_{\delta_{m}}\right)\right]\right\} \\
& B_{c}=-2 D_{c}\left(a \eta_{\delta_{m}}+\eta_{\delta_{s c}}\right)-3 E_{c} n_{\delta}^{2}-3 E_{m} n_{\delta}^{2}-a\left(6 E_{c}+R\right) n_{\delta_{m}} n_{\delta} \\
& A_{c}=\left(D_{c}+2 E_{c} n_{\delta}\right) n_{\delta c}^{2} \\
& B_{s c}=F_{c}^{\prime}\left(n_{\delta s c}\right) \\
& \mathrm{B}_{\mathrm{m}}=\mathrm{B}_{\mathrm{Sc}} \\
& D_{m}=-\frac{1}{2}\left[B_{m}+3 E_{m} n_{\delta}^{2}\right] \frac{1}{n_{\delta}}
\end{aligned}
$$

The results calculated using this model are shown in parenthesis in Table 2-5 in Section 2.5 . 


\section{APPENDTX D}

CONDUCTION-ONLY TREATMENT OF CONDENSATION-INDUCED MELTING

Epstein and Cho ${ }^{12}$ have considered the transient melting of a semi-infinite solid due to the condensation of a semi-infinite space of vapor. A summary of the important equations is given in this appendix for reference purposes and to correct one typographical error. Selected results from applying this model to the fuel/steel are also presented. This appendix also contains the derivation of the effective heat of fusion to be used in transient problems.

\section{D.1 Equation Summary}

The problem geometry and nomenclature are given in Figure D-1. The temperature in the vapor region is constant in time and space. The transient, one-dimensional heat conduction equation is satisfied pointwise within the four remaining regions. The formulation does not allow density changes to accompany melting or solidification.

The temperature profiles are given by

$$
T=A_{r}+B_{r} \operatorname{ert}\left[\frac{y}{2\left(\alpha_{r} t\right)^{\frac{1}{2}}}\right]
$$

The phase-change boundaries are given by

$$
\delta_{r}=2 \lambda_{r}\left(\alpha_{r} t\right)^{\frac{1}{2}}
$$

where $\lambda_{r}$ is the dimensionless thickness to be determined from the solution. The quantity $\delta_{\mathrm{cv}}$ is the combined thickness of the condensate and its solid; this quantity is defined by using $\lambda_{c v}$ and $\alpha_{c}$ in Equation $\mathrm{D}-2$. The thickness of the liquid condensate region is given by 


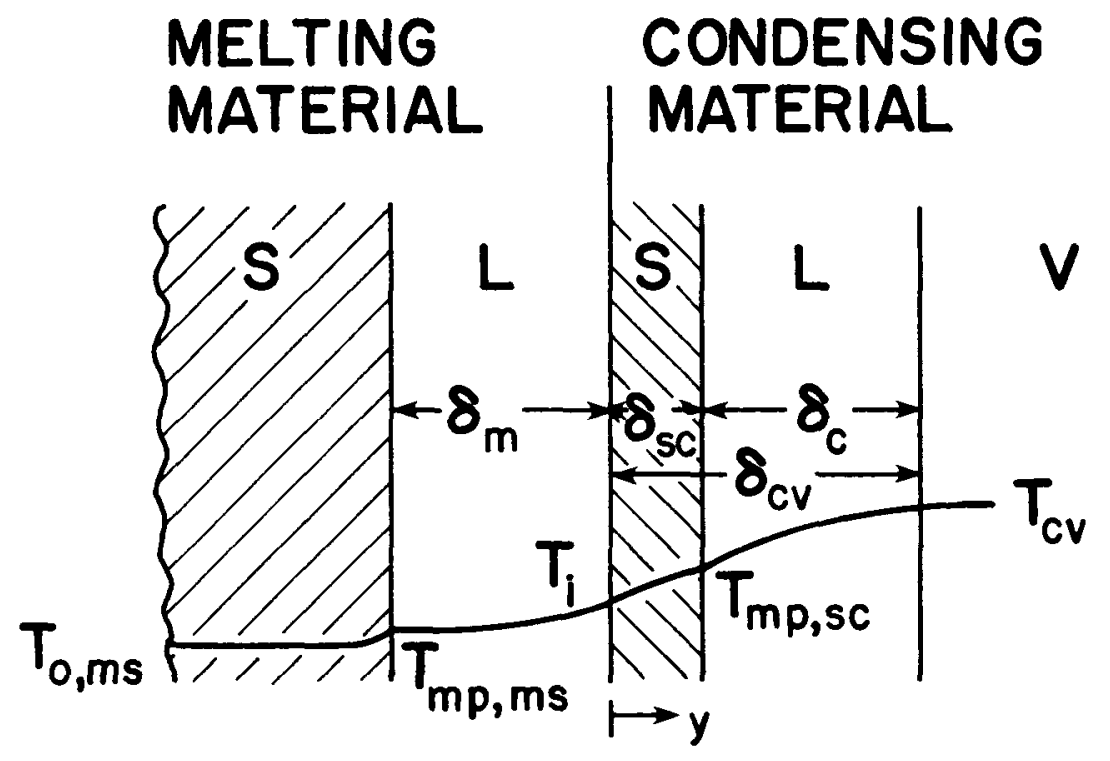

Figure D-1. Schematic of geometry used for a condution-only treatment of transient condensation and solidification of a material onto a melting substrate composed of a different material. 
Equation D-2 with

$$
\lambda_{c} \equiv \lambda_{c v}-\beta_{c v} \lambda_{s c}
$$

Application of eight of the boundary conditions results in obtaining forms for the four sets of coefficients in the temperature profiles, $(A, B)_{r}$, in terms of the three unknown $\lambda_{r}$. The remaining three boundary conditions result in producing the following nonlinear equations which must be solved to find the $\lambda_{r}$ :

$$
\begin{aligned}
& 0=\lambda_{c v} \exp \left(\lambda_{c v}^{2}\right)\left[\operatorname{erf}\left(\lambda_{c v}\right)-\operatorname{erf}\left(\beta_{c v} \lambda_{s c}\right)\right]-N_{c} \\
& 0=\frac{1}{\exp \left(\lambda_{\mathrm{m}}^{2}\right)\left[\operatorname{erf}\left(\lambda_{\mathrm{m}}\right)+\sigma \operatorname{erf}\left(\lambda_{\mathrm{sc}}\right)\right]} \\
& -\frac{\theta_{\mathrm{m}}}{\exp \left(\beta_{\mathrm{m}}^{2} \lambda_{\mathrm{m}}^{2}\right) \operatorname{erfc}\left(\beta_{\mathrm{m}} \lambda_{\mathrm{m}}\right)}-\frac{\lambda_{\mathrm{m}}}{\mathrm{N}_{\mathrm{m}}} \\
& \begin{aligned}
0=\frac{1}{\sigma}\left[\operatorname{erf}\left(\lambda_{\mathrm{m}}\right)\right. & \left.+\sigma \operatorname{erf}\left(\lambda_{\mathrm{sc}}\right)\right] \hat{\mathrm{N}}_{\mathrm{N}} \lambda_{\mathrm{sc}} \exp \left(\lambda_{\mathrm{sc}}^{2}\right) \\
& \left.+\theta_{\mathrm{cv}} \lambda_{\mathrm{cv}} \exp \left(\lambda_{\mathrm{cv}}^{2}\right) \exp \left[\left(1-\beta_{\mathrm{cv}}^{2}\right) \lambda_{\mathrm{sc}}^{2}\right]\right\}-\mathrm{N}_{\mathrm{c}}
\end{aligned}
\end{aligned}
$$

where

$$
\begin{aligned}
& \beta_{c v} \equiv\left(\frac{\alpha_{s c}}{\alpha}\right)^{\frac{1}{2}} \\
& \beta_{m} \equiv\left(\frac{a_{c}}{\alpha_{m s}}\right)^{\frac{1}{2}} \\
& \sigma \equiv \frac{k_{m}}{k_{s c}}\left(\frac{\alpha_{s c}}{\alpha_{m}}\right)^{\frac{1}{2}} \\
& \theta_{c v} \equiv \beta_{c v} \frac{k_{c}}{k_{s c}} \frac{T_{c v}-T_{m p, s c}}{T_{m p}, s c-T_{m p}, m s} \\
& \theta_{m} \equiv \beta_{m} \frac{k_{m s}}{k_{m}} \frac{T_{m p, m s}-T_{o, m s}}{T_{m p, s c}-T_{m p, m s}}
\end{aligned}
$$




$$
\begin{aligned}
N_{c} & \equiv \frac{c_{c}\left(T_{c v}-T_{m p, s c}\right)}{L_{c v} \pi^{\frac{1}{2}}} \\
N_{s c} & \equiv \frac{c_{s c}\left(T_{m p, s c}-T_{m p, m s}\right)}{L_{s c} \pi^{\frac{1}{2}}} \\
N_{m} & \equiv \frac{c_{m}\left(T_{m p, s c}-T_{m p, m s}\right)}{L_{m s} \pi^{\frac{1}{2}}}
\end{aligned}
$$

The above expression for $\theta_{\mathrm{m}}$ corrects a typographical error in Reference 12 .

In the present work, the $\lambda_{r}$ were found from Equations D-4 through 6 using a Newton-Raphson iterative technique. ${ }^{34}$ After the $\lambda_{r}$ have been found, the interface temperature between the molten substrate and the solidified condensate may be obtained from

$$
\frac{T_{i}-T_{m p, m s}}{T_{m p, s c}-T_{m p, m s}}=\frac{\operatorname{erf}\left(\lambda_{m}\right)}{\operatorname{erf}\left(\lambda_{m}\right)+\sigma \operatorname{erf}\left(\lambda_{s c}\right)}
$$

\section{D.2 Effective Heat of Fusion}

Analytical solutions to many transient melting problems are only obtainable if the substrate is initially at the melting temperature throughout. (An energy equation does not have to be satisfied within the solid for this case.) This is especially true for problems having finite geometry. This difficulty may be overcome by using an artificially higher heat of fusion for the melting substance. This effective heat of fusion is then used in a problem formulation which had the substrate at the melting temperature in order to simulate the actual situation where the substrate is not at the melting temperature. 
In the context of the current model, the effective heat of fusion $\mathrm{L}_{\mathrm{ms}}^{*}$ (to be used in $\mathrm{N}_{\mathrm{m}}$ ), is found by setting $\theta_{\mathrm{m}}=0$ and requiring the phase change rates, $\lambda_{r}$, to remain unchanged. Performing the algebra, the effective heat of fusin is given by

$$
L_{\mathrm{ms}}^{*} \equiv \mathrm{L}_{\mathrm{ms}}+\gamma_{\mathrm{ms}}\left(\mathrm{T}_{\mathrm{mp}, \mathrm{ms}}-\mathrm{T}_{\mathrm{o}, \mathrm{ms}}\right)
$$

where

$$
\gamma \equiv\left[\pi^{\frac{1}{2}} \beta_{\mathrm{m} m} \lambda_{\mathrm{m}} \exp \left(\beta_{\mathrm{m}}^{2} \lambda_{\mathrm{m}}^{2}\right) \operatorname{erfc}\left(\beta_{\mathrm{m}} \lambda_{\mathrm{m}}\right)\right]^{-1}
$$

Equation D-16 has the same form as the expression used previously for the effective heat of fusion in Equation 2,2-14. The correction term coefficient, $\gamma$, was unity in steady-state film-condensationinduced melting. In the present conduction-only model, $\gamma$ is a function of the melting rate and thus $L_{m s}^{*}$ is a function of the vapor temperature (as well as the substrate temperature).

\section{3 Results}

The results of applying this conduction-only model to the fuel/steel system are shown in Table $\mathrm{D}-1$. The numbers in parenthesis are the results obtained when condensate solidification is neglected in the modeling. ${ }^{\dagger}$ The dimensionless result $\lambda$ describes both the region thickness and the mass flux at the phase change interface since

$$
\delta=2 \lambda(\alpha t)^{\frac{1}{2}} \quad, \quad \text { or } \quad \frac{\delta}{2(\alpha t)^{\frac{1}{2}}}=\lambda
$$

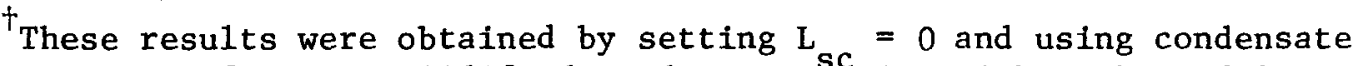
properties for the solidified-condensate region within the model.
} 
TABLE D-1

Dimensionless Results for Conduction-0nly Treatment of Transient Condensation of Fuel onto Me1ting Stee1

\begin{tabular}{|l|l|l|l|l|l|l|}
\hline$T_{c v},[K]$ & \multicolumn{2}{|c|}{4000} & \multicolumn{2}{c|}{5000} & \multicolumn{2}{c|}{6000} \\
\hline$T_{o, m s},[K]$ & 800 & 1200 & 800 & 1200 & 800 & 1200 \\
\hline$T_{i},[K]$ & $\begin{array}{c}2142 \\
(2142)\end{array}$ & $\begin{array}{c}2370 \\
(2369)\end{array}$ & $\begin{array}{c}2391 \\
(2392)\end{array}$ & $\begin{array}{c}2628 \\
(2628)\end{array}$ & $\begin{array}{c}2612 \\
(2614)\end{array}$ & $\begin{array}{c}2855 \\
2856)\end{array}$ \\
\hline$\lambda_{m}$ & $\begin{array}{c}0.2682 \\
(0.2681)\end{array}$ & $\begin{array}{c}0.4612 \\
(0.4607)\end{array}$ & $\begin{array}{c}0.3640 \\
(0.3644)\end{array}$ & $\begin{array}{c}0.5496 \\
(0.5496)\end{array}$ & $\begin{array}{c}0.4330 \\
(0.4337)\end{array}$ & $\begin{array}{c}0.6127 \\
(0.6130)\end{array}$ \\
\hline$\lambda_{s c}$ & $\begin{array}{c}0.2452 \\
(0)\end{array}$ & $\begin{array}{c}0.2037 \\
(0)\end{array}$ & $\begin{array}{c}0.1521 \\
(0)\end{array}$ & $\begin{array}{c}0.1103 \\
(0)\end{array}$ & $\begin{array}{c}0.0928 \\
(0)\end{array}$ & $\begin{array}{c}0.0526 \\
(0)\end{array}$ \\
\hline$\lambda_{\mathrm{cv}}$ & $\begin{array}{c}0.4597 \\
(0.4850)\end{array}$ & $\begin{array}{c}0.4379 \\
(0.4584)\end{array}$ & $\begin{array}{c}0.5765 \\
(0.5894)\end{array}$ & $\begin{array}{c}0.5581 \\
(0.5671)\end{array}$ & $\begin{array}{c}0.6852 \\
(0.6920)\end{array}$ & $\begin{array}{c}0.6692 \\
(0.6730)\end{array}$ \\
\hline$\gamma$ & $\begin{array}{c}3.533 \\
(3.534)\end{array}$ & $\begin{array}{c}2.403 \\
(2.404)\end{array}$ & $\begin{array}{c}2.788 \\
(2.786)\end{array}$ & $\begin{array}{c}2.134 \\
(2.134)\end{array}$ & $\begin{array}{c}2.458 \\
(2.455)\end{array}$ & $\begin{array}{c}1.991 \\
(1.990)\end{array}$ \\
\hline
\end{tabular}

(The results in parentheses are obtained if fuel-condensate solidification is neglected.) 
and

$$
\dot{\mathrm{m}}=\rho \frac{\mathrm{d} \delta}{\mathrm{dt}}=\rho\left(\frac{\alpha}{\mathrm{t}}\right)^{\frac{1}{2}} \lambda \quad, \quad \text { or } \quad \frac{\dot{\mathrm{m}}}{\rho}\left(\frac{\mathrm{t}}{\alpha}\right)^{\frac{1}{2}}=\lambda
$$

(The quantity $\lambda_{c v}$, not $\lambda_{c}$, is used to obtain $\dot{\mathrm{m}}_{\mathrm{cv}}{ }$ )

The results in this table illustrate two items which were seen for steady-state film-condensation-induced melting (\$2.4): Fuelcondensate solidification does occur within the temperature ranges of interest, but it is not important to specifically include this effect in the modeling. The biggest discrepancy created by neglecting the solidification would be overestimation of the condensate thickness (and condensation rate) by $5 \%$ (for $\mathrm{T}_{\mathrm{cv}}=4000 \mathrm{~K}$ and $\mathrm{T}_{\mathrm{o}, \mathrm{ms}}=800 \mathrm{~K}$ ). The melting rate, melt thickness, interface temperature, and heat-offusion correction show less than $0.1 \%$ variations for neglecting condensate solidification.

The heat-of-fusion correction factor, $\gamma$, is seen to be a factor of 2 to 3 greater than the value $(\gamma=1)$ used for steady-state film condensation in Section 2. The values of $\gamma$ given in Table D-1 could be used to correctly simulate the transient melting of the solid without actually solving an energy equation in the solid. (Of course, it was necessary to solve the energy equation in order to determine $\gamma$.$) On the other hand, attempting to do this simulation using \gamma=1$ in the effective heat of fusion would produce the following results:

- overestimate the melting rate (by as much as a factor of 2 at low $\mathrm{T}_{\mathrm{cv}}$ and low $\mathrm{T}_{\mathrm{o}, \mathrm{ms}}$ )

- underestimate the solidification rate (by 30 to $50 \%$ ) 
- yield the correct condensation rate (within $7 \%$ )

- minimize the effect of $\mathrm{T}_{\mathrm{o}, \mathrm{ms}}$ on the melting rate The effective heat of fusion is thus partially responsible for the large discontinuties in melt-related quantities in the simulated transient presented in Section 4, since the transient portion uses $\gamma>1$ and the steady-state portion uses $\gamma=1$.

The results given in Table $D-1$ have been unfolded into dimensional form and displayed in Table $\mathrm{D}-2$. The effects of $\mathrm{T}_{\mathrm{cV}}$ and $\mathrm{T}_{\mathrm{o}, \mathrm{ms}}$ on the results are in the same directions as found for the steady-state film-condensation-induced melting cases examined in Section 2.4. The condensation heat flux line, $q_{\mathrm{cv}}^{\prime \prime}$, is particularly interesting. This quantity shows the least sensitivity to $\mathrm{T}_{\mathrm{cv}}$ and $\mathrm{T}_{\mathrm{o}, \mathrm{ms}}$. Indeed, the condensatin heat flux may be approximated to within $\pm 7 \%$ by the following expression:

$$
q_{c v}^{\prime \prime}=6.457 t^{-\frac{1}{2}}
$$

for $T_{c v} \varepsilon(4000 \mathrm{~K}, 6000 \mathrm{~K})$ and $\mathrm{T}_{\mathrm{o}, \mathrm{ms}} \varepsilon(800 \mathrm{~K}, 1200 \mathrm{~K})$ and where $\mathrm{q}_{\mathrm{cv}}^{\prime \prime}$ is in $\left[\mathrm{MW} / \mathrm{m}^{2}\right]$ and $t$ is in $[\mathrm{s}]$. In contrast, the melting rate shows factorof-2 variations for the temperatures considered. The ratio of the melting mass flux to the condensation mass flux is, however, relatively insensitive to $\mathrm{T}_{\mathrm{cv}}$ and is given within $7 \%$ by the following representative values:

$$
\frac{\dot{\mathrm{m}}_{\mathrm{ms}}}{\dot{\mathrm{m}}_{\mathrm{cv}}}= \begin{cases}1.0, & \text { for } \mathrm{T}_{\mathrm{o}, \mathrm{ms}}=800 \mathrm{~K} \\ 1.6, & \text { for } \mathrm{T}_{\mathrm{o}, \mathrm{ms}}=1200 \mathrm{~K}\end{cases}
$$

Thus, the melting mass flux is best found using the condensation mass flux which is to be found from the relatively constant value of the condensation heat flux. 
TABLE D-2

Film Thickness and Phase-Change Rates for a Conduction-Only Treatment of Transient Fuel Condensation Onto Melting Steel ( $t$ is in [s]).

\begin{tabular}{|l|l|l|l|l|l|l|}
\hline$T_{\mathrm{cv}},[\mathrm{k}]$ & \multicolumn{3}{|c|}{4000} & \multicolumn{2}{|c|}{5000} & \multicolumn{2}{|c|}{6000} \\
\hline $\mathrm{T}_{\mathrm{o}, \mathrm{ms}},[\mathrm{K}]$ & 800 & 1200 & 800 & 1200 & 800 & 1200 \\
\hline $\mathrm{T}_{\mathrm{i}},[\mathrm{k}]$ & 2142 & 2370 & 2391 & 2628 & 2612 & 2855 \\
$\delta_{\mathrm{m}},[\mathrm{mm}]$ & $1.029 \mathrm{t}^{\frac{1}{2}}$ & $1.770 \mathrm{t}^{\frac{1}{2}}$ & $1.397 \mathrm{t}^{\frac{1}{2}}$ & $2.109 \mathrm{t}^{\frac{1}{2}}$ & $1.662 \mathrm{t}^{\frac{1}{2}}$ & $2.352 \mathrm{t}^{\frac{1}{2}}$ \\
$\delta_{\mathrm{sc}},[\mathrm{mm}]$ & $0.399 \mathrm{t}^{\frac{1}{2}}$ & $0.331 \mathrm{t}^{\frac{1}{2}}$ & $0.252 \mathrm{t}^{\frac{1}{2}}$ & $0.182 \mathrm{t}^{\frac{1}{2}}$ & $0.156 \mathrm{t}^{\frac{1}{2}}$ & $0.088 \mathrm{t}^{\frac{1}{2}}$ \\
$\delta_{\mathrm{c},},[\mathrm{mm}]$ & $0.487 \mathrm{t}^{\frac{1}{2}}$ & $0.513 \mathrm{t}^{\frac{1}{2}}$ & $0.879 \mathrm{t}^{\frac{1}{2}}$ & $0.912 \mathrm{t}^{\frac{1}{2}}$ & $1.211 \mathrm{t}^{\frac{1}{2}}$ & $1.247 \mathrm{t}^{\frac{1}{2}}$ \\
$\dot{\mathrm{m}}_{\mathrm{ms}},\left[\mathrm{kg} / \mathrm{m}^{2} \cdot \mathrm{s}\right]$ & $3.474 \mathrm{t}^{-\frac{1}{2}}$ & $5.975 \mathrm{t}^{-\frac{1}{2}}$ & $4.716 \mathrm{t}^{-\frac{1}{2}}$ & $7.120 \mathrm{t}^{-\frac{1}{2}}$ & $5.609 \mathrm{t}^{-\frac{1}{2}}$ & $7.937 \mathrm{t}^{-\frac{1}{2}}$ \\
$\dot{\mathrm{m}}_{\mathrm{sc}},\left[\mathrm{kg} / \mathrm{m}^{2} \cdot \mathrm{s}\right]$ & $1.673 \mathrm{t}^{-\frac{1}{2}}$ & $1.390 \mathrm{t}^{-\frac{1}{2}}$ & $1.020 \mathrm{t}^{-\frac{1}{2}}$ & $0.740 \mathrm{t}^{-\frac{1}{2}}$ & $0.612 \mathrm{t}^{-\frac{1}{2}}$ & $0.347 \mathrm{t}^{-\frac{1}{2}}$ \\
$\dot{\mathrm{m}}_{\mathrm{cv}},\left[\mathrm{kg} / \mathrm{m}^{2} \cdot \mathrm{s}\right]$ & $3.720 \mathrm{t}^{-\frac{1}{2}}$ & $3.543 \mathrm{t}^{-\frac{1}{2}}$ & $4.585 \mathrm{t}^{-\frac{1}{2}}$ & $4.438 \mathrm{t}^{-\frac{1}{2}}$ & $5.357 \mathrm{t}^{-\frac{1}{2}}$ & $5.233 \mathrm{t}^{-\frac{1}{2}}$ \\
$\mathrm{q}_{\mathrm{cv}}^{\prime \prime},\left[\mathrm{MW} / \mathrm{m}^{2}\right]$ & $6.309 \mathrm{t}^{-\frac{1}{2}}$ & $6.009 \mathrm{t}^{-\frac{1}{2}}$ & $6.840 \mathrm{t}^{-\frac{1}{2}}$ & $6.621 \mathrm{t}^{-\frac{1}{2}}$ & $6.863 \mathrm{t}^{-\frac{1}{2}}$ & $6.703 \mathrm{t}^{-\frac{1}{2}}$ \\
$\mathrm{~h}_{\mathrm{cv}},\left[\mathrm{kV} / \mathrm{m}^{2} \cdot \mathrm{k}\right]$ & $1.972 \mathrm{t}^{-\frac{1}{2}}$ & $2.146 \mathrm{t}^{-\frac{1}{2}}$ & $1.629 \mathrm{t}^{-\frac{1}{2}}$ & $1.742 \mathrm{t}^{-\frac{1}{2}}$ & $1.320 \mathrm{t}^{-\frac{1}{2}}$ & $1.396 \mathrm{t}^{-\frac{1}{2}}$ \\
\hline
\end{tabular}




\section{APPENDIX E}

EQUATION SUMMARY FOR STNGLE-FILM TREATMENT OF STEADY-STATE CONDENSATIONINDUCED MELTING

The derivation presented in Section 3.2.2 leads to a system of 7 nonlinear algebraic equations. The technique used in Appendix $B$ is used to solve these equations. The quantities $D$ and $n_{\delta}$ are the "primary" unknowns. The final forms of the equations are presented below.

The following quantities are fixed:

$$
\begin{aligned}
& E=-\frac{1}{6} \\
& B=0 \\
& G=0
\end{aligned}
$$

The following quantities are defined during each iteration in terms of the primary unknowns:

$$
\begin{aligned}
& \mathrm{H}=\left[-\frac{2}{n_{\delta}}+3 \frac{\mathrm{Pr}}{\mathrm{N}} n_{\delta}^{2}\left(\mathrm{D}+E \eta_{\delta}\right)\right] \div\left(\frac{\mathrm{L}_{\mathrm{cv}}}{\mathrm{L}_{\mathrm{ms}}^{*}}-1\right) \\
& \mathrm{J}=\left(\frac{1}{n_{\delta}}-\mathrm{H}\right) \frac{1}{n_{\delta}} \\
& \mathrm{A}=-\frac{1}{3} \frac{\mathrm{N}}{\operatorname{Pr}} \frac{\mathrm{L}_{\mathrm{cv}}}{\mathrm{L}_{\mathrm{ms}}^{*}} \mathrm{H}
\end{aligned}
$$

\footnotetext{
The equation numbering pattern used in this appendix has been selected to correspond to that used in Section 3.2.2 in order to be able to show the equation matchup.
} 
The following equations* are to be satisfied (using a NewtonRaphson iterative procedure ${ }^{34}$ ):

$$
\begin{aligned}
0=F^{\prime \prime}\left(\eta_{\delta}\right)+\varepsilon 3 F\left(n_{\delta}\right) F^{\prime}\left(\eta_{\delta}\right) \\
0=2 J \eta_{\delta}+3 \operatorname{Pr}\left[F\left(n_{\delta}\right)-\frac{2}{3} D H \eta_{\delta}^{3}\right. \\
\left.-\frac{1}{4}(2 D J+3 E H) \eta_{\delta}^{4}-\frac{3}{5} E J \eta_{\delta}^{5}\right]
\end{aligned}
$$

\footnotetext{
* If the convective momentum terms had been retained in this problem, the quantity $E$ would be a primary unknown rather than having the value $-1 / 6$. Satisfaction of the integral momentum equation, bringing the number of final nonlinear equations to 3 , would replace the condition given by Equation E-2. This solution would then correspond to the one-material solution presented in Reference 13.
} 